\title{
INFLUÊNCIA DOS PARÂMETROS CLIMÁTICOS NA FLUTUAÇÃO POPULACIONAL E ESTIMATIVA DE CORRELAÇÃO ENTRE ESPUMAS, NINFAS E ADULTOS DE CIGARRINHAS DAS PASTAGENS, Deois flavopicta STAL, 1854 (HomOPTERA-CERCOPIDAE), EM Brachiaria decumbens STAPF
}

\author{
MAURO PICINATO COTTAS \\ Engenheiro Agronomo
}

Orientador: EVONEO BERTI FILHO

Dissertação apresentada à Escola Superior de Agricultura "Luiz de Queiroz", da Universidade de São Paulo, para obtenção do título de Mestre em Ciências Biológicas. Área de Concentração: Entomo. logia.

PIRACICABA

Estado de São Paulo - Brasil

Novembro, 1984 
.ii.

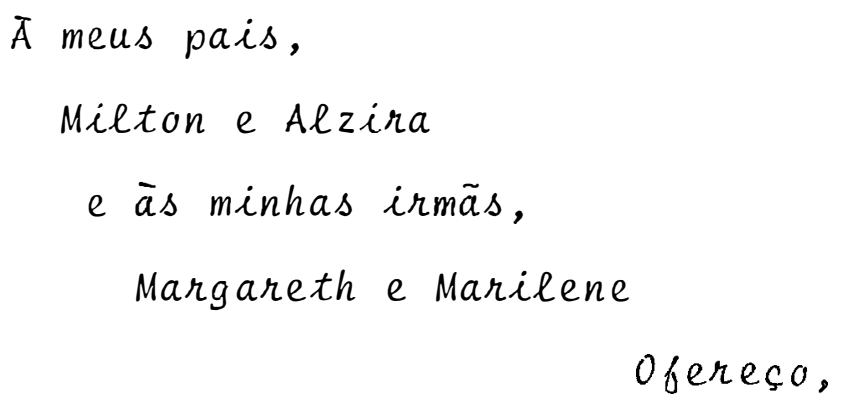

A minha esposa, Lucia Helena

$e$ aos meus filhos,

Paulo Eduardo,

Paulo Henrique e

Paulo Roberto

Dedico. 


\section{AGRADEC IMENTOS}

- Ao Engo Agro Roberto Martins Franco, proprietärio da Fazenda Lageado, onde foi realizado o presente experimento;

- Ao Técnico Agricola Roberto Carlos Parizat$t i$, pela colaboração nos levantamentos populacionais, contagem das espécies, sexagem e separação dos instares ninfais;

- Ao Professor Dr. Evoneo Berti Fizho, pela orientação;

- A Dra. Zuleide Alves Ramiro, pela colaboraçao e incentivos durante o curso e trabalhos de campo;

- Ao Sr. Milton Cottas, pelas leituras diär ruas dos elementos climáticos;

- A Dra. Marinëia de Lara Haddad, pela colabo ração na anālise estatística;

- Aos Professores do Departamento de Entomolo gia da ESALQ, pela oportunidade e realização do curso;

- A Shell Química S/A pelo apoio e incentivo;

- A todos que direta ou indiretamente colaboraram para a realização do presente trabalho. 


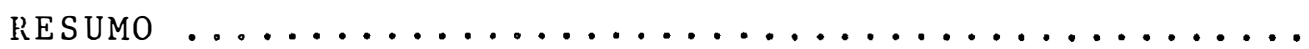
vi

SUMMARY viii

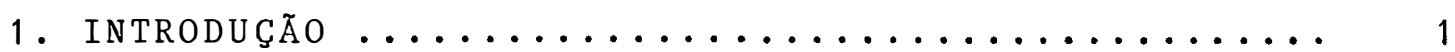

2. REVis $̃$ o de literatura $\ldots \ldots \ldots \ldots \ldots \ldots \ldots \ldots \ldots \ldots$

2.1. Espēcies, taxonomia, distribuição geogräfica. 4

2.2. Morfologia e Biologia ..................... 6

2.3. Prejuizos e plantas hospedeiras ........... 11

2.4. Levantamentos e flutuação populacional ..... 12

2.5. Influēncia dos parāmetros climáticos ....... 16

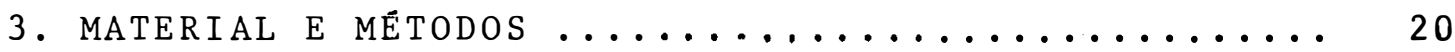

3.1. Localização ...................... 20

3.2. Levantamentos populacionais ............ 20

3.3. Levantamento dos parámetros climáticos e cor relação entre formas e estágios amostrados .. 22

3.4. Correlação entre estägios amostrados ....... 23

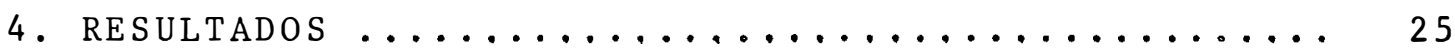

4.1. Influência dos parāmetros climảticos e sua correlação com os diferentes estágios da popu

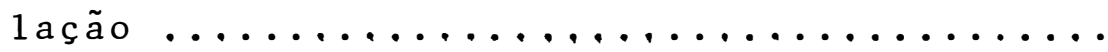

4.1.1. Influência dos paràmetros climáticos no nümero de espumas e na população de ninfas, adultos e de fèmeas e machos ..... 31

4.2. Correlação entre estägios amostrados ....... 35 4.2.1. Correlação simples entre os estägios. 35 
4.3.2. Anālise de regressão simples pelo programa de "Curvas" .............. 49

4.4. Comparação do número médio de adultos nos diferentes nümeros de redadas, nas diferentes épocas de amostragens ................. 49

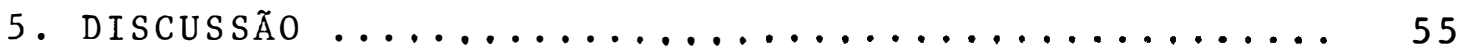

5.1. Levantamentos populacionais ........... 55

5.2. Influência dos parāmetros climáticos e sua correlação com os diferentes estägios da popü

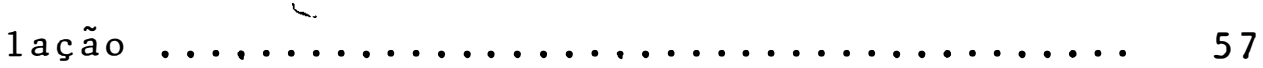

5.3. Correlação entre os èstägios amostrados .... 59 5.3.1. Correlação simples entre os estágios. 59 5.3.2. Correlação através dos 25 modelos de

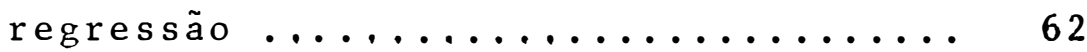

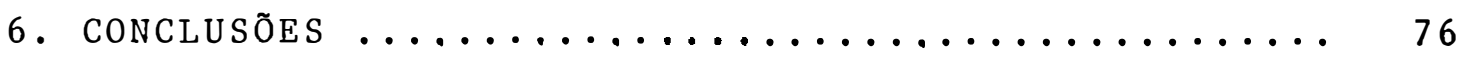

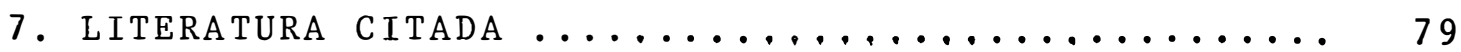




\author{
INFLUENCIA DOS PARĀMETROS CLIMATICOS NA FLUTUAÇĀO \\ POPULACIONAL E ESTIMATIVA DE CORRELAÇĀO ENTRE ESPUMAS, \\ NINFAS E ADULTOS DE CIGARRINHAS DAS PASTAGENS \\ Deois flavopicta Stal, 1854 (HOMOPTERA-CERCOPIDAE) \\ EM Brachiaria decumbens Stapf.
}

\author{
Autor: MAURO PICINATO COTTAS \\ Orientador: Evoneo Berti Filho
}

\title{
Resumo
}

o trabalho teve como finalidade desenvolver métodos para levantamentos populacionais de cigarrinhas das pastagens Deois flavopicta em pastagens de Brachiaria decumbens, verificando-se a possível correlação existente entre os diferentes estágios da população. Procurou-se também cor relacionar esses estágios com alguns fatores climáticos do local do experimento, além da sua influência na flutuação populacional da praga. As amostragens foram quinzenais, em 4 locais de uma mesma pastagem, utilizando-se redes entomoló gicas para amostragem de adultos e pontos de $0,25 \mathrm{~m}^{2}$ para amostragems de espumas e ninfas. 0 experimento foi instalado no município de Sales Oliveira, Estado de São Paulo. Os resultados mostraram a ocorrência das cigarrinhas de setem- 
- vii.

bro a maio, com 3 picos populacionais nesse período, não se verificando diferenças na flutuação populacional nas äreas isoladas, quando comparadas com a área total. A precipitação pluviométrica foi o parâmetro climático que influenciou significativamente em diferentes estágios. Para cada estāgio determinou-se a variável isolada e o conjunto daquelas que influiram na curva populacional de determinado estágio com as respectivas equações representativas. A amostragem de ninfas pode ser substituída pela de espumas, para a mesma época de levantamento. Verificou-se correlação entṛe espumas e ninfas e espumas e adultos 15 dias após a amostragem de espumas, sendo também verificado correlação de espumas com adultos amostrados 30 dias após, mas não entre espumas e ninfas após esse mesmo período. Recomenda-se a utilização de 100 redadas por ponto de avaliação, face a menor variação das médias obtidas nas diferentes épocas de avaliação. 
viii.

\title{
INFLUENCE OF THE CLIMATIC PARAMETERS IN THE FLUCTUATION
}

\author{
POPULATION AND ESTIMATION OF CORRELATION AMONG \\ SPITTLE NYMPHS AND ADULTS OF THE GRASS FROGHOPPER \\ Deois flavopicta Stal, 1854 (Homoptera, Cercopidae) \\ ON Brachiaria decumbens stapf.
}

Author: MAURO PICINATO COTTAS

Adviser: EVONEO BERTI FILHO

\section{SUMMARY}

This research deals with the development of methods to survey populations of the grass froghopper Deois Glavopicta on Brachiaria decumbens pastures, in order to observe possible correlations among the different stages of the insect. These stages were also correlated with climatic factors of the region and their influencesin the population fluctuacion of the pest. The samplings were fortnightly taken from four areas of the same pasture, by using nets to collect adults and .25 square meter points to collect nymphs. The experiment was set in Sales de 0liveira, state of São Paulo, Brazil. The results have indicated' the occurrence of the grass froghoppers from september to may, with three population peaks in this period and no differences in the population fluctuation were observed in the isolated areas, when compared with the total area. The rainfall was the climatic parameter that most significantly influenced 
the different stages. For each stage it was determined the isolated variable and the group of variables which influenced the population curve of a given stage with the respective representative equations. The sampling of nymphs may be substituted by spittle countings for the same survey period. It was observed correlation between spittles and nymphs, as well as between spittles and adults, 15 days after spittle sampling; it was also observed correlation of spittles and adults 30 days after, but not between spittles and nymphs after this same period. A number of 100 sweepings per point of sampling is recommended, because of the lower variation of the means obtained in the different periods of evaluation. 


\section{INTRODUÇÃO}

Nos ültimos anos, com os incentivos oferecidos à pecuária, as àreas de pastagens do país vêm aumentando gradativamente e, com elas, a ocorrência de pragas, causando grandes prejuizos. Dentre estas podense destacar as cigarri nhas (Homoptera-Cercopidae) como uma das principais.

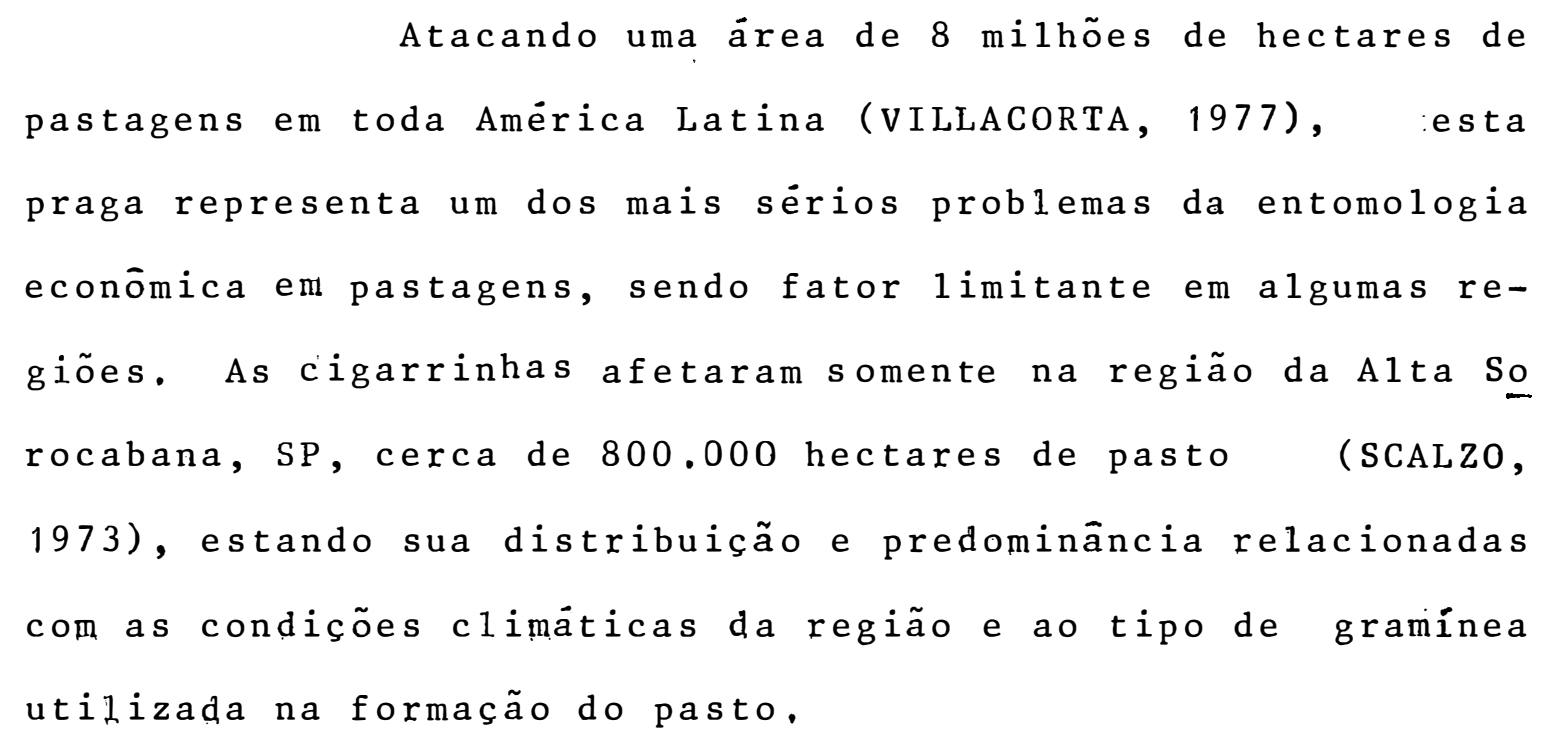


os prejuízos causados são devidos à sucção de seiva pelas ninfas e adultos. Estesültimos, além de sugarem a selva, introduzem uma toxina que leva o capim à morte, cau sando o que se chama "queima do pasto". Desta maneira, ocor rendo altas infestações, haverä uma diminuição na capacidade suporte da pastagem, além de impalatabilidade do capim ao gado, que o rejeita também em razão da presença das espumas na região do colo da planta, fazendo com que ocorra uma diminui ção do nümero de cabeças por ärea, do ganho de peso, além da produção de leite. Danos dessa natureza são citados por diversos autores em diversas regiões, onde as perdas chegam até $40 \%$ das pastagens.

Programas de pesquisas visando o controle das cigarrinhas em pastagens, não têm alcançado os seus objetivos tendo em vista o desconhecimento da praga no que diz res peito a sua biologia, bem como fatores ecológicos que atuam no comportamento e na densidade populacional da mesma, fatores estes que, segundo EL-KADI (1977a, 1977b) influem decis vamente na eficiēncia dos métodos empregados. Este mesmo au tor citou que, para melhor conhecer o comportamento biológico da praga, seus danos econômicos e para desenvolver métodos eficientes de controle, os trabalhos de pesquisas devem ser iniciados com padronização de métodos de levantamentos populacionais.

Muitos ensaios com vârios tipos de produtos 
têm sido feitos, mas geralmente os autores não utilizam o mesmo método de levantamento para obtenção dos dados. Tanto as amostragens como as contagens diferem de um autor para outro, com relação principalmente aos estágios dos inse tos utilizados para tais fins. Assim alguns consideram em suas contagens apenas insetos adultos, outros consideram o numero de ninfas e existem aqueles que apenas contam o número de espumas por unidade de ärea. Entre estes ültimos, alguns avaliam uma espuma como contendo uma ninfa, outros atri buem ao número total de espumas o grau de infestação.

De acordo com FONTES (1977) somente a utiliza cão de uma mesma técnica de amostragem, para avaliação de fe nômenos biológicos idênticos, pode levar a resultados comparáveis e a conclusões corsistentes.

Esta pesquisa foi reạizada face a não existência de trabalhos correlacionando número de adultos, ninfas e espumas de cigarrinhas das pastagens e aos poucos estudos sobre a influência dos paràmetros climáticos na sua curva populacional tendo em vista que a avaliação de determinados produtos pode ser diferente, quando considerados para um ou outro estágio do inseto. 


\section{REVISÃO DE LiterATURA}

2.1. Espécies, taxonomia, distribuição geogräfica

A época de maior ocorrēncia de cigarrinhas coincide com o período de maiores precipitações pluviométricas e altas temperaturas, impedindo assim a recuperação do pasto da época seca e alterando negativamente a produção.

As pastagens geralmente são atacadas por mais de uma espécie, havendo predominância de uma delas. No Esta do de São Paulo, segundo EL-KADI (1977a), GALlo et ali $i$ (1978) e SILVEIRA NETO (1976) as espécies mais comumente encontradas são: Zulia entreriana (Berg. 1879); Deois blavopic ta (Sta1, 1854); Mahanarva fimbriolata ( $\mathrm{Sta1}$ ) e Deois schach (Fabr, 1787). Segundo GUAGLIUMI (1972) no nordeste do Brasil, além destas, ocorrem ainda as espécies Aeneolamia selec ta $(\mathrm{w} 1 \mathrm{k}$,$) e Deois incompleta (W1k.).$ 
A espëcie Z. entreriana, segundo GUAGLIUMI (1972), é conhecida como a praga de maior importância nas pastagens do sul e sulheste do Estado da Bahia, enquanto que D. flavopicta, considerada como praga potencial da cana, tem sido relatada como praga dos arrozais e pastagens no sul do pais, apesar de ocorrer em diversos Estados.

Em Minas Gerais, REIS et a $i$ i (1978) observaram que 2. entreriana ocorre em todo Estado, enquanto que $D$. blavopicta predomina no oeste, centro e sul.

De acordo com EL-KADI (1978) as pastagens do Estado de São Paulo são predominantemente atacadas pelas espécies D. flavopicta (85\%) e Z, entreriana (15\%). cotTas e RAMIRO (1981) verificaram o inverso na região do Pontal do Paranapanema r SP, onde a predominância è de Z, entreriana, principalmente devido à espécie de capim naquela região.

No Estado do Espírito Santo, DOMINGUES e SANTos (1975) citaram que as maiores infestações foram constata das na região norte, onde, principalmente a espécie Z. entre riana esta difundida em quase todas as regiões. Segundo MORA (1972) os surtos, neste Estado, são mais acentuados nos municipios 1 imite ao sul da Bahia e a leste de Minas Gerais onde a população da referida praga atinge um grau elevadiss mo . 


\begin{abstract}
.6 .
Trabalhando com cigarrinhas, DeBONA (1967) me diu seu grau de infestação em capim pangola e GUAGLIUMI ( $1971 b)$ estabeleceu sua distribuição geogräfica e as possib 1 idades de controle no nordeste do Brasil.
\end{abstract}

\title{
2.2. Morfologia e Biologia
}

De acordo com PASS e RED (1965), PADILHA e ESQUILIANO (1966), DOMINGUES e SANTOS (1975), o ovo das cigarrinhas de pastagens e cana-de-açucar é descrito como sen do de forma eliptica, inicialmente de coloração amarela ou creme, empalidecendo à médida que se desenvolve. Suas dimen sões variam de um minimo de $0,25 \mathrm{~mm}$ de largura a um máximo de $1,10 \mathrm{~mm}$ de comprimento.

Gom relação ao período de incubação, EEWKES (1963/64/69) estudando a espécie Aeneolamia varia saccharina, anteriormente denominada de Tomaspis saccharina, cigarri nha da cana em Trinidad, encontrou para este período, uma du ração de 14 a 50 dias em condições favorâveis e de 200 a 210 dias para condições adversas.

FREIRE et a $i$ i (1968) encontraram para a espé cie Tomaspis liturata, atualmente Mahanarva fimbriolata, um período de aproximadamente 20 dias, enquanto que GUAGLIUMI (1972), para esta mesma espécie, verificou que este periodo 
pode variar de 20 a 25 dias.

Para 2. entreriana no Estado do Espirito Santo, DOMINGUES e SANTOS (1975) citaram um periodo de incubação de 7 a 10 dias com uma viabilidade de $50 \%$ para condiçóes de laboratório. RAMOS (1976), no Estado da Bahia, verificou um periodo de 14 a 22 dias com maior frequência de eclosão aos 26 dias, a uma temperatura média de $24,5^{\circ} \mathrm{C}$ e U,R. média de $76,4 \%$ e um período de 22 dias a uma temperatura média de $24,7^{\circ} \mathrm{C}$ e $72,0 \%$ de U.R., respectivamente para as condições de laboratório e campo. Esse periodo segundo GonçALVES (1969) pode ultrapassar 200 dias.

$$
\text { Com relação a } V \text {. flavopicta, PACHEco }
$$

verificou que o período médio de incubação dos ovos normais foi de 16,58 dias, com uma viabilidade média de 49,75\%, enquanto que os ovos em diapausa permanecem em média 287,6 dias até a eclosão das ninfas.

Pelas descrições de CORONADO (1964), DOMINGUES e SANTOS (1975) e SILVEIRA NETO (1976) a ninfa recém eclodida é de coloração alaranjada, passando a creme com o decorrer do desenvolvimento, mantendo apenas algumas manchas da coloração inicial. São semelhantes aos adultos, diferin do destes pelo tamanho, e ausēncia de asas, Vivem fixas em raizes superficiais ou coletos de plantas hospedeiras, envo 1 tas por uma espuma característica, que segundo Gilbeau (1908), 
citado por CostA LIMA (1942), é o resultado do líquido expelido pelo ânus, acrescido de uma substāncia mucilaginosa secretada pelas glāndulas de Bateli. Para constatação do núme ro de instares, os autores empregaram diversos métodos, baseando-se no tamanho do corpo, largura da cápsula cefálica, estruturas das antenas e desenvolvimento das tecas alares. Assim, encontraram uma variaşão de 4 a 5 instares. Como exemplo desta variação podense citar o trabalho de William (1921), citado por FEWKES (1960), que considerou a existência de apenas 4 instares, enquanto que FEWKES (1960/69), FEW KES et a $i$ i (1971), PADILHA e ESQUILIANO (1966), PASS e RED (1965), BYER (1965) e GUAGLIUMI (1972) encontraram 5 instares.

Quanto a duração do periodo ninfal, CORONADO (1964), PASS e RED (1965) e FAGAN e KUITERT (1969), observaram para as diferentes espécies estudadas, um mínimo de 19 dias e um máximo de 60 dias e maior frequēncia de 24 a 50 dias ,

GUAGLIUMI (1972) citou para M. fimbriolata um período de 30 a 40 dias até mais de 60 a 70 dias, dependendo das condições microclimäticas do solo.

DOMINGUES e SANTOS (1975) citaram para a espé cie Z, entreriana um período de 26 a 39 dias, em condições de laboratório. RAMOS (1976), para a mesma espécie, verifi- 
cou um período ninfal de 20 a 26 dias, com uma média de 23,9 dias à temperatura de $24,7^{\circ} \mathrm{C}$ e $79,6 \%$ de U.R. em 1 aboratörio.

A descrição dos adultos de cigarrinhas das pastagens pode ser encontrada nos trabalhos de GALLO et a $i i$ (1978), GUAGLIUMI (1972), DOMINGUES e SANTOS (1975) e SILVEI RA NETO (1976) que pode ser assim resumidas, para as três principais espécies que ocorrem no Estado de São Paulo:

Zulia entreriana - de menor tamanho, com $7 \mathrm{~mm}$ de comprimento, coloração preta brilhante com uma fa $\underline{i}$ xa transversal branco amarelada nas asas anteriores. Podem apresentar polimorfismo, ou seja, outras manchas no sentido longitudina 1 das asas.

Deois flavopicta - $10 \mathrm{~mm}$ de comprimento, coloração pardo escura ou preta, com as asas anteriores apresentando faixas amareladas em forma de $V$ e 2 faixas transversais na extremidade, Região ventral de coloração averme 1 hada .

Mahanarva fimbriolata - $13 \mathrm{~mm}$ de comprimento, coloração variāvel averme1hada, castanho averme1 hada a preto, com asas anteriores orladas de preto. 
10.

vel entre as espécies e mesmo na própria espécie, dependendo das condições. Assim, BECK (1963), para a espécie Prosapia bicincta, citou que a longevidade em casa de vegetação foi de 30 dias, ao passo que PASS e RED (1965) encontraram uma duração de 6 semanas à temperatura de 22 a $35^{\circ} \mathrm{C}$, acrescentando que a $5^{\circ} \mathrm{C}$ estes adultos vivem menos de 2 semanas. Por outro lado, BYER (1965) encontrou uma longevidade média de 23,7 dias para a fèmea e 22,7 dias para o macho, à temperatura de $26,7^{\circ} \mathrm{C}$ e $70,0 \%$ de U.R.. FAGAN e KUITERT (1969), para a mesma espécie, observaram uma duração de 21 dias, sem se referir ao sexo, BYER e TALIAFERRO (1967) verificaram que um macho dessa espécie viveu durante 33 dias a $27,0^{\circ} \mathrm{C}$ e $80,0 \%$ de U.R. .

Em Pernambuco, RIBEMBOIM e CISNEIROS

$(1967)$

encontraram para M. indica uma longevidade de 11 a 28 dias em condições de campo e 9 dias em laboratório.

GUAGLIUMI (1972) verificou para M, posticata a longevidade de 1 semana para o macho e de 3 semanas para a fèmea.

DOMINGUES e SANTOS (1975) referiramrse a Z.en treriana com uma duração de vida entre 5 e 23 dias, sendo 9 dias para o macho, quando copulou, e 7 a 16 dias quando sem cópula. RAMOS (1976), para a mesma espécie, verificou que a longevidade da fèmea foi de 18,6 dias e do macho 9,85 dias 
a uma temperatura média de $24,7^{\circ} \mathrm{C}$ e $79,6 \%$ de U.R..

Para D. flavopicta, PACHECo (1981) verificou que a longevidade média das fêmeas foi de 12,46 dias e dos machos de 9,8 dias.

\subsection{Prejuizos e plantas hospedeiras}

$$
\text { GUAGLIUMI (1971a, 1971b, 1972) e GONÇALVES }
$$

(1969) citaram que os prejuízos causados pelas cigarrinhas são devidos à sucção constante de seiva pelos insetos e prin cipalmente pela introdução de toxinas pelos adultos; as plan tas atacadas têm o seu desenvcivimento prejudicado, amarelecem e morrem, dependendo da intensidade do ataque.

Os surtos de grande intensidade de infestação ocorrem na época das àguas, coincidindo com o periodo de maior crescimento das forrageiras (DOMINGUES e SANTos, 1975), diminuindo assim consideravelmente a capacidade de suporte do pasto. WILSON et alii (1962) reportaram que, devido ao ataque, essa capacidade suporte em Trinidad foi reduzida per la metade, VENTOCILLA (1968) verificou que na região sul da Bahia e no Norte do Espirito Santo, a capacidade suporte foi reduzida de 2 cabeças/ha para 0,8 cabeças/ha. REIS relatou perdas de 20 a $40 \%$ das pastagens na zona de Mucuci -MG, enquanto que CosenzA (1974) observou a destruição de 
1200 ha de capim colonião e sorgo.

Devido a presença das espumas na região do co leto e à queima causada ao capim, o gado, quando não o refuga, come forçosamente quantidades menores, afetando assim a produção de carne e leite. Como a praga geralmente se esten de sobre grandes extenções de pastos, os prejuizos podem ser inca 1 culäveis.

Com base nos trabalhos de GUAGLIUMI

$(1970$, $1971 \mathrm{a}, 1971 \mathrm{~b}, 1972)$, MORA (1972), MATIOLI (1976) e SILVEIRA NETO (1976) as cigarrinhas vivem praticamente em todas grami neas, das quais pode-se citar como suscetiveis: colonião, pangola, gordura, imperial, angolinha, quicuio, amargoso, angola, jaraguá, sempre verde, bermuda, cidrão, assú, napiè, estrêla; braquiāria, elefante, sorgo, erva cidreira, etc..

\subsection{Levantamentos e flutuação populacional}

Segundo EL-KADI (1977) o grau de infestação anual cresce numa progressão geométrica, dependendo do poten cial populacional do inicio da primeira geração. Como geral mente esta população é relativamente baixa, despertará a atenção dos pecuaristas da segunda geração em diante quando o campo infestado jà é grande. 
(1978), a atividade das cigarrinhas inicia-se no mês de agos to e se estende até o final de maio, sendo que entre dezembro e março registram-se os maiores niveis populacionais, tendo o gēnero Zulia suas atividades iniciadas poucas semanas antes do gènero Deois.

MILANEZ (1980), com a finalidade de estudar a flutuação populacional de cigarrinhas das pastagens em Nova Odessa e Piracicaba, através de amostragens quinzenais com redes entomológicas, num total de 50 redadas por tratamento, verificou que as mesmas começaram a aparecer a partir de novembro, com as espëcies ?, Glavopicta e Z. entreriana apresentando seus picos populacionais em fevereiro e marco, com preferēncia aos capins Brachiaria decumbens e jaraguá, respectivamente,

FAZOLIM et aiii (1977), em levantamentos de cigarrinha de pastagens em Nova Odessa, SP, com o uso de armadilha de Malaise, coletaram durante dois anos (1974 a 1976) em maior nümero, espécies da família Cercopidae, sendo em or dem decrescente: M. fimbriolata, Z, entreriana; T. flavepicta e $D$, schach.

FORTI et alii (1977), em Nova Odessa, sP, trabalhando com armadilha luminosa modelo Luiz de Queiroz, realizando levantamentos e flutuação populacional de algumas 
pragas em pastagens, verificaram que através do uso desta a madilha foi possivel coletar 30 espécies de insetos, sendo o periodo de maiores niveis populacionais, de dezembro a março, com um pico em fevereiro, verificado também para as cigarrinhas da familia Cercopidae.

COTTAS e RAMIRO (1981), em ensaio de flutuação populacional de $Z$. entreriana e $D$. flavopicta na região do Pontal do Paranapanema, SP, verificaram que a primeira tem suas atividades iniciadas no mês de setembro, algumas se manas antes da segunda, sendo que ambas espécies apresentam maiores picos populacionais, na região em estudo, em dezembro e janeiro.

MENDES (1976) em Araras, SP, trabalhando com armadilha luminosa em cana, verificou que a espécie M. fimbriolata ocorreu de novembro a abril, com o pico na primeira quinzena de março.

$$
\text { DOMINGUES e SANTOS (1975) no Espirito Santo, }
$$
utilizando-se para levantamentos de adultos, redes entomologicas de $50 \mathrm{~cm}$ de diâmetro, dandorse 40 golpes a partir de um ponto central da ärea e para as formas jovens demarcando-se aleatöriamente áreas de $1 \mathrm{~m}^{2}$, onde se contou todas as ninfas presentes. Concluiram que as maiores infestações ocor reram em dezembro, caindo em janeiro e dando uma ascenção mä xima em fevereiro. 
No Paranā, BIANCO e VILLACORTA (1978a, 1978b) realizaram trabalhos de dinâmica populacional de cigarrinhas das pastagens em diferentes forrageiras e preferēncia de $D$. blavopicta por espécies de gramineas. Evidenciaram o pico populacional da praga no verão, para todas forrageiras, estú dadas, nas quais coletaram 3 espécies: D. flavopicta, Z. entreriana e M. fimbriolata. Comparando os dados obtidos, observaram que Brachiaria decumbens ofereceu melhores condições ao desenvolvimento da praga. Nos ensaios de preferēncia de $D$. Glavopicta por espécies de forrageiras, realizado em gaiolas, observaram que esta espécie apresenta preferēncia para se desenvolver em $B$. decumbens e Digitaria decumbens quando comparadas com Panicum maximum.

A braquiäria pode ser a graminea mais suscetí vel ao ataque das cigarrinhas, mas, há dentro deste gêneróde forrageira, espécies mais resistentes que toleram mais os da nos causados, como por exemplo B. humidicola (GALvão e LIMA, 1977; NEHRING, 1976 e COTTAS e RAMIRO, 1981).

MELO (1982) em estudos populacionais da cigar rinha das pastagens D. flavopicta, observou que ocorreram de setembro/outubro a abril/maio ( 8 meses), com acme ninfal em fins de outubro, sendo variävel o pico populacional de adultos. Verificou também que a amostragem de ninfas, que è demorada, pode ser substituida pela contagem de espumas, ganhandorse tempo e assim utilizando maior número de amostras. 
Devido a razão sexual no campo de 0,24 a rede de varredura tende a capturar mais machos que fèmeas.

\subsection{Influência dos parâmetros climáticos}

De acordo com EL-KADI (1978) o desenvolvimento das cigarrinhas está subordinado ao comportamento climätí co durante a época das chuvas, sendo que a eclosão das primeiras ninfas e gerações subsequentes são influenciadas por alguns fatores, entre os quais se destacam temperatura e um dade .

Segundo SILVEIRA NETO et alii (1968 e 1976) as cigarrinhas são bastante influenciadas pela umidade do ar e principalmente pelo balanço hídrico da região, na faixa des favorável, sendo que conseguem resistir à seca entrando em diapausa no estágio de ovo. MENDES (1974) verificou que a curva populacional média da praga, no seu período de ocorrência, foi explicada em $80,8 \%$ pelos elementos climäticos, sendo den tre estes $55,9 \%$ representado pelas temperaturas do solo, sen do o aparecimento de M. fimbriolata condicionado ao excedente hidrico do solo. Por outro lado, souzA (1967) em Campos, RJ, reportou que os fatores meteorolögicos que mais influir ram sobre o desenvolvimento de M. fimbriolata foram temperatura e umidade, Considerou ainda que a temperatura mînima foi mais importante, pois se houvesse condições apenas de 
umidade, o inseto nảo interromperia sua diapausa.

BRASIL (1967) afirmou que, além de exigentes em umidade, as cigarrinhas não suportam calor e luminosidade direta, com o que concordou BALTAR FILHO (1967). AZZI e DOD SON (1971) concluíram que o período de maior atividade das cigarrinhas é precedido de meses quentes e úmidos, enquanto que GUAGLIUMI (1972) afirmou que o desenvolvimento do inseto está estritamente relacionado com as chuvas.

VILLACORTA (1977) no Paraná, verificou que a incidência de cigarrinhas é influenciada pelo fotoperiodismo, onde os dias curtos (durante o inverno) induzem as fémeas a colocar ovos hibernantes, os quais eclodirão na primavera, estando a presença destes insetos mais ligadas às condições de temperatura e umidade de uma determinada região.

VENTOCILLA (1969) reportou que os grandes su tos de 2 , entreriana ocorreram após precipitação pluviométri ca superior a $80 \mathrm{~mm}$. DOMINGUES e SANTOS (1975), no Espírito Santo, concluiram que as primeiras chuvas do ano, em setembro, proporcionaram umidade suficiente para desenvolver os ovos que estavam em diapausa, dando a primeira geração em no vembro, confirmando ser o período chuvoso do ano ideal para ocorrência de maior número de ninfas e adultos. SouzA (1976) observou que as condições de precipitação pluvial variando entre 750 e $1000 \mathrm{~mm}$, temperatura entre 20 e $30^{\circ} \mathrm{C}$ e altitude 
de zero a 1000 metros favorecem o aparecimento de Z. entreriana.

DeBONA et alii (1967), estudando as espécies T. flavopicta e M. entreriana, no Estado de São Paulo, verificaram correlação entre a precipitação pluvial e o nümero de insetos coletados, enquanto MILANEZ (1980) verificou que a flutuação populacional de cigarrinhas adultas não esteve correlacionada com a temperatura máxima e umidade relativa para nenhum dos anos estudados, sendo encontrada correlação positiva com a precipitação pluvial de até 2 meses antes da ocorrência da praga e evapotranspiração potencial no mesmo mes e um e dois meses antes da coleta da praga, o mesmo autor verificou que houve correlação positiva com a temperatura minima, principalmente quando confrontada com os dados do mesmo mes e do mes anterior ao da coleta,

Para D. blavopicta, PACHECo (1981) verificou que a umidade relativa do ar influencia o desenvolvimento dessa espécie. MELo (1982) verificou, para esta mesma espé cie, que dos parámetros climäticos estudados, a temperatura minima e a umidade relativa minima foram consideradas de maior importāncia, sendo que a precipitação pluviométrica pa ra a população de adultos somente não foi significativa em um dos anos estudados. 
.19.

des das cigarrinhas estä subordinado às baixas temperaturas noturnas, ao declínio do conteüdo hídrico do solo e ao aumen to das atividades dos inimigos naturais no local da infestação . 


\section{Material e Métodos}

3.1. Localização

O trabalho foi desenvolvido em uma pastagem de 8 ha formada com o capim Brachiaria decumbens Stapf, loca lizada na Fazenda Lageado, municipio de Sales 0liveira, Esta do de São Paulo, durante o periodo de setembro/79 a maio/80.

\subsection{Levantamentos populacionais}

Dessa pastagem escolheram-se 4 áreas de 1,0 ha as quais denominou-se de locais A, B, C e D. Por ocasião dos levantamentos, para cada um desses locais determinavam-se 10

pontos ao acaso, com uma ärea pré-estabelecida de $0,25 \mathrm{~m}^{2}$ pa ra cada ponto. Em cada um desses pontos, contava-se o número total de espumas e ninfas. Estas ülimas foram coletadas 
e acondicionadas em vidros com álcool, sendo levadas para o laboratório, onde procedeu-se a separação por estágio de desenvolvimento, baseando-se para isto nos trabalhos de GUAGLIUMI ( 1972 ).

Para amostragem de adultos, a partir de cada um dos pontos de $0,25 \mathrm{~m}^{2}$, foram dadas 25 redadas na direçaó de cada lado destes, perfazendonse um total de 100 redadas por ponto. Para tal utilizounse de redes entomológicas de $38 \mathrm{~cm}$ de diâmetro e $50 \mathrm{~cm}$ de fundo. Todo material coletado em cada uma dessas séries de redadas (25), foram acondiciona dos em vidros com álcool e levados para laboratório, onde procedeu-se a separação e contagem das formas adultas coleta das .

Estes 10 pontos de $0,25 \mathrm{~m}^{2}$ de cada local foram determinados de tal forma que as redadas de um não inter ferissem nas redadas dos outros.

Assim sendo, para cada local foi efetuada uma amostragem de 1000 redadas para coleta de adultos e $2,5 \mathrm{~m}^{2}$ para espumas e ninfas, para cada época de levantamento, perfazendo para a área total, 4000 redadas para adultos e $10 \mathrm{~m}^{2}$ para espuma e ninfa, em cada um dos 18 levantamentos, efetua - dos quinzenalmente. 
3.3. Levantamento dos parāmetros climáticos e correlacão entre formas e estāgios amostrados

Paralelamente aos levantamentos populacionais, foram anotados diariamente os parâmetros climáticos de Temperatura do Ar (Mäxima, Mínima e Média), Umidade Relativa do Ar (Máxima, Mínima e Média), Precipitação Pluviométrica, Temperatura do Solo $\mathrm{Nu}$ a $5 \mathrm{~cm}$ de profundidade (Máxima, Mínima e Média), Temperatura do Solo Coberto a 5 e 10 cm de profundidade (Máxima, Mínima e Média) no local do experimentọ. Para efeito de anälise estatística tais parâmetros foram denominados $\times 1$ a $\times 16$.

O nümero de espumas, formas jovens e adultos das cigarrinhas das pastagens foram correlacionadas com os parāmetros acima referidos, sendo que a aplicação dessas var riáveis meteorolögicas referiu-se ao período compreendido en tre uma e outra amostragem, isto é, 14 dias.

Os dados foram analisados através da Regressão Multipla, processada pelo Departamento de Matemática e Estatistica da Escola Superior de Agricultura "Luiz de Queiroz", utilizando-se o programa Step-Wise e o teste F aos niveis de $5 \%$ e de $1 \%$ de probabilidade. 


\subsection{Correlação entre estăgios amostrados}

Inicialmente os dados obtidos foram analisados através de Correlação Linear Simples, processada pelo De partamento de Matemática e Estatística da ESALQ, utilizando-se o teste $\mathrm{F}$ a $5 \%$ e $1 \%$ de probabilidade, procurando-se obter informações genéricas dos estägios e/ou metodologias mais correlacionadas entre si.

Partindorse dessa anälise simples e considerando-se que o nümero total de espumas è o de mais fäcil obtenção no campo, procurouese correlacionä-lo com o número to tal de ninfas e número total de adultos coletados em 25, 50, 75 e 100 redadas, respectivamente na mesma ēpoca, aqui denominada zero (0), 15 e 30 dias após o levantamento do nümero de espumas, Para isto, os dados de cada local foram analisa dos através de um programa denominado "Curvas", o qual testa 25 modelos diferentes de regressão simples, resultantes das combinações de 5 transformações das variảveis X e Y, ou sen ja :

$$
\begin{aligned}
& \text { (1) } X^{\prime}=X ; \quad Y^{\prime}=Y \\
& \text { (2) } X^{\prime}=1 / X ; \\
& \text { (3) } X^{\prime}=X^{2}=1 / Y \\
& \text { (4) } X^{\prime}=\sqrt{X} ; Y^{\prime}=Y^{2} \\
& \text { (5) } X^{\prime}=\text { L H } \quad ; \quad Y^{\prime}=\sqrt{Y}
\end{aligned}
$$


A equação final escolhida foi aquela que aprẹ sentava maior coeficiente de determinação $\left(R^{2}\right)$. 0 processamento foi realizado pelo Centro de Processamento de Dados do CENA.

Também efetuourse a anảlise da variância para o nümero médio de adultos coletados nas diversas sëries de redadas, nas diferentes épocas de amostragens, sendo as médias comparadas pelo teste Tukey a $5 \%$ de probabilidade, considerando-se o delineamento experimental como sendo em parce las subdivididas . 


\title{
4. Resultados
}

\author{
Os resultados obtidos no presente experimento \\ para cada local e os dados médios de todos locais se encon- \\ tram nas Tabelas 1 a 5 , onde para os locais, isoladamente, \\ cada valor apresentado representa a média das amostragens \\ realizadas em cada um dos 10 pontos previamente determina- \\ dos, em cada época de avaliação.
}

A infestação iñiciounse em fins de setembro, perdurando até fins de maio. A ocorrência de espumas e ninfas foi de setembro a abril ( 8 meses), enquanto que os adultos ocorreram de outubro a maio ( 8 meses).

Verificounse três picos populacionais, tanto para ninfas como para adultos, para todos locais, de onde se destacam os picos populacionais de março, tanto para ninfas como para adultos. 
.26 .

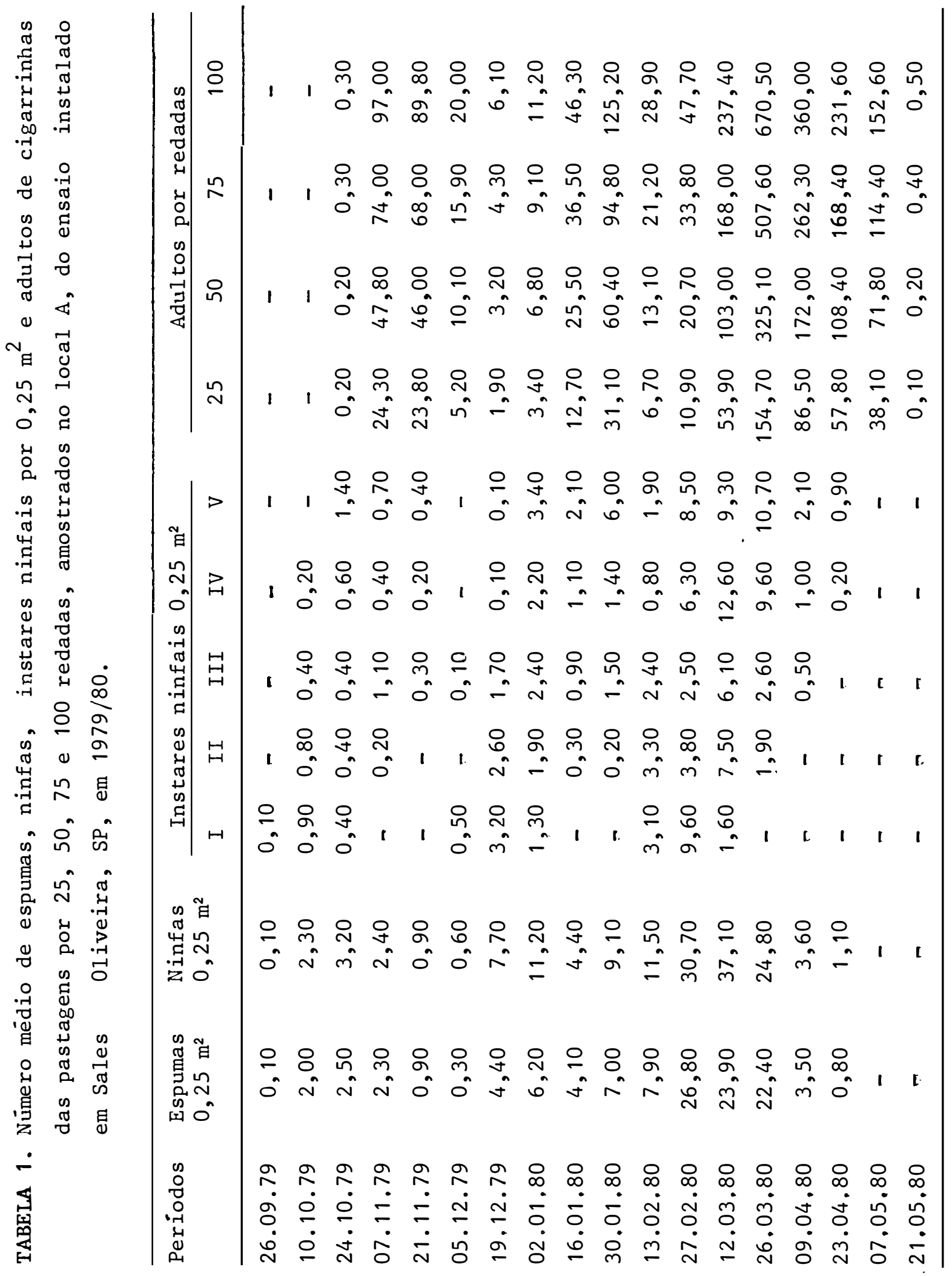




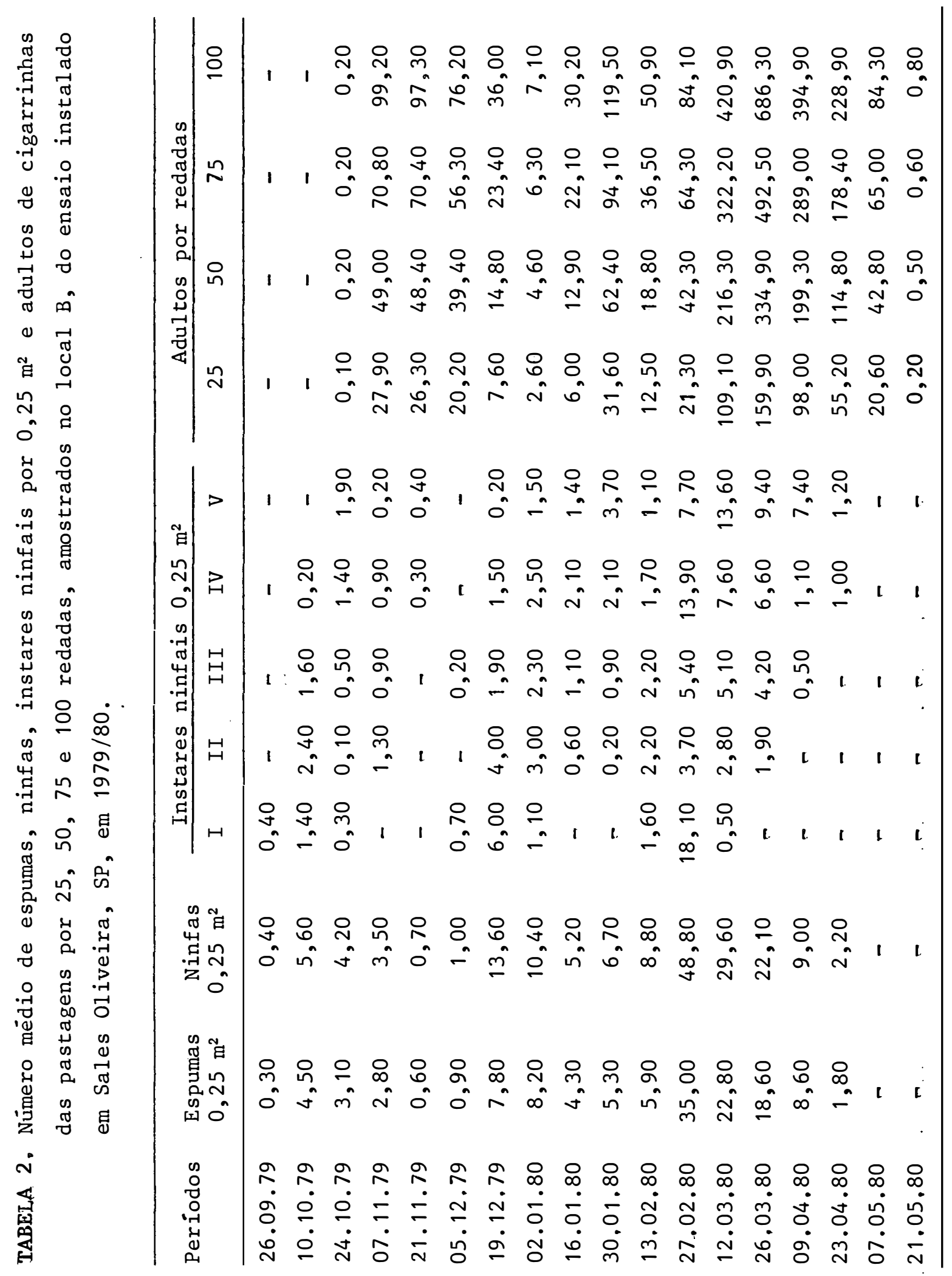




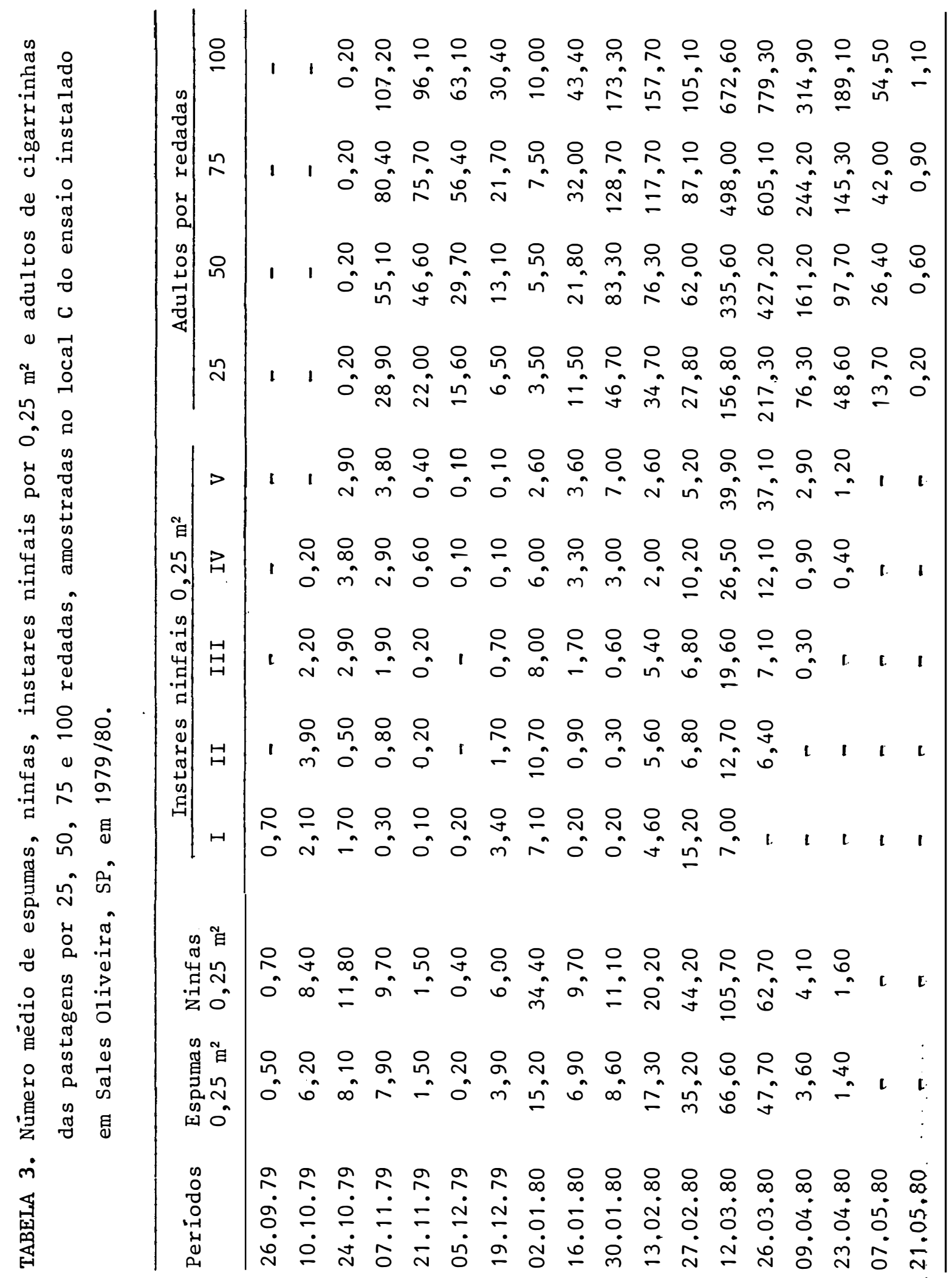




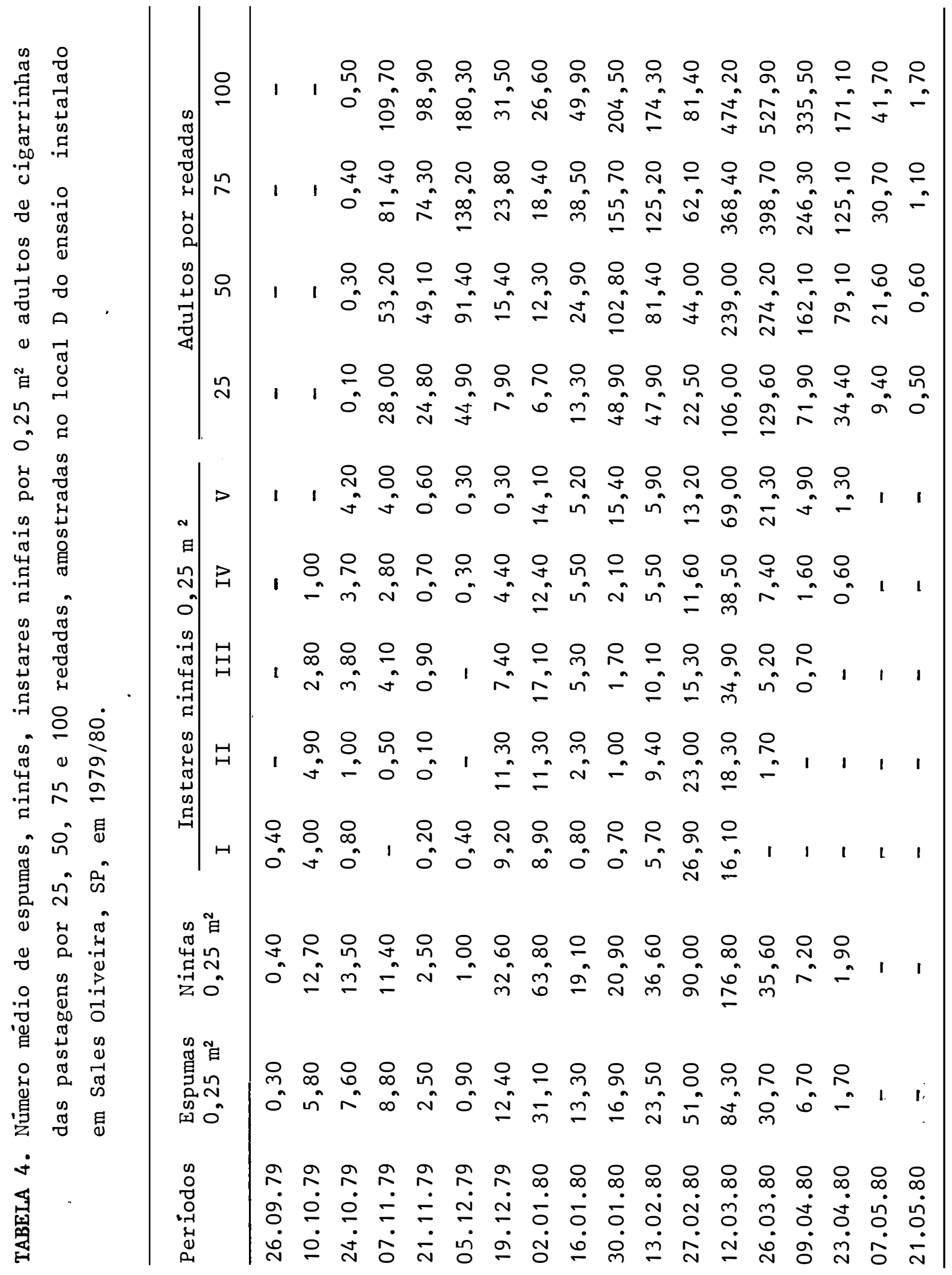




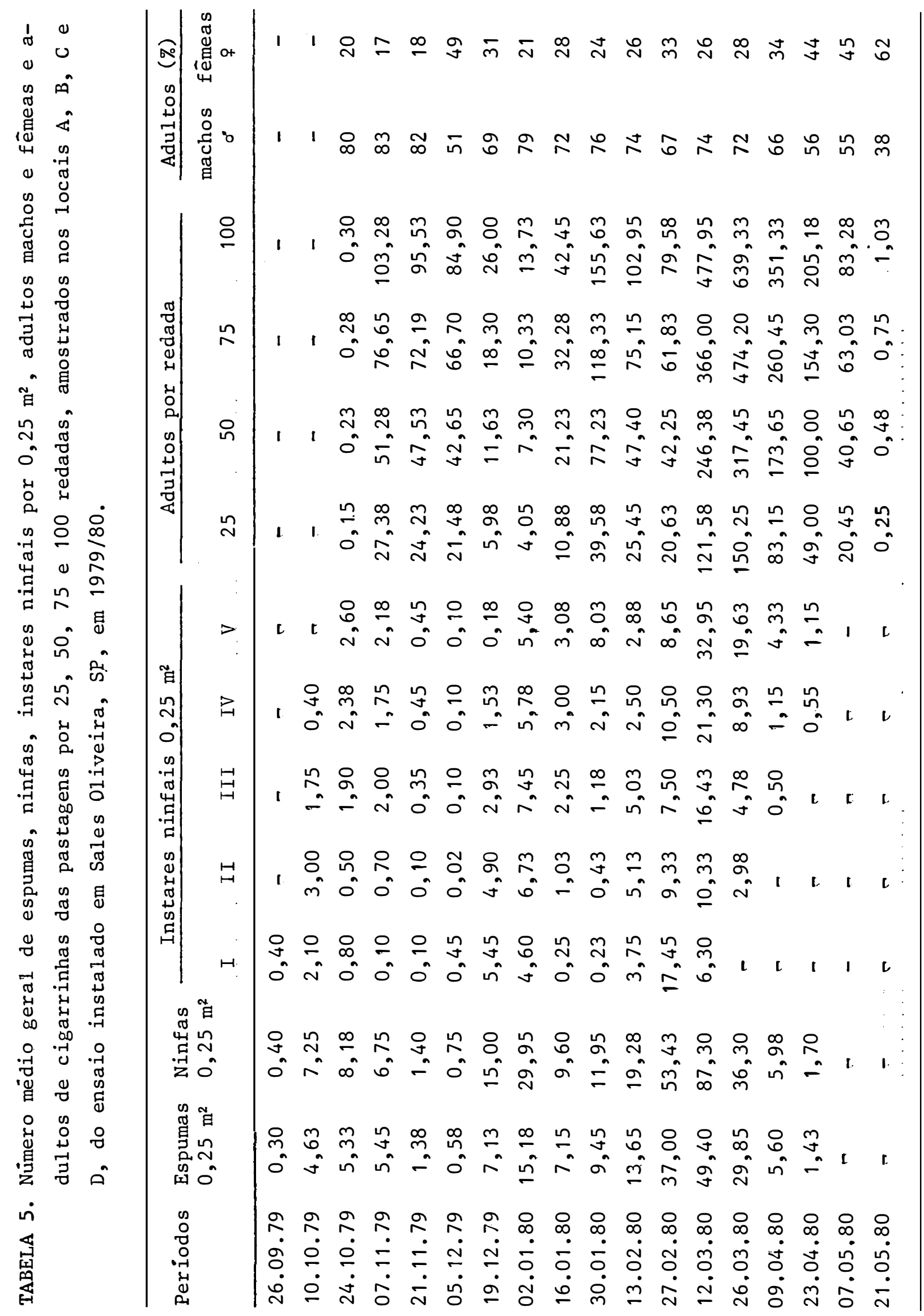


4.1. Influência dos parâmetros climáticos e sua correlação com os diferentes estágios da população

Na Tabela 6 encontram-se os dados dos parâmetros climáticos que foram correlacionados com os diferentes estágios da população de cigarrinhas das pastagens, obtidos em cada local.

4.1.1. Influência dos parāmetros climāticos no nūmero de espumas e na população de ninfas, adultos e de fêmeas e machos

Os resultados da análise de regressão mültipla entre os parāmetros climáticos, a contagem de espumas e os estágios de ninfas e adultos, se encontram resumidos nas Tabelas 7 e 8 . Nestas tabelas encontra-se os valores de $R^{2}$ para a variável que, isoladamente, mais influencia significa tivamente determinado estágio, sendo também encontrada a equação de regressão mültipla, incluindo todos os parāmetros que, em conjunto, exercem infquência significativa no referi do estágio em questão. Os valores de $R^{2}$ para a equação determinam em quanto esses paràmetros, conjuntamente, explicam a ocorrència de determinado estágio.

Assim sendo, verifica-se que, para espumas e ninfas, as variáveis que isoladamente mais se destacaram fo- 


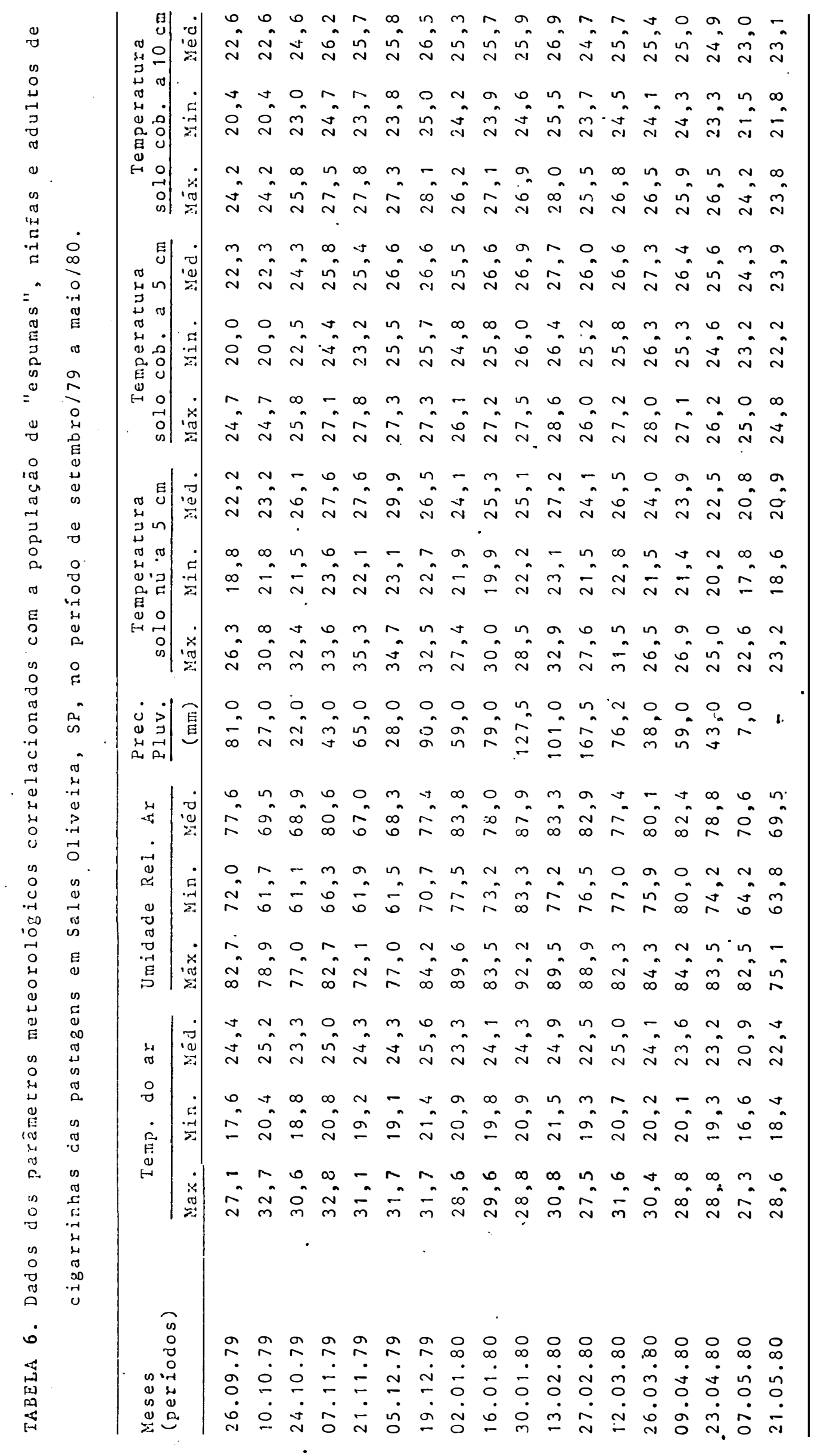




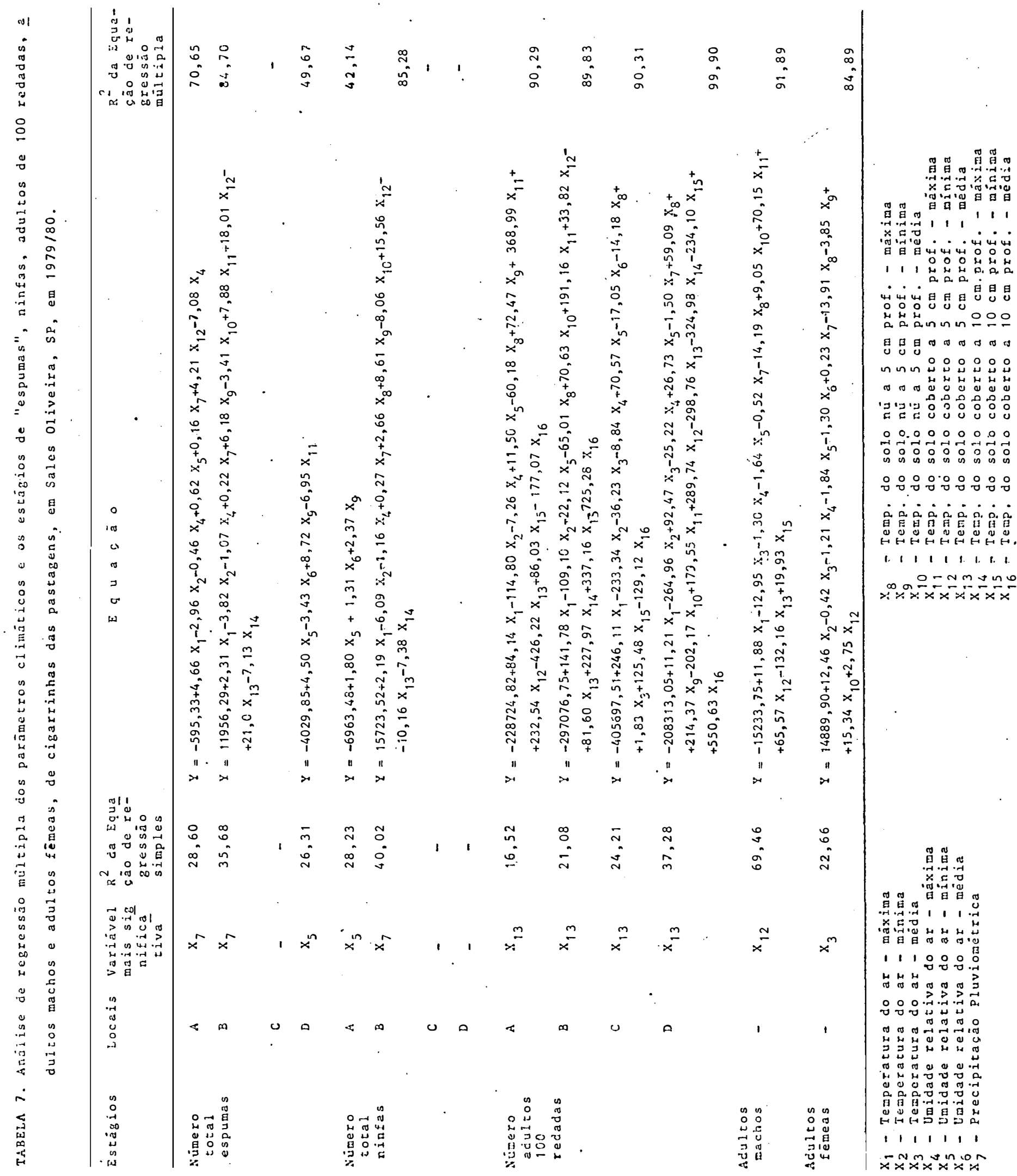




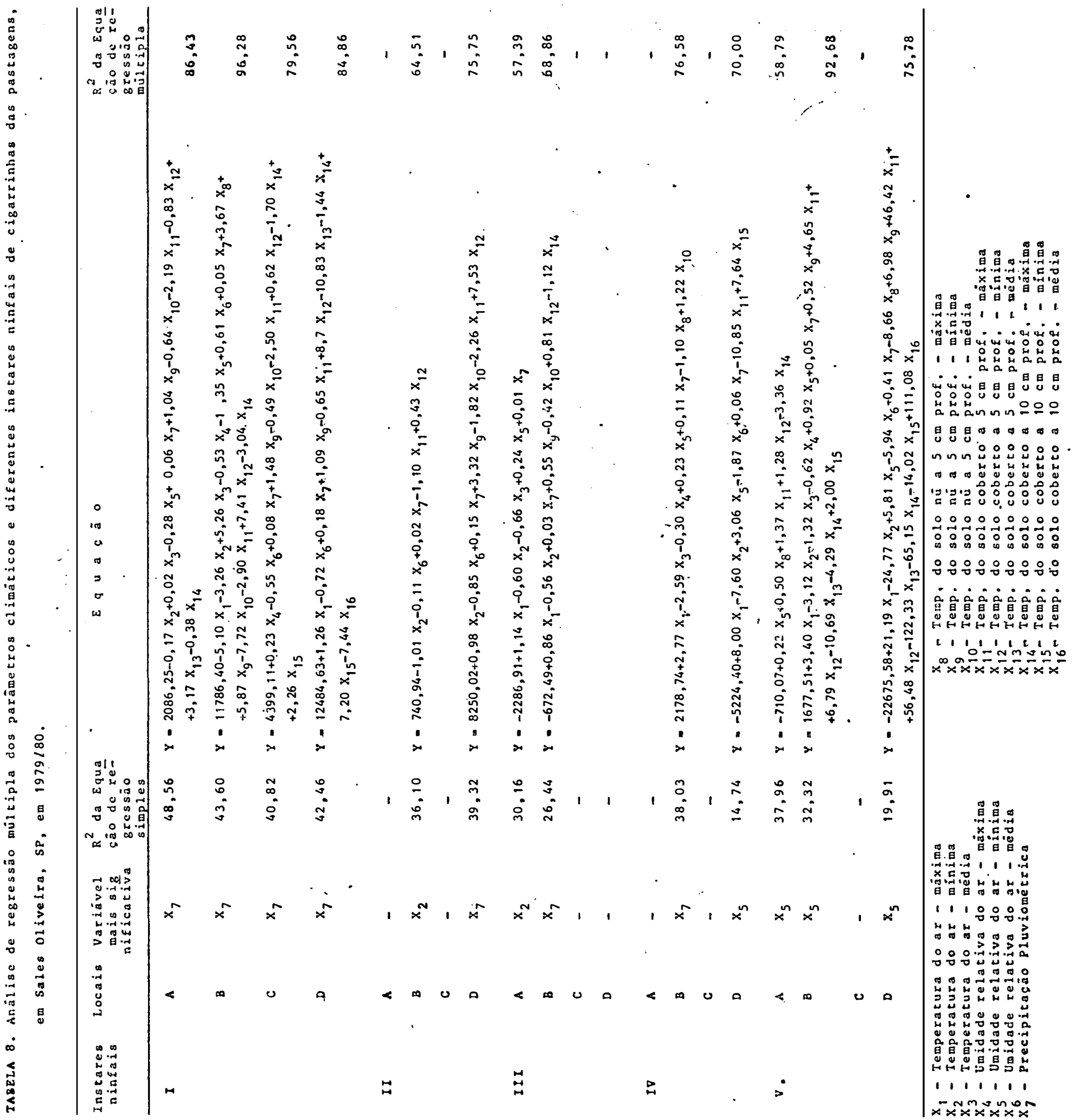


ram: precipitạ̧ão pluviométrica $\left(x_{7}\right)$, umidade relativa do ar $\left(x_{5}\right)$ e temperatura minima do ar $\left(x_{2}\right)$, enquanto que para a po pulação de adultos se destaca a temperatura média do solo co berto a $5 \mathrm{~cm}$ de profundidade $\left(X_{13}\right)$, Quanto a influēncia des tes parâmetros na relação sexual, verifica-se que machos e fêmeas são influenciados, respectivamente, pela temperatura minima do solo coberto a $5 \mathrm{~cm}$ de profundidade $\left(\mathrm{x}_{12}\right)$ e temperatura média do ar $\left(\mathrm{X}_{3}\right)$.

Para cada estâgio, em cada local, podense observar, pelas Tabelas 7 e 8 , a equạão de regressão mültipla, com todos os parâmetros que exerceram alguma influência significativa na população e o valor desta explicação é mostrado pelo respectivo $R^{2}$.

\subsection{Correlação entre os estāgios amostrados}

\subsubsection{Correlação simples entre os estāgios}

Para uma análise prévia dos dados populacionais amostrados, procuroumse correlacionänlos entre si, atra vés de uma anälise de regressão simples, obtendonse o coeficiente de correlação ( $r$ ) e respectivo valor de F para cada comparação, Assim, a Tabela 9 resume os resultados da comparação entre os diferentes instares ninfais entre si e com o nümero de espumas. Jä nas Tabelas 10 a 14 estão relacionados 
os instares ninfais ( $I$ a V) com o nümero de adultos coletados nas diferentes séries de redadas, para a mesma época de amostragem $(0), 15,30,45$ e 60 dias após o levantamento de ninfas. Os resultados da comparação entre o nümero total de ninfas e o numero total de espumas com o número de adultos coletados nas diferentes épocas e nümero de redadas, se encontram resumidos nas Tabelas 15 e 16. A Tabela 17 mostra os resultados das correlações entre o nümero total de ninfas e espumas com os numeros obtidos para diferentes instares ninfais, para a mesma época de amostragem, enquanto que na Tabela 18 estão os resultados da correlação entre o nûmero total de espumas com o número de ninfas na mesma época (0), 15, 30,45 e 60 dias após, a lèm da correlação entre ninfas de uma ëpoca com ninfas $15,30,45$ e 60 dias apös. A Tabela 19 reune os resultados da correlação entre o número de adultos nas diferentes séries de redadas com o nümero de adultos coletados na mesma série de redadas mas aos 15, 30,45 e 60 dias após e a Tabela 20 mostra os resultados da correlação entre os diferentes números de redadas para a mesma época de amostragem. 
TABELA 9. Coeficientes de correlação ( $r$ ) e teste "F" entre os instares ninfais, nümero total de ninfas e nüme ro total de espumas de cigarrinhas das pastagens, em Sales 01iveira, SP, em 1979/80.

\begin{tabular}{|c|c|c|c|c|c|c|}
\hline Estägios & $\begin{array}{c}\text { Insta } \\
\text { res }\end{array}$ & $\begin{array}{l}\text { Corre } \\
\text { lação }\end{array}$ & Estägios & $\begin{array}{c}\text { Insta } \\
\text { res }\end{array}$ & $r$ & $\mathrm{~F}$ \\
\hline Ninfas & $\mathrm{V}$ & $\mathrm{x}$ & Ninfas & I V & 0,55 & $19,01 * *$ \\
\hline $\mathrm{Ninfas}$ & V & $\mathrm{x}$ & Ninfas & I I I & 0,67 & $36,38 * *$ \\
\hline $\mathrm{Ninfas}$ & V & $\mathrm{X}$ & Ninfas & I I & 0,46 & $11,26 * *$ \\
\hline $\mathrm{Ninfas}$ & V & $\mathrm{X}$ & Ninfas & I & 0,28 & $2,65 \mathrm{~ns}$ \\
\hline $\mathrm{Ninfas}$ & V & $\mathrm{x}$ & $\begin{array}{r}\text { Ninfas } \\
\text { total }\end{array}$ & r & 0,90 & $159,05 * *$ \\
\hline Ninfas & V & $\mathrm{X}$ & Espumas & r & 0,51 & $16,00 * *$ \\
\hline $\mathrm{Ninfas}$ & IV & $\mathrm{X}$ & Ninfas & I I I & 0,88 & $186,28 * *$ \\
\hline $\mathrm{Ninf}$ as & IV & $\mathrm{x}$ & Ninfas & I I & 0,80 & $87,09 * *$ \\
\hline $\mathrm{Ninfas}$ & IV & $\mathrm{X}$ & Ninfas & I & 0,48 & $11,35 * *$ \\
\hline $\mathrm{Ninfas}$ & IV & $\mathrm{x}$ & $\begin{array}{r}\text { Ninfas } \\
\text { total }\end{array}$ & $\Gamma$ & 0,41 & $8,36 * *$ \\
\hline Ninfas & IV & $\mathrm{X}$ & Es pumas & n & 0,91 & $251,31 * *$ \\
\hline $\mathrm{Ninfas}$ & I I I & $\mathrm{X}$ & Ninfas & I I & 0,89 & $190,76 * *$ \\
\hline $\mathrm{Ninfas}$ & I I I & $\mathrm{x}$ & Ninfas & I & 0,61 & $21,32 * *$ \\
\hline $\mathrm{Ninfas}$ & I I I & $\mathrm{x}$ & $\begin{array}{r}\text { Ninfas } \\
\text { total }\end{array}$ & - & 0,57 & $19,38 * *$ \\
\hline Ninfas & I I I & $\mathrm{x}$ & Espumas & - & 0,92 & $277,79 * *$ \\
\hline Ninfas & I I & $\mathrm{x}$ & Ninfas & I & 0,78 & $56,20 * *$ \\
\hline $\mathrm{Ninfas}$ & I I & $\mathrm{x}$ & $\begin{array}{r}\text { Ninfas } \\
\text { total }\end{array}$ & $r$ & 0,44 & $8,68 * *$ \\
\hline Ninfas & I I & $\mathrm{x}$ & Es pumas & $\pi$ & 0,91 & $242,17 * *$ \\
\hline $\mathrm{Ninfas}$ & I & $\mathrm{x}$ & $\begin{array}{r}\text { Ninfas } \\
\text { tota } 1\end{array}$ & - & 0,51 & $10,30 * *$ \\
\hline $\mathrm{Ninf}$ as & I & $\mathrm{x}$ & Espumas & - & 0,69 & $32,97 * *$ \\
\hline $\begin{array}{r}\text { Ninfas } \\
\text { total }\end{array}$ & - & $\mathrm{X}$ & Espumas & - & 0,99 & $288,24 * *$ \\
\hline
\end{tabular}

** significativo ao nivel de $1 \%$. 
TABELA 10. Coeficientes de correlação ( $r$ ) e teste "F" entre instar ninfal $V$ e número de adultos de cigarrirha das pastagens, por 25, 50,75 e 100 redadas, amostrados na mesma época $(0), 15,30,45$ e 60 dias após, em Sales Oliveiras, SP, em 1979/80.

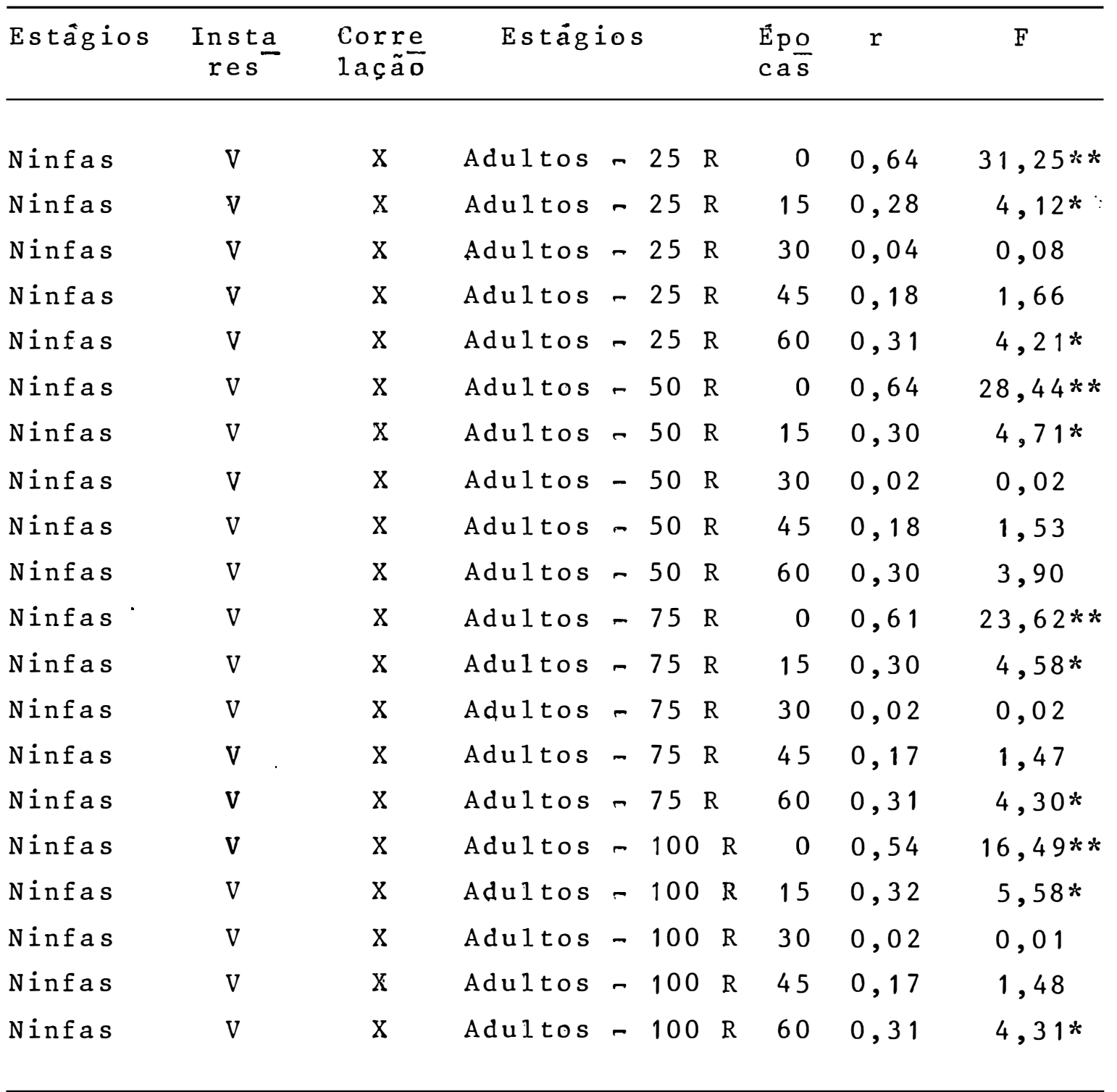

* significativo ao nivel de $5 \%$

** significativo ao nivel de $1 \%$

$R$ - corresponde ao nümero de redadas 
TABELA 1i. Coeficientes de correlação ( $x$ ) e teste "F" entre o instax ninfal IV e numero de adultos de cigarrinhas das pastagens por $25,50,75$ e 100 redadas, amostrados na mesma época (0), 15, 30,45 e 60 dias após, em Sales Oliveira, SP, em 1979/80.

\begin{tabular}{|c|c|c|c|c|c|c|c|c|}
\hline \multirow{2}{*}{$\begin{array}{l}\text { Estägios } \\
\text { Ninfas }\end{array}$} & \multirow{2}{*}{$\begin{array}{c}\text { Insta } \\
\text { res } \\
\text { IV }\end{array}$} & \multirow{2}{*}{$\begin{array}{c}\text { Corre } \\
\text { lação } \\
\text { X }\end{array}$} & \multicolumn{3}{|c|}{ Estägios } & \multirow{2}{*}{$\begin{array}{c}\text { Êpo } \\
\text { cas } \\
0\end{array}$} & \multirow{2}{*}{$\frac{r}{0,32}$} & \multirow{2}{*}{$\begin{array}{l}F \\
6,08 *\end{array}$} \\
\hline & & & Adultos & -25 & $\mathrm{R}$ & & & \\
\hline $\mathrm{Ninf}$ as & IV & $\mathrm{X}$ & Adu 1 tos & -25 & $\mathrm{R}$ & 15 & 0,56 & $24,10 * *$ \\
\hline Ninfas & IV & $\mathrm{X}$ & Adu 1 tos & -25 & $\mathrm{R}$ & 30 & 0,34 & $7,26 * *$ \\
\hline Ninfas & IV & $\mathrm{X}$ & Adultos & -25 & $\mathrm{R}$ & 45 & 0,05 & 0,11 \\
\hline Ninfas & IV & $\mathrm{x}$ & Adultos & -25 & $\mathrm{R}$ & 60 & 0,30 & $5,03 *$ \\
\hline Ninfas & IV & $\mathrm{X}$ & Adultos & -50 & R & 0 & 0,05 & 0,12 \\
\hline Ninf as & IV & $\mathrm{x}$ & AduJtos & -50 & $\mathrm{R}$ & 15 & 0,58 & $26,76 * *$ \\
\hline Ninf as & IV & $\mathrm{x}$ & Adul tos & -50 & $\mathrm{R}$ & 30 & 0,37 & $8,76 * *$ \\
\hline Ninfas & IV & $\mathrm{X}$ & Adultos & -50 & $\mathrm{R}$ & 45 & 0,03 & 0,04 \\
\hline Ninfas & IV & $\mathrm{X}$ & Adultos & -50 & $\mathrm{R}$ & 60 & 0,29 & $4,54 *$ \\
\hline Ninfas & IV & $\mathrm{X}$ & Adultos & -75 & $\mathrm{R}$ & 0 & 0,08 & 0,29 \\
\hline Ninfas & IV & $\mathrm{X}$ & Adultos & -75 & $\mathrm{R}$ & 15 & 0,58 & $26,49 * *$ \\
\hline Ninfas & IV & $\mathrm{X}$ & Adultos & -75 & $\mathrm{R}$ & 30 & 0,37 & $8,82 * *$ \\
\hline Ninfas & IV & $\mathrm{X}$ & Adultos & -75 & $\mathrm{R}$ & 45 & 0,02 & 0,03 \\
\hline Ninfas & IV & $\mathrm{X}$ & Adultos & -75 & $\mathrm{R}$ & 60 & 0,29 & $4,73 *$ \\
\hline Ninfas & IV & $\mathrm{X}$ & Adultos & -100 & $R$ & 0 & 0,11 & 0,56 \\
\hline Ninfas & IV & $\mathrm{X}$ & Adultos & -100 & $R$ & 15 & 0,54 & $21,65 * *$ \\
\hline Ninfas & IV & $\mathrm{X}$ & Adultos & -100 & $R$ & 30 & 0,38 & $9,12 *$ \\
\hline Ninfas & I V & $\mathrm{X}$ & Adultos & -100 & $R$ & 45 & 0,02 & 0,02 \\
\hline Ninfas & IV & $\mathrm{x}$ & Adu 1 tos & $\therefore \quad 100$ & $R$ & 60 & 0,29 & $4,82 *$ \\
\hline
\end{tabular}

* significativo ao nível de $5 \%$ $* *$ significativo ao nivel de $1 \%$ 。 
TABELA 12. Coeficientes de correlação (r) e teste "F" entre o instar ninfal III e nümero de adultos de cigarm rinhas das pastagens por $25,50,75$ e 100 redadas, amostrados na mesma. ëpoca (0), 15, 30, 45 e 60 dias apòs, em Sales 0liveira, SP, em 1979/80.

\begin{tabular}{|c|c|c|c|c|c|c|c|c|c|}
\hline \multirow{2}{*}{$\frac{\text { Estägios }}{\text { Ninfas }}$} & \multirow{2}{*}{$\begin{array}{c}\begin{array}{c}\text { Insta } \\
\text { res }\end{array} \\
\text { III }\end{array}$} & \multirow{2}{*}{$\frac{\operatorname{Corr}_{\text {e ção }}}{x}$} & \multicolumn{4}{|c|}{ Estägios } & \multirow{2}{*}{$\frac{E_{\mathrm{po}}}{\mathrm{cas}}$} & \multirow{2}{*}{$\frac{r}{0,33}$} & \multirow{2}{*}{$\frac{F}{6,55 *}$} \\
\hline & & & Adu 1 tos & - & 25 & $\mathrm{R}$ & & & \\
\hline Ninfas & I I I & $\mathrm{x}$ & Adu 1 tos & - & 25 & $\mathrm{R}$ & 15 & 0,46 & $14,15 * *$ \\
\hline Ninfas & I I I & $\mathrm{x}$ & Adu 1 tos & 7 & 25 & $\mathrm{R}$ & 30 & 0,47 & $14,31 * *$ \\
\hline Ninfas & I I I & $\mathrm{X}$ & Adultos & $n$ & 25 & $\mathrm{R}$ & 45 & 0,09 & 0,46 \\
\hline Ninfas & I I I & $\mathrm{x}$ & Adu 1 tos & - & 25 & $\mathrm{R}$ & 60 & 0,30 & $4,81 *$ \\
\hline Ninfas & I I I & $\mathrm{X}$ & Adu1tos & $n$ & 50 & $\mathrm{R}$ & 0 & 0,03 & 0,05 \\
\hline Ninfas & I I I & $\mathrm{X}$ & Adu 1 tos & - & 50 & $\mathrm{R}$ & 15 & 0,48 & $15,76 * *$ \\
\hline Ninfas & I I I & $\mathrm{x}$ & Adu 1 tos & - & 50 & $\mathrm{R}$ & 30 & 0,49 & $16,66 * *$ \\
\hline Ninfas & I I I & $\mathrm{X}$ & Adu 1 tos & - & 50 & $\mathrm{R}$ & 45 & 0,12 & 0,74 \\
\hline $\mathrm{Ninf}$ as & I I I & $\mathrm{X}$ & Adu 1 tos & - & 50 & $\mathrm{R}$ & 60 & 0,29 & $4,33 *$ \\
\hline Ninfas & I I I & $\mathrm{x}$ & Adu 1 tos & - & 75 & $\mathrm{R}$ & 0 & 0,07 & 0,23 \\
\hline Ninfas & I I I & $\mathrm{x}$ & Adultos & - & 75 & $\mathrm{R}$ & 15 & 0,48 & $15,33 * *$ \\
\hline Ninfas & I I I & $\mathrm{X}$ & Adu 1 tos & - & 75 & $\mathrm{R}$ & 30 & 0,49 & $16,67 * *$ \\
\hline Ninfas & I I I & $x$ & Adu 1 tos & - & 75 & $\mathrm{R}$ & 45 & 0,12 & 0,82 \\
\hline Ninfas & I I I & $x$ & Adultos & $r$ & 75 & $\mathrm{R}$ & 60 & 0,29 & $4,55 *$ \\
\hline Ninfas & I I I & $\mathrm{X}$ & Adultos & $r$ & 100 & $R$ & 0 & 0,10 & 0,46 \\
\hline Ninfas & I I I & $\mathrm{X}$ & Adu 1 tos & - & 100 & $R$ & 15 & 0,47 & $14,45 * *$ \\
\hline Ninfas & I I I & $X$ & Adultos & $c$ & 100 & $R$ & 30 & 0,49 & $16,66 * *$ \\
\hline Ninfas & I I I & $\mathrm{X}$ & Adu 1 tos & $r$ & 100 & $R$ & 45 & 0,13 & 0,92 \\
\hline Ninfas & I I I & $X$ & Adu Itos & - & 100 & $R$ & 60 & 0,29 & $4,52 \%$ \\
\hline
\end{tabular}

* significativo ao nivel de $5 \%$ ** significativo ao nive 1 de $1 \%$ 
TABELA 13. Coeficientes de correlą̧ão (r) e teste "F": entre o instar ninfal II e nưmero de adultos de cigarri nhas das pastagens por 25, 50, 75 e 100 redadas, amostrados na mesma época $(0), 15,30,45$ e 60 dias após, em Sales Oliveira, SP, em 1979/80.

\begin{tabular}{|c|c|c|c|c|c|c|c|c|}
\hline \multirow{2}{*}{$\begin{array}{l}\text { Estägios } \\
\text { Ninfas }\end{array}$} & \multirow{2}{*}{$\begin{array}{l}\text { Insta } \\
\text { res } \\
\operatorname{II}\end{array}$} & \multirow{2}{*}{$\begin{array}{c}\text { Corre } \\
\text { 1 ação } \\
\qquad\end{array}$} & \multicolumn{3}{|c|}{ Estägios } & \multirow{2}{*}{$\begin{array}{r}\text { Expo } \\
\text { cas } \\
0\end{array}$} & \multirow{2}{*}{$\frac{r}{0,30}$} & \multirow{2}{*}{$\frac{F}{4,80 *}$} \\
\hline & & & Adu 1 tos & -25 & $\mathrm{R}$ & & & \\
\hline Ninfas & I I & $\mathrm{X}$ & Adu 1 tos & -25 & $\mathrm{R}$ & 15 & 0,37 & $7,60 * *$ \\
\hline Ninfas & I I & $\mathrm{X}$ & Adultos & $r 25$ & $\mathrm{R}$ & 30 & 0,44 & $11,39 * *$ \\
\hline Ninfas & I I & $\mathrm{X}$ & Adultos & -25 & $\mathrm{R}$ & 45 & 0,11 & 0,63 \\
\hline Ninfas & I I & $\mathrm{X}$ & Adu 1 tos & -25 & $\mathrm{R}$ & 60 & 0,23 & 2,76 \\
\hline Ninfas & I I & $\mathrm{X}$ & Adu 1 tos & -50 & $\mathrm{R}$ & 0 & 0,09 & 0,34 \\
\hline $\mathrm{Ninf}$ as & I I & $\mathrm{X}$ & Adu 1 tos & -50 & $\mathrm{R}$ & 15 & 0,39 & $8,60 * *$ \\
\hline Ninfas & I I & $\mathrm{X}$ & Adultos & -50 & $\mathrm{R}$ & 30 & 0,47 & $13,65 * *$ \\
\hline Ninfas & I I & $\mathrm{X}$ & Adu 1 tos & -50 & $\mathrm{R}$ & 45 & 0,15 & 1,03 \\
\hline Ninfas & I I & $\mathrm{X}$ & Adultos & -50 & $\mathrm{R}$ & 60 & 0,21 & 2,25 \\
\hline Ninfas & I I & $\mathrm{X}$ & Adu 1 tos & -75 & $\mathrm{R}$ & 0 & 0,12 & 0,69 \\
\hline Ninfas & I I & $\mathrm{X}$ & Adultos & -75 & $\mathrm{R}$ & 15 & 0,39 & $8,62 * *$ \\
\hline Ninfas & I I & $\mathrm{X}$ & Adultos & -75 & $\mathrm{R}$ & 30 & 0,47 & $13,30 * *$ \\
\hline $\mathrm{Ninfas}$ & I I & $\mathrm{X}$ & Adu 1 tos & -75 & $\mathrm{R}$ & 45 & 0,15 & 1,09 \\
\hline Ninfas & I I & $\mathrm{X}$ & Adultos & $\therefore 75$ & $\mathrm{R}$ & 60 & 0,21 & 2,28 \\
\hline Ninfas & I I & $\mathrm{X}$ & Adu 1 tos & -100 & $R$ & 0 & 0,14 & 0,87 \\
\hline Ninfas & I I & $X$ & Adu 1 tos & -100 & $R$ & 15 & 0,38 & $8,06 * *$ \\
\hline Ninfas & I I & $\mathrm{X}$ & Adu 1 tos & -100 & $R$ & 30 & 0,46 & $12,97 * *$ \\
\hline Ninfas & I I & $x$ & Adultos & -100 & $R$ & 45 & 0,15 & 1,16 \\
\hline Ninfas & I I & $\mathrm{x}$ & Adu 1 tos & $=100$ & $R$ & 60 & 0,21 & 2,21 \\
\hline
\end{tabular}

* significativo ao nível de $5 \%$ ** significativo ao nivel de $1 \%$ 
TABELA 14. Coeficientes de correlação (r) e teste "F" entre - instar ninfal I e numero de adultos de cigarrinhas das pastagens por 25, 50, 75 e 100 redadas, amostrados na mesma época (0), 15, 30, 45 e 60 dias apōs, em Sales 01iveira, SP, em 1979/80.

\begin{tabular}{|c|c|c|c|c|c|c|c|c|c|}
\hline \multirow{2}{*}{$\begin{array}{l}\text { Estágios } \\
\text { Ninfas }\end{array}$} & \multirow{2}{*}{$\begin{array}{c}\text { Insta } \\
\text { res } \\
\text { I }\end{array}$} & \multirow{2}{*}{$\begin{array}{c}\text { Corre } \\
\text { lação } \\
x\end{array}$} & \multicolumn{4}{|c|}{ Estágios } & \multirow{2}{*}{$\begin{array}{r}\text { Epo } \\
\text { cas } \\
0\end{array}$} & \multirow{2}{*}{$\begin{array}{c}r \\
0,24\end{array}$} & \multirow{2}{*}{$\begin{array}{c}F \\
2,33\end{array}$} \\
\hline & & & Adu 1 tos & - & 251 & $\mathrm{R}$ & & & \\
\hline Ninfas & I & $\mathrm{X}$ & Adu 1 tos & - & 251 & $\mathrm{R}$ & 15 & 0,31 & 3,88 \\
\hline Ninfas & I & $\mathrm{X}$ & Adu 1 tos & $m$ & 251 & $\mathrm{R}$ & 30 & 0,48 & $10,84 * *$ \\
\hline Ninfas & I & $\mathrm{X}$ & Adultos & $r$ & 251 & $\mathrm{R}$ & 45 & 0,11 & 0,45 \\
\hline Ninfas & I & $\mathrm{X}$ & Adultos. & $n$ & 251 & $\mathrm{R}$ & 60 & 0,30 & 3,75 \\
\hline Ninfas & I & $\mathrm{X}$ & Adultos & r & 501 & $\mathrm{R}$ & 0 & 0,14 & 0,74 \\
\hline Ninfas & I & $\mathrm{X}$ & Adultos & - & 501 & $\mathrm{R}$ & 15 & 0,32 & 4,10 \\
\hline Ninfas & I & $X$ & Adultos & - & 501 & $\mathrm{R}$ & 30 & 0,52 & $13,45 * *$ \\
\hline Ninfas & I & $\mathrm{X}$ & Adultos & - & 501 & $\mathrm{R}$ & 45 & 0,14 & 0,71 \\
\hline Ninfas & I & $\mathrm{X}$ & Adultos & - & 501 & $\mathrm{R}$ & 60 & 0,27 & 3,03 \\
\hline Ninfas & I & $\mathrm{X}$ & Adultos & - & 751 & $\mathrm{R}$ & 0 & 0,20 & 1,54 \\
\hline Ninfas & I & $\mathrm{X}$ & Adultos & - & 751 & $\mathrm{R}$ & 15 & 0,31 & 3,98 \\
\hline Ninfas & I & $\mathrm{X}$ & Adultos & - & 751 & $\mathrm{R}$ & 30 & 0,52 & $13,81 * x$ \\
\hline Ninfas & I & $\mathrm{x}$ & Adu 1 tos & - & 751 & $\mathrm{R}$ & 45 & 0,14 & 0,74 \\
\hline Ninfas & I & $\mathrm{X}$ & Adultos & - & 751 & $\mathrm{R}$ & 60 & 0,28 & 3,17 \\
\hline Ninfas & I & $\mathrm{X}$ & Adu 1 tos & - & 100 & $R$ & 0 & 0,24 & 2,17 \\
\hline Ninfas & I & $\mathrm{X}$ & Adu 1 tos & - & 100 & $R$ & 15 & 0,32 & 4,18 \\
\hline Ninfas & I & $\mathrm{X}$ & Adultos & - & 100 & $R$ & 30 & 0,52 & $13,77 * *$ \\
\hline Ninfas & I & $X$ & Adu 1 tos & - & 100 & $R$ & 45 & 0,15 & 0,81 \\
\hline Ninfas & I & $\mathrm{X}$ & Adu 1 tos & - & 100 & $R$ & 60 & 0,28 & 3,04 \\
\hline
\end{tabular}

$* *$ significativo ao nivel de $1 \%$, 
TABELA 15. Coeficientes de correlação $(r)$ e teste "F" entre o número total de ninfas e nûmero de adultos de cigarrinhas das pastagens por $25,50,75$ e 100 re dadas, amostrados na mesma época (0), 15, 30, 45 e 60 dias apōs, em Sales Oliveira, SP, em 1979/ 80 .

\begin{tabular}{|c|c|c|c|c|c|c|c|c|c|}
\hline \multicolumn{2}{|c|}{ Estägios } & \multirow{2}{*}{$\begin{array}{c}\text { Corre } \\
\text { 1 ação } \\
\qquad x\end{array}$} & \multicolumn{4}{|c|}{ Estägios } & \multirow{2}{*}{$\begin{array}{r}\text { Epo } \\
0 \\
0\end{array}$} & \multirow{2}{*}{$\begin{array}{c}\boldsymbol{r} \\
0,47\end{array}$} & \multirow{2}{*}{$\begin{array}{c}\mathrm{F} \\
11,71 * *\end{array}$} \\
\hline Ninfas & tota 1 & & Adu 1 tos & - & 25 & $\mathrm{R}$ & & & \\
\hline Ninfas & tota 1 & $x$ & Adu 1 tos & - & 25 & $\mathrm{R}$ & 15 & 0,47 & $11,60 * *$ \\
\hline Ninfas & tota 1 & $\mathrm{X}$ & Adu 1 tos & - & 25 & $\mathrm{R}$ & 30 & 0,18 & 1,45 \\
\hline Ninfas & tota 1 & $\mathrm{x}$ & Adu 1 tos & - & 25 & $\mathrm{R}$ & 45 & 0,13 & 0,71 \\
\hline Ninfas & $\operatorname{tota} 1$ & $\mathrm{X}$ & Adultos & - & 25 & $\mathrm{R}$ & 60 & 0,48 & $11,09 * *$ \\
\hline Ninfas & tota 1 & $\mathrm{X}$ & Adu 1 tos & - & 50 & $\mathrm{R}$ & 0 & 0,40 & $7,86 \% *$ \\
\hline Ninfas & tota 1 & $\mathrm{X}$ & Adu 1 tos & - & 50 & $\mathrm{R}$ & 15 & 0,50 & $13,92 * *$ \\
\hline Ninfas & tota 1 & $x$ & Adu 1 tos & - & 50 & $\mathrm{R}$ & 30 & 0,21 & 1,91 \\
\hline Ninfas & tota 1 & $\mathrm{X}$ & Adu 1 tos & - & 50 & $\mathrm{R}$ & 45 & 0,12 & 0,55 \\
\hline $\mathrm{Ninfas}$ & tota 1 & $\mathrm{x}$ & Adu 1 tos & - & 50 & $\mathrm{R}$ & 60 & 0,47 & $10,41 * *$ \\
\hline Ninfas & tota 1 & $x$ & Adu 1 tos & - & 75 & $\mathrm{R}$ & 0 & $0 ; 34$ & $5,26 *$ \\
\hline Ninfas & tota 1 & $\mathrm{X}$ & Adultos & - & 75 & $\mathrm{R}$ & 15 & 0,50 & $13,98 * *$ \\
\hline Ninfas & tota 1 & $\mathrm{X}$ & Adu 1 tos & $m$ & 75 & $\mathrm{R}$ & 30 & 0,21 & 1,96 \\
\hline $\mathrm{Ninfas}$ & tota 1 & $\mathrm{X}$ & Adu 1 tos & n & 75 & $\mathrm{R}$ & 45 & 0,11 & 0,53 \\
\hline Ninfas & tota 1 & $\mathrm{X}$ & Adu 1 tos & $m$ & 75 & $\mathrm{R}$ & 60 & 0,48 & $11,12 * *$ \\
\hline Ninfas & tota 1 & $\mathrm{X}$ & Adu 1 tos & $r$ & 100 & $R$ & 0 & 0,27 & 3,29 \\
\hline Ninfas & tota 1 & $\mathrm{X}$ & Adultos & $n$ & 100 & $R$ & 15 & 0,51 & $14,09 * *$ \\
\hline Ninfas & tota 1 & $\mathrm{X}$ & Adu 1 tos & - & 100 & $R$ & 30 & 0,22 & 2,00 \\
\hline Ninfas & tota 1 & $x$ & Adultos & $r$ & 100 & $R$ & 45 & 0,11 & 0,49 \\
\hline Ninfas & tota 1 & $\mathrm{x}$ & Adu I tos & - & 100 & $R$ & 60 & 0,48 & $11,09 * *$ \\
\hline
\end{tabular}

* significativo ao nivel de $5 \%$

** significativo ao nível de $1 \%$ 
TABELA 16. Coeficientes de correlação ( $r$ ) e teste "F" entre o nûmero total de espumas e nümero de adultos de cigarrinhas das pastagens por 25, 50, 75 e 100 re dadas, amostrados na mesma epoca (0), $15,30,4 \overline{5}$ e 60 dias apōs, em Sales oliveira, SP, em 1979/80.

\begin{tabular}{|c|c|c|c|c|c|c|c|c|}
\hline \multirow{2}{*}{$\begin{array}{l}\text { Estägios } \\
\text { Espumas }\end{array}$} & \multirow{2}{*}{$\begin{array}{c}\text { Insta } \\
\text { res } \\
-\end{array}$} & \multirow{2}{*}{ 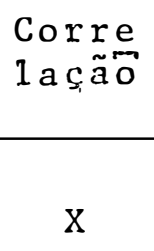 } & \multicolumn{3}{|c|}{ Estägios } & \multirow{2}{*}{$\begin{array}{r}\text { Exo } \\
\text { cas } \\
0\end{array}$} & \multirow{2}{*}{$\begin{array}{c}x \\
0,35\end{array}$} & \multirow{2}{*}{$\begin{array}{l}F \\
7,03 *\end{array}$} \\
\hline & & & Adultos & -25 & $\mathrm{R}$ & & & \\
\hline Espumas & - & $\mathrm{X}$ & Adultos & -25 & $\mathrm{R}$ & 15 & 0,43 & $11,74 * *$ \\
\hline Espumas & - & $\mathrm{x}$ & Adultos & $r 25$ & $\mathrm{R}$ & 30 & 0,46 & $14,07 * *$ \\
\hline Espumas & r & $\mathrm{x}$ & Adultos & -25 & $\mathrm{R}$ & 45 & 0,14 & 1,02 \\
\hline Espumas & - & $\mathrm{X}$ & Adultos & -25 & $\mathrm{R}$ & 60 & 0,27 & 3,80 \\
\hline Espumas & - & $\mathrm{x}$ & Adultos & -50 & $\mathrm{R}$ & 0 & 0,08 & 0,31 \\
\hline Espumas & - & $\mathrm{X}$ & Adultos & -50 & $\mathrm{R}$ & 15 & 0,45 & $12,95 * \div$ \\
\hline Espumas & $m$ & $\mathrm{x}$ & Adultos & -50 & $R$ & 30 & 0,49 & $16,60 * *$ \\
\hline Espumas & - & $\mathrm{X}$ & Adu 1 tos & -50 & $\mathrm{R}$ & 45 & 0,16 & 1,44 \\
\hline Es pumas. & - & $\mathrm{x}$ & Adultos & -50 & $\mathrm{R}$ & 60 & 0,25 & 3,20 \\
\hline Espumas & - & $\mathrm{X}$ & Adu 1 tos & -75 & $\mathrm{R}$ & 0 & 0,11 & 0,60 \\
\hline Espumas & - & $\mathrm{x}$ & Adu 1 tos & -75 & $\mathrm{R}$ & 15 & 0,44 & $12,61 * *$ \\
\hline Espumas & - & $\mathrm{x}$ & Adu 1 tos & -75 & $\mathrm{R}$ & 30 & 0,49 & $16,50 * *$ \\
\hline Espumas & - & $\mathrm{x}$ & Adultos & -75 & $\mathrm{R}$ & 45 & 0,17 & 1,51 \\
\hline Espumas & - & $\mathrm{x}$ & Adultos & -75 & $\mathrm{R}$ & 60 & 0,26 & 3,34 \\
\hline Espumas & - & $\mathrm{X}$ & Adultos & -100 & $R$ & 0 & 0,15 & 1,08 \\
\hline Espumas & - & $\mathrm{x}$ & Adultos & -100 & $R$ & 15 & 0,42 & $11,31 * \%$ \\
\hline Espumas & - & $\mathrm{X}$ & Adultos & -100 & $R$ & 30 & 0,49 & $16,32 * x$ \\
\hline Espumas & on & $\mathrm{X}$ & Adultos & -100 & $R$ & 45 & 0,17 & 1,59 \\
\hline Espumas & - & $\mathrm{X}$ & Adultos & -100 & $R$ & 60 & 0,25 & 3,30 \\
\hline
\end{tabular}

* significativo ao nivel de $5 \%$ $* *$ significativo ao nivel de $1 \%$ 
TABELA 17, Coeficientes de correlação (r) e teste "F" entre o nümero total de espumas e ninfas e os diferentes instares ninfais de cigarrinhas das pastagens, amostrados na mesma época (0), em sales 01 i veira, SP, em 1979/80.

\begin{tabular}{|c|c|c|c|c|c|c|c|c|}
\hline \multicolumn{2}{|c|}{ Estägios } & \multirow{2}{*}{$\begin{array}{c}\text { Insta } \\
\text { res } \\
-\end{array}$} & \multirow{2}{*}{$\begin{array}{l}\text { Corre } \\
\text { laşão } \\
\qquad x\end{array}$} & \multicolumn{2}{|c|}{ Estágios } & \multirow{2}{*}{$\begin{array}{c}\text { Insta } \\
\operatorname{res} \\
1-\end{array}$} & \multirow{2}{*}{$\begin{array}{c}\mathrm{r} \\
0,99\end{array}$} & \multirow{2}{*}{$\begin{array}{c}F \\
283,24 * *\end{array}$} \\
\hline Espumas & & & & $N$ infas & tota 1 & & & \\
\hline Espumas & & - & $\mathrm{X}$ & Ninfas & & I & 0,69 & $32,97 * *$ \\
\hline Espumas & & - & $\mathrm{x}$ & $\mathrm{N}$ infas & & I I & 0,91 & $2.42,17 * *$ \\
\hline Espumas & & m & $\mathrm{X}$ & $\mathrm{N}$ infas & & I I I & 0,92 & $277,79 * \%$ \\
\hline Espumas & & $m$ & $\mathrm{x}$ & $\mathrm{N}$ infas & & IV & 0,91 & $251,31 * *$ \\
\hline Espumas & & - & $\mathrm{X}$ & $\mathrm{N}$ infas & & V & 0,51 & $16,01 * *$ \\
\hline Ninfas & tota 1 & r & $\mathrm{X}$ & $\mathrm{N}$ infas & & I & 0,51 & $10,30 \%$ \\
\hline Ninfas & tota 1 & r & $\mathrm{x}$ & $\mathrm{N}$ infas & & J. J. & 0,44 & $8,68 * *$ \\
\hline Ninfas & tota 1 & $m$ & $\mathrm{x}$ & $\mathrm{N}$ inf as & & I I I & 0,57 & $19,38 * *$ \\
\hline Ninfas & total & $r$ & $\mathrm{X}$ & Ninfas & & I.V & 0,41 & $8,36 * *$ \\
\hline Ninfas & tota 1 & - & $\mathrm{X}$ & $N$ inf $f$ a & & $V$ & 0,90 & $159,05 \% *$ \\
\hline
\end{tabular}

$* *$ significativo ao nivel de $1 \%$ 
TABELA 18. Coeficientes de correlação (r) e teste "F" entre o nümero total de espumas e ninfas e o nümero total de ninfas de cigarrinhas das pastagens, amostrados na mesma ëpoca (0), 15, 30, 45 e 60 dias apōs, em Sales 01 iveira, SP, em 1979/80.

\begin{tabular}{lllllll}
\hline Estägios Eocas & $\operatorname{Corre}$ \\
1 ação
\end{tabular}$\quad$ Estägios Epocas $\quad r \quad F$

\begin{tabular}{lcccccc}
\hline Espumas & 0 & $X$ & Ninfas & 0 & 0,99 & $283,24 * *$ \\
Espumas & 0 & $X$ & Ninfas & 15 & 0,23 & 3,34 \\
Espumas & 0 & $X$ & Ninfas & 30 & $-0,09$ & 0,42 \\
Espumas & 0 & $X$ & Ninfas & 45 & $-0,24$ & 2,26 \\
Espumas & 0 & $X$ & Ninfas & 60 & $-0,22$ & 1,57 \\
Ninfas & 0 & $X$ & Ninfas & 15 & 0,60 & $31,96 * *$ \\
Ninfas & 15 & $X$ & Ninfas & 30 & 0,44 & $11,92 * *$ \\
Ninfas & 30 & $X$ & Ninfas & 45 & 0,40 & $7,01 *$ \\
Ninfas & 45 & $X$ & Ninfas & 60 & 0,42 & $6,58 *$ \\
Ninfas & 0 & $X$ & Ninfas & 30 & 0,06 & 0,18 \\
Ninfas & 15 & $X$ & Ninfas & 45 & 0,23 & 2,13 \\
Ninfas & 30 & $X$ & Ninfas & 60 & 0,23 & 1,75 \\
Ninfas & 0 & $X$ & Ninfas & 45 & $-0,32$ & $4,33 *$ \\
Ninfas & 15 & $X$ & Ninfas & 60 & $-0,39$ & $5,49 *$ \\
Ninfas & 0 & $X$ & Ninfas & 60 & $-0,38$ & $5,01 *$ \\
& & & & & & \\
\hline
\end{tabular}

* significativo ao pível de $5 \%$ * significativo ao nivel de $1 \%$ 
TABELA 19. Coeficientes de correlação ( $r$ ) e teste "F" entre o nümero total de adultos de cigarrinhas das pastagens por 25, 50, 75 e 100 redadas, amostrados na mesma época (0), 15, 30, 45 e 60 dias após, em Sa les de 01 iveira, SP, em 1979/80,

\begin{tabular}{|c|c|c|c|c|c|c|}
\hline Estägios & $\begin{array}{l}E_{\mathrm{po}} \\
\mathrm{cas}\end{array}$ & $\begin{array}{l}\text { Corre } \\
\text { lação }\end{array}$ & Estágios & $\begin{array}{l}\text { Epoo } \\
\text { cas }\end{array}$ & $r$ & F \\
\hline dultos-25 R & 0 & $\mathrm{x}$ & Adultos -25 R & 15 &, 33 & $6,83 *$ \\
\hline Adultos -50 R & 0 & $\mathrm{x}$ & Adultos -50 R & 15 & 0,07 & \\
\hline Adultos-75 R & 0 & $\mathrm{x}$ & Adultos-75 R & 15 & 0,01 & \\
\hline Adultos- $100 \mathrm{R}$ & 0 & $\mathrm{X}$ & Adultos $-100 \mathrm{R}$ & 15 & 0,02 & 0,03 \\
\hline Adultos-25 R & 0 & $\mathrm{X}$ & Adultos -25 R & 30 & 0,01 & 0,01 \\
\hline Adultos $-50 R$ & 0 & $\mathrm{X}$ & Adultos $-50 R$ & 30 & 0,31 & $5,24 *$ \\
\hline Adultosn75 R & 0 & $\mathrm{X}$ & Adultos-75 R & 30 & 0,34 & $6,77 *$ \\
\hline Adultos $-100 R$ & 0 & $\mathrm{X}$ & Adultosm 100 R & 30 & 0,37 & $7,99 * *$ \\
\hline Adultos 25 R & 0 & $\mathrm{x}$ & Adultos 25 R & 45 & 0,21 & 2,47 \\
\hline Adu 1 tos -50 R & 0 & $\mathrm{X}$ & Adultos $n 50$ R & 45 & 0,43 & $10,91 * *$ \\
\hline Adultos-75 R & 0 & $\mathrm{X}$ & Adultos-75 R & 45 & 0,45 & $12,03 * *$ \\
\hline Adultos $-100 \mathrm{R}$ & 0 & $\mathrm{X}$ & Adultos $-100 \mathrm{R}$ & 45 & 0,42 & $10,45 * *$ \\
\hline Adultos $-25 \mathrm{R}$ & 0 & $\mathrm{X}$ & Adultos $-25 \mathrm{R}$ & 60 & 0,40 & $9,04 * *$ \\
\hline Adultos -50 R & 0 & $\mathrm{X}$ & Adultos -50 R & 60 & 0,33 & $5,44 *$ \\
\hline Adultos-75 R & 0 & $\mathrm{X}$ & Adultos-75 R & 60 & 0,30 & $4,46 *$ \\
\hline Adultosn $100 \mathrm{R}$ & 0 & $\mathrm{X}$ & Adultos $-100 \mathrm{R}$ & 60 & 0,23 & 2,42 \\
\hline Adultos-25 R & 15 & $\mathrm{X}$ & Adultos-25 R & 30 & 0,42 & $12,26 * *$ \\
\hline Adultosm 50 R & 15 & $\mathrm{X}$ & Adultos -50 R & 30 & 0,44 & $13,79 * *$ \\
\hline Adultosm 75 R & 15 & $\mathrm{X}$ & Adultos-75 R & 30 & 0,43 & $12,21 * *$ \\
\hline Adultosin $100 \mathrm{R}$ & 15 & $\mathrm{X}$ & Adultos-100 R & 30 & 0,44 & $13,92 * *$ \\
\hline Adultos $-25 \mathrm{R}$ & 15 & $\mathrm{X}$ & Adultos-25 R & 45 & 0,20 & 2,28 \\
\hline Adultos -50 R & 15 & $\mathrm{X}$ & Adultos -50 R & 45 & 0,19 & 2,15 \\
\hline Adultos-75 R & 15 & $\mathrm{X}$ & Adultos-75 R & 45 & 0,20 & 2,39 \\
\hline Adultos $-100 \mathrm{R}$ & 15 & $\mathrm{X}$ & Adultos $-100 R$ & 45 & 0,21 & 2,46 \\
\hline Adu1tos -25 R & 15 & $\mathrm{X}$ & Adultos $-25 \mathrm{R}$ & 60 & 0,51 & $17,27 * *$ \\
\hline Adultosn 50 R & 15 & $X$ & Adultos -50 R & 60 & 0,54 & $19,49 * *$ \\
\hline Adultos-75 R & 15 & $X$ & Adultos-75 R & 60 & 0,55 & $21,12 * *$ \\
\hline Adultos-100 R & 15 & $\mathrm{X}$ & Adultos $-100 \mathrm{R}$ & 60 & 0,55 & $20,56 * *$ \\
\hline Adultos-25 R & 30 & $\mathrm{X}$ & Adultos-25 R & 45 & 0,43 & $13,26 * *$ \\
\hline$-50 R$ & 30 & $\mathrm{x}$ & Adultos -50 R & 45 & 0,45 & $* *$ \\
\hline $.75 \mathrm{R}$ & 30 & $\mathrm{X}$ & $s-75 R$ & 45 & 0,44 & $99 * *$ \\
\hline$-100 \mathrm{R}$ & 30 & $\mathrm{X}$ & $-100 \mathrm{R}$ & 45 & 0,45 & $14,50 * *$ \\
\hline$-25 \mathrm{R}$ & 3 & $\mathrm{X}$ & Adultos $-25 R$ & 60 & 0,25 & 3, \\
\hline$-50 \mathrm{R}$ & 30 & $\mathrm{X}$ & $-50 R$ & & 0,26 & 3 \\
\hline $1 \operatorname{tos}-75 \mathrm{R}$ & 30 & $\mathrm{x}$ & Adultos -75 R & & 0,26 & 3,71 \\
\hline Adultos $100 \mathrm{R}$ & 30 & $\mathrm{X}$ & Adultos $-100 \mathrm{R}$ & 60 & 0,27 & 3,98 \\
\hline Adultos $-25 \mathrm{R}$ & 45 & $\mathrm{X}$ & Adultos $-25 \mathrm{R}$ & 60 & 0,43 & $11,84 * *$ \\
\hline Adultos-50 R & 45 & $\mathrm{X}$ & Adultos -50 R & 60 & 0,43 & $11,31 * *$ \\
\hline Adultos-75 R & 45 & $\mathrm{X}$ & Adultos-75 R & 60 & 0,44 & $12,28 * *$ \\
\hline Adultos $-100 R$ & 45 & $\mathrm{x}$ & Adultos $-100 \mathrm{R}$ & 60 & 0,45 & $12,90 * *$ \\
\hline & & & & & & \\
\hline$* *$ signific & & & e $1 \%$ & & & \\
\hline
\end{tabular}


TABELA 20. Coeficientes de correlação ( $r$ ) e teste "F" entre o número total de adultos de cigarrinhas das pastagens, amostrados na mesma época $(0,15,30,45$ e 60 dias), por diferentes numeros de redadas (25, 50,75 e 100 redadas), em Sales 01 iveira, em $1979 / 80$.

\begin{tabular}{|c|c|c|c|c|c|c|c|}
\hline Estagios & & $\begin{array}{l}\text { Epo } \\
\text { cas }\end{array}$ & $\begin{array}{l}\text { Corre. } \\
\text { lação }\end{array}$ & Estägios & $\begin{array}{l}\text { Epoo } \\
\text { cas }\end{array}$ & $r$ & $\mathrm{~F}$ \\
\hline du 1 tos -25 & $\mathrm{R}$ & 0 & $x$ & Adultos -50 R & 0 & 0,79 & $86,44 * *$ \\
\hline Adu 1 to $s-25$ & $\mathrm{R}$ & 0 & $x$ & Adultos-75 R & 0 & 0,68 & $44,12 * *$ \\
\hline Adu 1 tos -25 & $\mathrm{R}$ & 0 & $\mathrm{X}$ & Adúltos-100 R & 0 & 0,58 & $25,33 * *$ \\
\hline Adu 1 tos -50 & $\mathrm{R}$ & 0 & $\mathrm{X}$ & Adultos-75 R & 0 & 0,98 & $1105,43 * *$ \\
\hline Adu 1 tos -50 & $\mathrm{R}$ & 0 & $\mathrm{X}$ & Adultos $-100 \mathrm{R}$ & 0 & 0,93 & $308,87 * *$ \\
\hline dultos -75 & $\mathrm{R}$ & 0 & $\mathrm{x}$ & Adultos $-100 \mathrm{R}$ & 0 & 0,97 & $835,91 * *$ \\
\hline Adultos -25 & $\mathrm{R}$ & 15 & $\mathrm{x}$ & Adultos -50 R & 15 & 0,99 & $8378,41 * *$ \\
\hline Adu 1 tos -25 & $\mathrm{R}$ & 15 & $x$ & Adultos-75 R & 15 & 0,99 & $4735,97 * *$ \\
\hline Adultos -25 & $\mathrm{R}$ & 15 & $\mathrm{x}$ & Adultos $-100 \mathrm{R}$ & 15 & 0,98 & $1302,68 * *$ \\
\hline Adultos -50 & $\mathrm{R}$ & 15 & $\mathrm{x}$ & Adultos-75 R & 15 & 0,99 & $18346,89 * *$ \\
\hline Adultos -50 & $\mathrm{R}$ & 15 & $\mathrm{x}$ & Adultos $-100 \mathrm{R}$ & 15 & 0,98 & $1497,51 * *$ \\
\hline 1 tos -75 & $\mathrm{R}$ & 15 & $\mathrm{x}$ & Adultos $-100 R$ & 15 & 0,98 & $06,62 * *$ \\
\hline Adultos -25 & $\mathrm{R}$ & 30 & $\mathrm{X}$ & Adultos -50 R & 30 & 0, & $9139,64 * *$ \\
\hline Adultos -25 & $\mathrm{R}$ & 30 & $X$ & Adultos-75 R & 30 & 0 & $5230,55 * *$ \\
\hline Adu 1 tos -25 & $\mathrm{R}$ & 30 & $x$ & Adultos $-100 R$ & 30 & 0,99 & $3991,86 * *$ \\
\hline Adultos -50 & $\mathrm{R}$ & 30 & $\mathrm{x}$ & Adultos -75 R & 30 & 0,99 & $19396,02 * *$ \\
\hline Adultos -50 & $\mathrm{R}$ & 30 & $x$ & Adu1tos $-100 \mathrm{R}$ & 30 & 0,99 & $9756,60 * *$ \\
\hline Adu 1 tos -75 & $\mathrm{R}$ & 30 & $x$ & Adultosm $100 \mathrm{R}$ & 30 & 0,99 & $28039,76 * *$ \\
\hline Adu 1 tos -25 & $\mathrm{R}$ & 45 & $x$ & Adultos $-50 R$ & 45 & 0,99 & $11592,14 * *$ \\
\hline Adultos -25 & $\mathrm{R}$ & 45 & $\mathrm{x}$ & Aduitos-75 R & 45 & 0,99 & $5641,94 * *$ \\
\hline Adultose 25 & $\mathrm{R}$ & 45 & $x$ & Adultos $=100 \mathrm{R}$ & 45 & 0,99 & $4206,80 * *$ \\
\hline Adu 1 to $s-50$ & $\mathrm{R}$ & 45 & $\mathrm{X}$ & Adultos-75 R & 45 & 0,99 & $22319,34 * *$ \\
\hline Adu 1 tos $n 50$ & $\mathrm{R}$ & 45 & $x$ & Adu1tos 100 R & 45 & 0,99 & $10489,30 * *$ \\
\hline Adultos -75 & $\mathrm{R}$ & 45 & $x$ & Adultos $100 \mathrm{R}$ & 45 & 0,99 & $29573,63 * *$ \\
\hline Adultosn 25 & $\mathrm{R}$ & 60 & $\mathrm{x}$ & Adultos $=50$ R & 60 & 0,99 & $3922,08 * *$ \\
\hline Adu 1 tos 25 & $\mathrm{R}$ & 60 & $x$ & Adultos -75 R & 60 & 0,99 & $5147,83 * *$ \\
\hline Adu 1 tos -25 & $\mathrm{R}$ & 60 & $x$ & Adultos $100 \mathrm{R}$ & 60 & 0,99 & $3813,89 * *$ \\
\hline Adu 1 tose 50 & $\mathrm{R}$ & 60 & $x$ & Adultos-75 R & 60 & 0,99 & $5433,72 * *$ \\
\hline Adu 1 tos -50 & $\mathrm{R}$ & 60 & $\mathrm{x}$ & Adultos $100 \mathrm{R}$ & 60 & 0,99 & $3905,23 * *$ \\
\hline Adu 1 tos $=75$ & $\mathrm{R}$ & 60 & $x$ & Adultos $-100 \mathrm{R}$ & 60 & 0,99 & $25584,08 * *$ \\
\hline
\end{tabular}

** significativo ao nivel de $1 \%$. 
4.3.2. Análise de regressão simples pelo programa de "Curvas"

Partindomse dos resultados obtidos na anälise de regressão simples e considerandorse que o número de espumas ề o de mais fácil obtenção no campo, procurou-se correla cionänlo com os demais estâgios da população, através do método de Curvas. Os resultados dessa anälise para os diferen tes estâgios e numero de redadas se encontram resumidos nas Tabelas 21,22 e 23, respectivamente, para a mesma época de amostragem das espumas, 15 e 30 dias após esta. Nestas tabe las são apresentados, para cada par de correlação em cada 10 cal, os valores de $R^{2}$ e F, seguidos da equação, que dentre as 25 testadas, melhor explica essa correlação.

4.4. Comparação do número médio de adultos nos diferentes números de redadas, nas diferentes épocas de amostra gens

Procurando-se determinar qual, dentre as séries de redadas, seria mais indicada para se adotar no campo, efetuourse uma anảlise de variância para o nümero médio de adultos coletados nos diferentes numeros de redadas, nas diferentes épocas de amostragens, em relação a data de avaliação de espumas, Os resultados desta anälise se encontram re sumidos na Tabela 24 , onde se observam resultados de F signi- 
ficativos, somente quando se compara ao numero de redadas.Tam bẹm foi significativo o valor de $F$ para a anảise de regressão para redadas, enquanto que para épocas não se observou efeitos significativos. 
TABELA 21. Equação de regressão simples efeluada para os diferentes locais de amostragens, dos dados obtidos nos levantamentos de campo de Deois flavopicta, em pastagens de Brachiaria decumbens, no muni cipio de Sales 01 iveira, SP, em 1979/80, para a mesma época de amostragern.

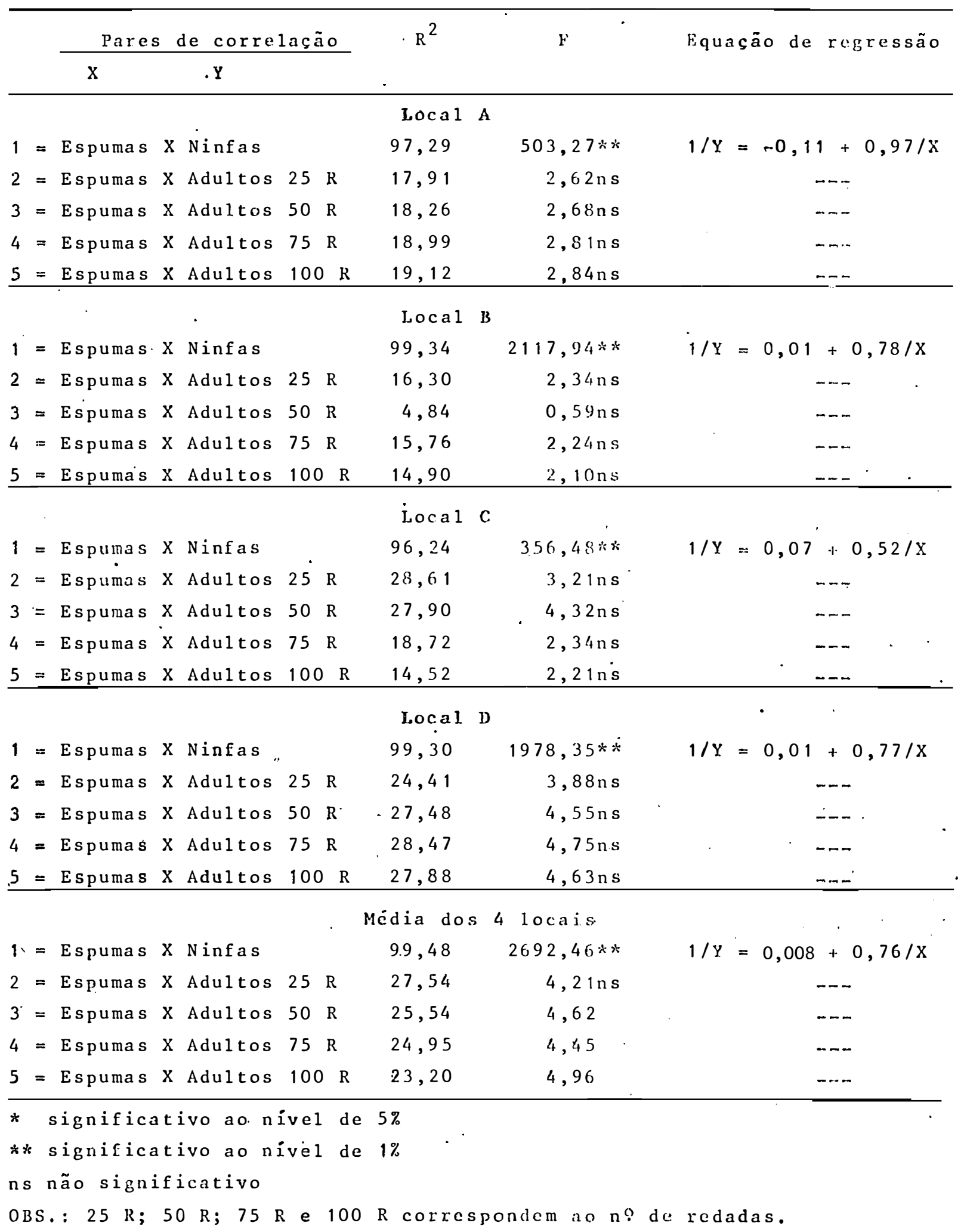


TABElo 22. Equação de regressão simples, efetuada para os diferentes locais de amostragens, dos dados obtidos nos. levantamentos de campo de .52. Deois flavopicta, em pastagens de bhachiahia decumbcus, no município de sales 01 iveira, SP, em 1979/80, para espumas de uma épo ca e ninfas e adultos coletados 15 dias após.

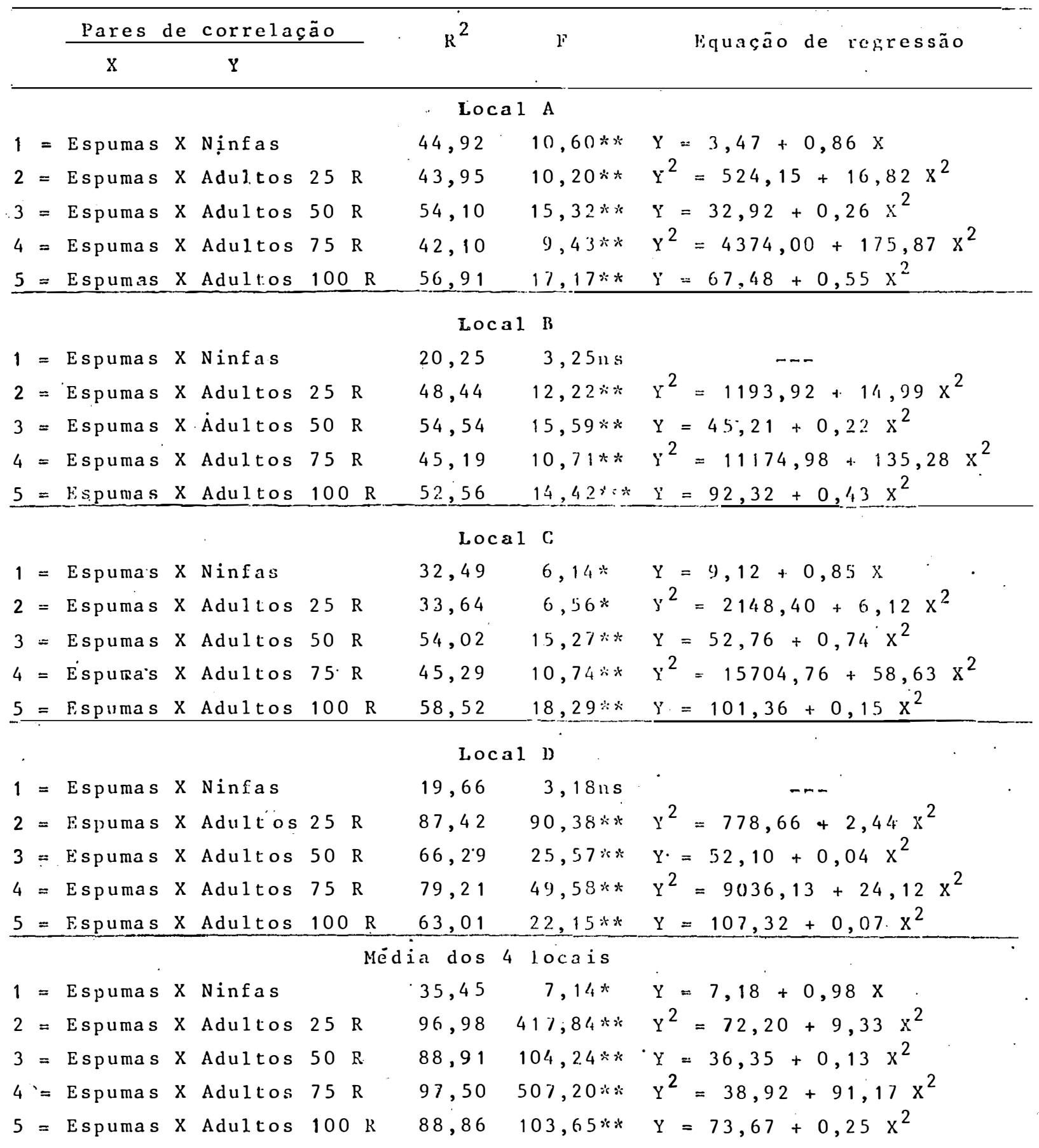

* significativo ao nivel de $5 \%$

** significativo ao nivel de $1 \%$

ns não significativo

OBS.: 25.R; $50 \mathrm{R} ; 75 \mathrm{R}$ e 100 R correspondem ao no de redadas, 
TABELA 23. Equação de regressão simples efecuada para os diferentes locais de amostragens, dos dados obtidos nos levantamentos de campo de Deois flavopicta, em pastagens de Brachiaria decumbens, no munici pio de Sales 0liveira, SP, en 1979/80, para espumas de uma época e ninfas e adultos coletados 30 dias após.

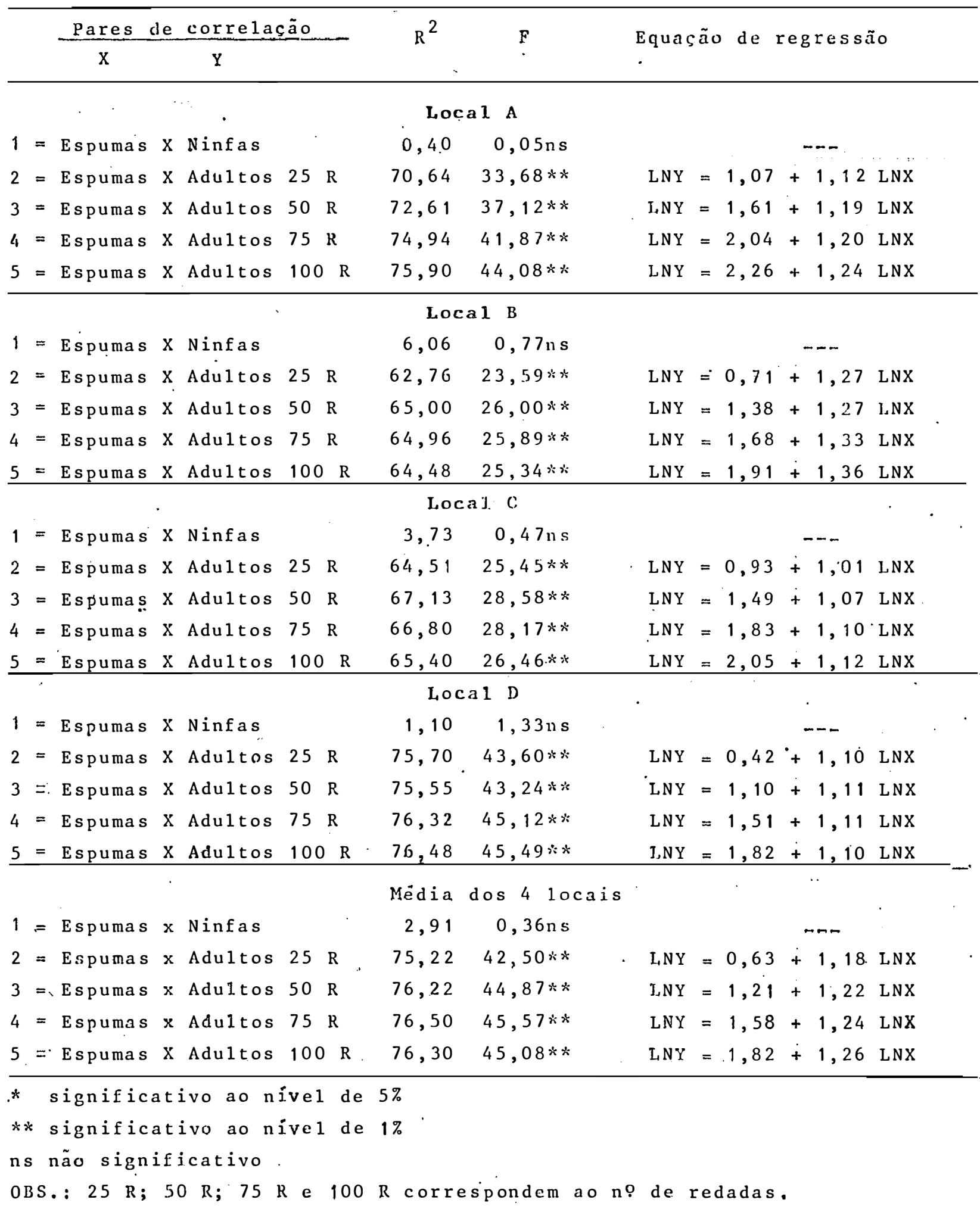


TABELA 24. Anälise de variância efetuada para o nümero médio de adultos coletados nas diversas redadas em diferentes épocas de amostragem, para os dados obtidos nos levantamentos de campo de Deois blavopicta, em pastagens de Brachiaria decumbens, no municipio de Sales 01 iveira, SP, em $1979 / 801 /$.

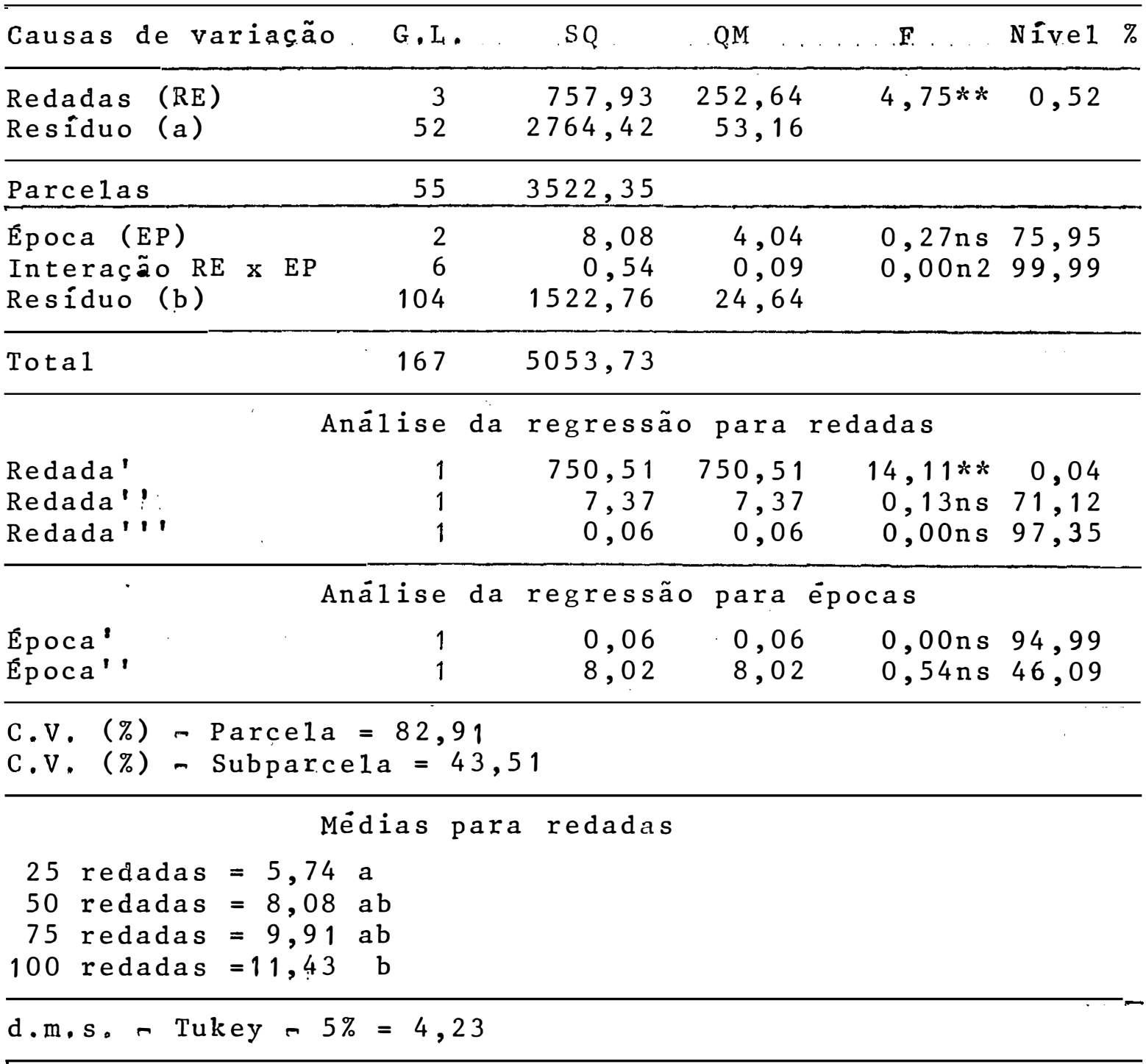

Mëdias para ëpocas

0 dias apös $=8,66$ a

15 dias apös $=9,10$ a

30 dias após $=8,62$ a

(1) - dados previamente transformados em $\sqrt{\mathrm{x}+0,5}$, (**) significativo ao nivel de $1 \%$ de probabilidade. OBS. mêdias seguidas de mesma letra não diferem entre si. 


\section{DISCUSSÃo}

5.1. Levantamentos populacionais

Conforme os resultados apresentados anteriormente, verificou-se somente a ocorrência de $D$. flavopicta em niveis populacionais significativos, uma vez que a ocorrência de outras espécies como Z. entreriana e M. fimbriolata perfaziam menos de $1 \%$ da população amostrada, confirmando os resul tados de $S \AA(1981)$.

EL-KADI (1978) citou essa espécie como predomí nante no Estado de São Paulo ( $85 \%$ ), enquanto CotTAS e RAMIRO (1981) contestaram esse dado, afirmando que a predominância das espécies está na dependência da espécie de capim atacada. Este fato é observado no presente trabalho, onde a ocorrência de D. flavopicta praticamente se deve à pastagem de B. decumbens, uma vez que em pastos vizinhos formados com capim colo- 
.56 .

nião (Panicum maximum), a predomināncia era de $Z$. entreriana. Essa observação vem confirmar os resultados obtidos por MILA NEZ (1980) e BIANCO e VILLACORTA (1978b), que citaram a preferēncia de Deois flavopicta por $B$. decumbens.

Com relação ao período de ocorrência verifica-se, pela comparação dos dados obtidos com aqueles citados na 1 iteratura, que ocorre variação de acordo com a região em estudo, não se podendo generalizar para todo Estado, dados obtidos numa região. Neste ensaio observoumse que as cigarrinhas ocorreram de setembro a maio, diferindo do período de ocorrência citados nos trabalhos de EL-KADI (1978) e MILANEZ (1980). Quanto ao pico populacional da praga, observa-se a mesma variação quando comparado com aqueles citados na literatura. Portanto, podense afirmar que tanto o período de ocorrência quanto os picos populacionais dessa espécie de c $\underline{i}$ garrinha, diferem de acordo com a região em estudo, não se podendo generalizar os dados obtidos.

Ao se analisarem, conjuntamente, os resultados (Tabelas 1 a 5 ) verificarse que, de uma maneira geral, o comportamento populacional das cigarrinhas coletadas nos diferentes locais, mas dentro da mesma pastagem, se manteve ba sicamente o mesmo. Isto mostra que para ensaios ou traba1hos que visem unicamente o estudo de flutuação populacional, não hā necessidade de se amostrar toda ärea, uma vez que se obterà o mesmo comportamento populacional, independentemente 
da ärea colhida. Neste ensaio observou-se que o pico popula cional principal da praga, ocorreu no mês de março, tanto pa ra ninfas como para adultos, resultados em parte semelhantes aos de EL-KADI (1978), MILANEZ (1980), FORTI et alii (1977), e relativamente diferentes daqueles observados por CotTAs e RAMIRO (1981) e MELO (1982).

Com os dados obtidos (Tabela 5) e com base nos dados de biologia da praga citados na literatura, pode-se afirmar que no presente ensaio obteve-se 3 gerações, sen do a primeira oriunda dos ovos que se encontravam em diapausa, a segunda oriunda dos adultos provenientes dessa 1 a gera ção (novembro), enquanto a terceira geração, proveniente dos adultos de janeiro, foi a responsável pelo pico populacional de marco e pela postura dos ovos que vão entrar em diapausa e originar a 1ạ geração da próxima infestação.

5.2. Influência dos parãmetros climáticos e sua correlação com os diferentes estágios da população

Vảrios são os parāmetros climáticos que direta ou indiretamente influem no desenvolvimento normal de determinado estágio da população de cigarrinhas das pastagens. Como pode ser verificado pelos dados (Tabelas 7 e 8), através das equações de regressão mültipla, diversos parâmetros atuando conjuntamente determinam, em muito, o aumento ou o decrēscimo dessa população. Por outro lado, verifica-se tam 
bém que para locais sob as mesmas condições climáticas, ocor rem muitas diferenças quanto às variäveis atuantes, sendo es te ponto facilmente notado quando se analise a variável isoladamente. Exceção feita ao nümero de ninfas do instar:I e ao número de adultos, nos demais obteve-se para cada local a influência de determinda variável.

Para o nümero total de espumas e ninfas, veri fica-se que a variável que, isoladamente, mais explicou a curva populacional desses estágios foi a precipitacão pluvio métrica seguida pela umidade relativa do ar (mínima), concor dando em parte com os resultados de SOUZA (1967), GUAGLIUMI (1972), DeBONA et alii (1967), MILANEZ (1980), MELO (1982) e PACHECO (1981). Para estes estägios foram observadas explicações em torno de $85 \%$ para alguns locais, enquanto para outros, sob as mesmas condições, esta explicação ficou em torno de $40 \%$, com mudanças nos paràmetros atuantes.

Analisandorse os instares ninfais (Tabela 8), observa-se que a precipitação pluviométrica exerce bastante influência nos instares mais jovens, sendo seguida pela temperatura minima do ar, -e medida que estes se desenvolvem. Já para o final desse desenvolvimento notanse, alëm da precipit tação pluviomētrica, a influência da umidade relativa do ar, que se torna muito importante no instar $V$. Dos instares nin fais, o instar I é o que mais sofre influência dos parâmetros climáticos, os quais explicaram em torno de $85 \%$ da cur- 
va populacional.

A população de adultos também foi muito bem explicada pelos parāmetros climäticos, em torno de $90 \%$, sendo destacada isoladamente a temperatura média do solo coberto a $5 \mathrm{~cm}$ de profundidade, dado este que vem confirmar os re sultados obtidos por MENDES (1976), apesar deste ter traba1hado com M. Gimbriolata em cana-de-açúcar. Por outro lado, a proporção sexual, além da temperatura mínima do solo a 5 cm de profundidade, que exerceu isoladamente uma influencia de 69,5\% na curva populacional de machos, com os elementos climäticos conjuntamente explicando em $92 \%$, também foi influenciada pela temperatura média do ar em $23 \%$ para fëmeas, com uma explicação total de $85 \%$ para a equação.

\subsection{Correlação entre os estāgios amostrados}

\subsection{1."Correlacão simples entre os estāgios}

Pelos resultados obtidos (Tabela 9) observa-se que a correlação. é maior entre instares vizinhos, isto $\bar{e}$, entre os instares $\mathrm{V}$ e IV, IV e III, III e II, II e I. Es ta correlação tende a diminuir à medida em que os mesmos se afastam, como por exemplo entre os instares V e I. Nota-se também que o instar V está mais correlacionado com o nümero total de ninfas, enquanto que os demais, se correlacionam mais com o número total de espumas. 
Verificarse (Tabela 10) que de uma maneira ge ral o instar $V$ estä mais correlacionado com o número de adu 1 tos coletados na mesma época de amostragem das ninfas, principalmente nos levantamentos com menores nümeros de redadas, sendo esta correlação diminuída à medida em que se aumenta este número. Já o instar IV (Tabela 11) mais se correlacio na com adultos 15 e 30 dias após sua amostragem, sendo maior aos 15 dias, independente do nümero de redadas. Resultados semelhantes são observados para o instar III (Tabela 12) que está mais correlacionado com adultos 15 e 30 dias após, sendo neste caso obtidas correlações basicamente iguais para os dois parâmetros. Resultados próximos e inversos aos anterio res, são notados para o instar II (Tabela 13) onde estes, apesar de correlacionados com adultos 15 e 30 dias após, pos suem uma maior correlação com estes últimos. Por outro lado, os dados (Tabela 14) indicam que as ninfas de instar I, somente estão correlacionadas com adultos de 30 dias após, independentemente dò número de redadas.

Correlacionando-se o nümero total de ninfas com o nümero de adultos nas diferentes épocas e nümero de re dadas (Tabela 15), verifica-se que estes mais se correlaciona com o nümero de adultos coletados na mesma época e 15 dias apōs, principalmente nos levantamentos com menores nüme tos de redadas e com os levantamentos de 60 dias após, independentemente do nümero de redadas. Já o número total de es 
pumas (Tabela 46) se correlaciona mais com adultos coletados aos 15 e 30 dias apos, independente do nümero de redadas.

Analisandomse conjuntamente os dados das Tabe las 9,16 e 17 poderse explicar a diferença acima descrita, uma vez que o nümero toral de ninfas está mais correlacionado com ninfas de instar $V$ e estas, por sua vez, mais se correlacionam com adultos coletados na mesma época (Tabela 10). Os demais instares se correlacionam mais com espumas (Tabela 9) e estas, como já foi visto anteriormente, se correlacionam mais com adultos 15 e 30 dias após.

08 resultados (Tabela 18), mostram claramente que o nümero total de espumas está correlacionado somente com o nümero total de ninfas, para a mesma época de amostragem. Por outro lado, o nümero de ninfas de uma época estä correlacionado com o nümero de ninfas 15,45 e 60 dias após, mostrando, assim, que o nümero avaliado numa determinada épo ca se mantèm por 15 dias, caindo aos 30 dias e voltando a se repetir 45 e 60 dias após. Resultados idênticos são apresen tados na Tabela 19, onde se observa que o nümero de adultos de uma época não possue nenhuma correlação, quando comparado com o nümero de adultos coletados 30 dias após.

Observamse, tambèm, que o nưmero de redadas não tem influência nas correlações entre adultos e demais es tägios (Tabela 20), mootrando assim que por este tipo de aná 
.62

1 ise, qualquer uma das séries de redadas pode ser adotada pa ra levantamentos das formas adultas de cigarrinhas das pasta gens.

5.3.2. Correlação através dos 25 modelos de regressão

Para a mesma época de amostragem (Tabela 21) verifica-se que, de uma maneira geral, somente foi obtida uma correlaça altamente significativa, quando se correlacio nam espumas e ninfas. Resultados idênticos foram obtidos na anâlise de regressão simples (Tabelas 9, 17 e 18), podendo-se afirmar que num levantamento de cigarrinhas das pastagens, basta amostrar o número de espumas, que é de mais fácio obtenção, ganhando-se tempo na amostragem. Esse resulta do vem confirmar aquele obtido por MELO (1982). Quanto a equação de regressão, verifica-se que, em todos locais foi obtido o mesmo tipo; a equação representativa da média dos 4 locais é indicada na Figura 1.

Analisando-se os resultados da correlação entre espumas e adultos de diferentes redadas, nota-se que em nenhum dos locais foi obtida alguma correlação, sendo estes resultados idênticos àqueles da anālise de regressão simples ( Tabela 16). 
.63.

GRAFICO DO I MODELO $\rightarrow 1 Y Y=0.42473989 E-03+.760740594 / X \mid$

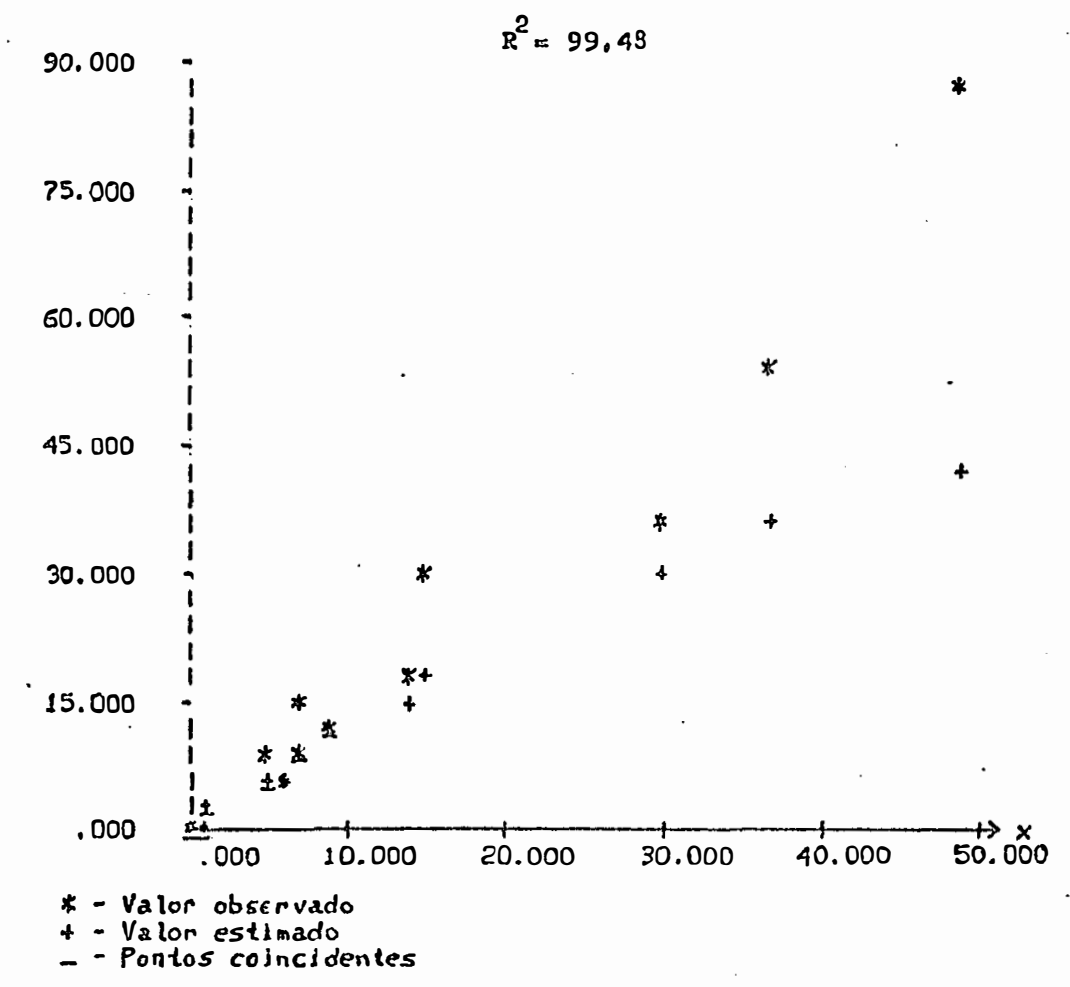

FIGURA 1. Equação de regressão entre espumas e ninfas de c1garrinhas das pastagens, Deois flavopicta, para a mesma época de amostragem, em Brachiaria decumbens no municipio de Sales oliveira, SP, em 1979/80. 
.64.

Para amostragem de 15 dias apös a amostragem de espuma (Tabela 22), verifica-se que ao se correlacionar espumas com ninfas, obtëm-se resultados diferentes de local para local. Assim, para os locais B e D se obteve correlação significativa, enquanto que no local A e C esta o foi a $1 \%$ e $5 \%$ respectivamente, sendo que para a média dos 4 locais tambëm se verificou correlação. Ao se comparar este resulta do com aquele obtido na regressão linear (Tabela 18), nota-se que por este ültimo não existe nenhuma correlação. Apesar disto pode-se dizer, que embora muito baixa, ainda existe alguma correlação entre o número de espumas e o número de ninfas 15 dias após, pois foi obtido o mesmo tipo de equação de regressão (Figura 2) em todos locais de F significativo.

Ao se correlacionar espumas com adultos em di ferentes redadas, notam-se correlações altamente significatí vas em todos locais e na média dos 4 locais, sendo que as equações de regressão obtidas, variam com o número de redadas, sendo obtido um modelo de regressão para 25 e 75 redadas (Figuras 3 e 4) e outro para 50 e 100 redadas (Figuras 5 e 6).

Ao se analisar os resultados para correlações de 30 dias após (Tabela 23) verifica-se, claramente, que o nümero de espumas não se correlaciona com o nümero de ninfas, em qualquer dos locais e mesmo na média dos 4 locais, sendo 

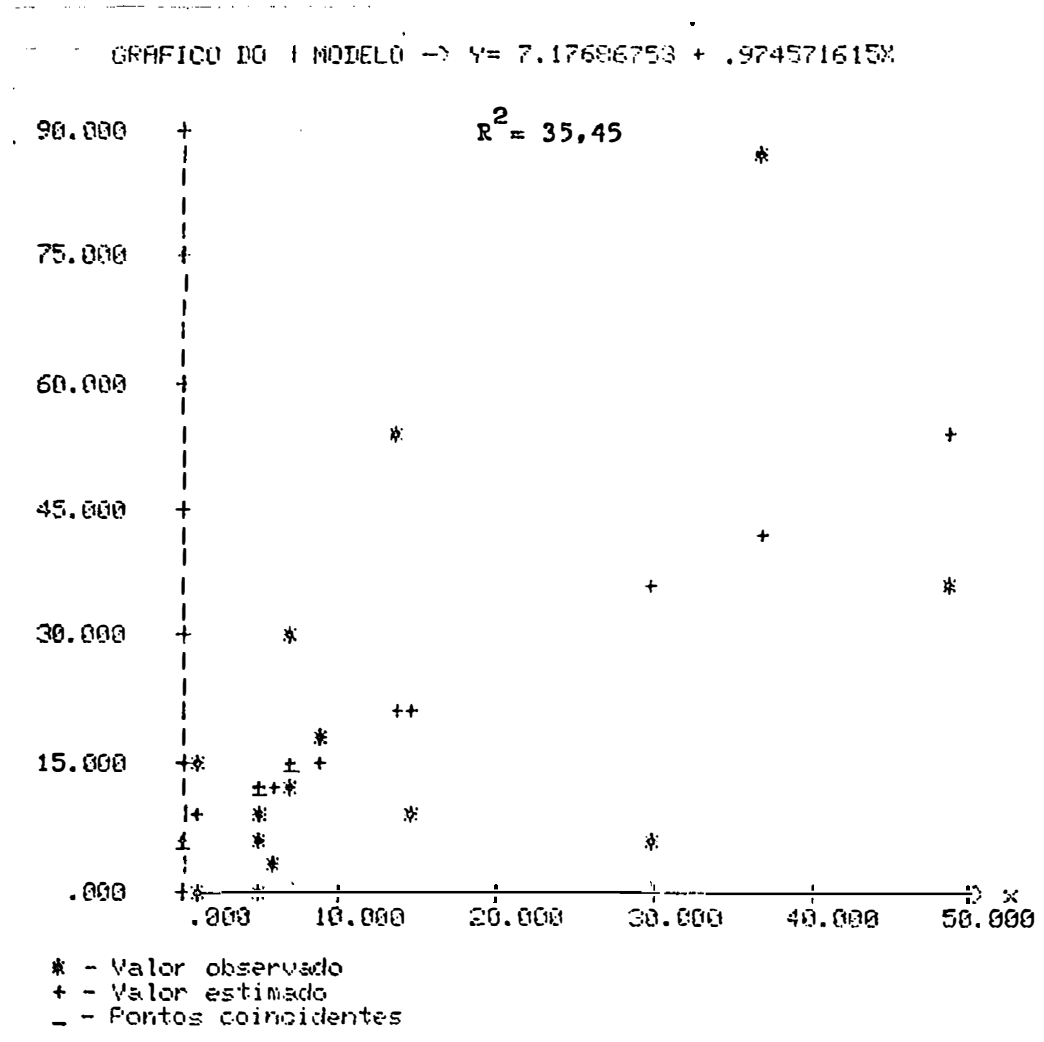

FIGURA 2. Equação de regressão entrre espumas e ninfas de cigarrinhas das pastagens, Deois flavopicta, para amostragem de ninfas 15 dias após a de espumas, em Brachiaria decumbens, no municipio de Sales 01 ive ra, SP, em $1979 / 80$. 


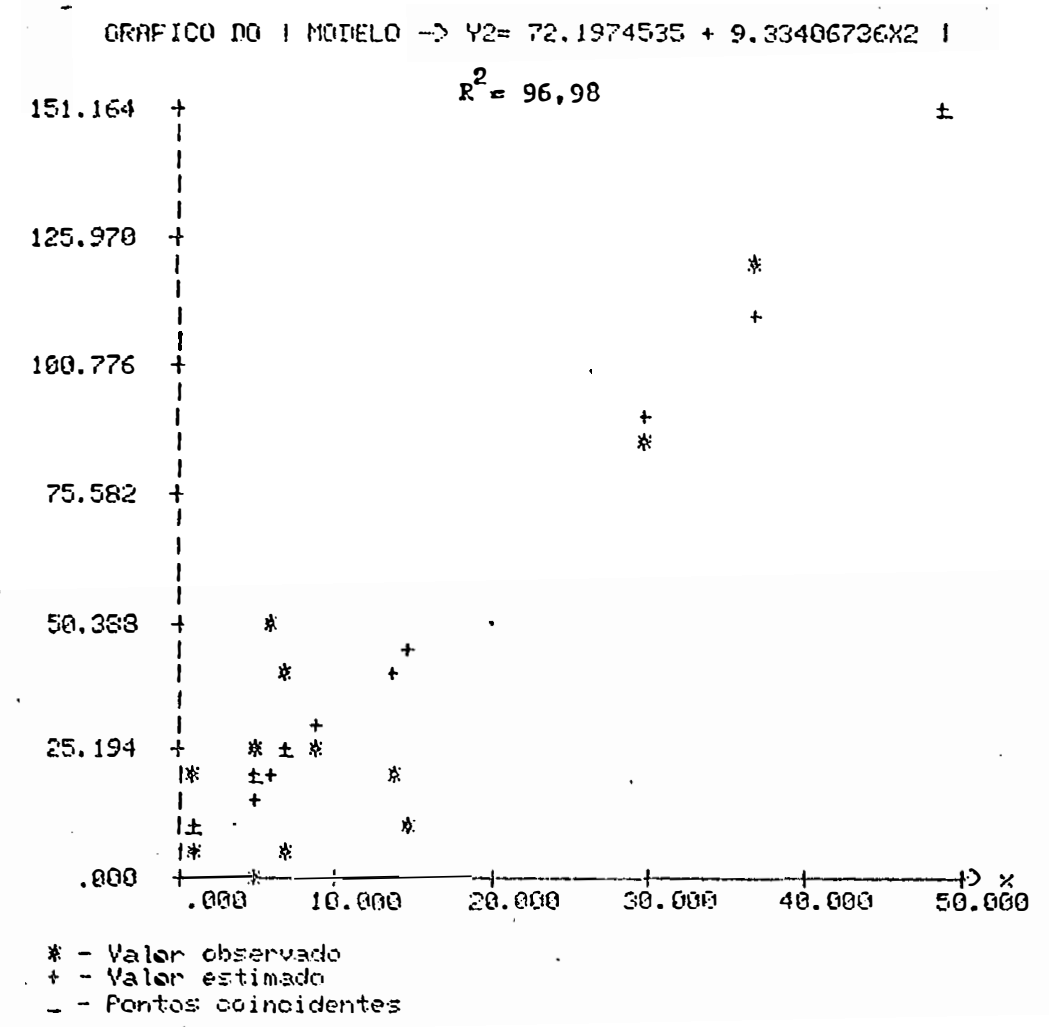

FIGURA 3. Equação de regressão entre espumas e adultos de ci. garrinhas das pastagens, Deois flavopicta, para amostragem de adultos coletados em 25 redadas 15 di as apos a amostragem de espumas, em Brachiaria decumbens, no municipio de Sales oliveira, SP, em $1979 / 80$ 


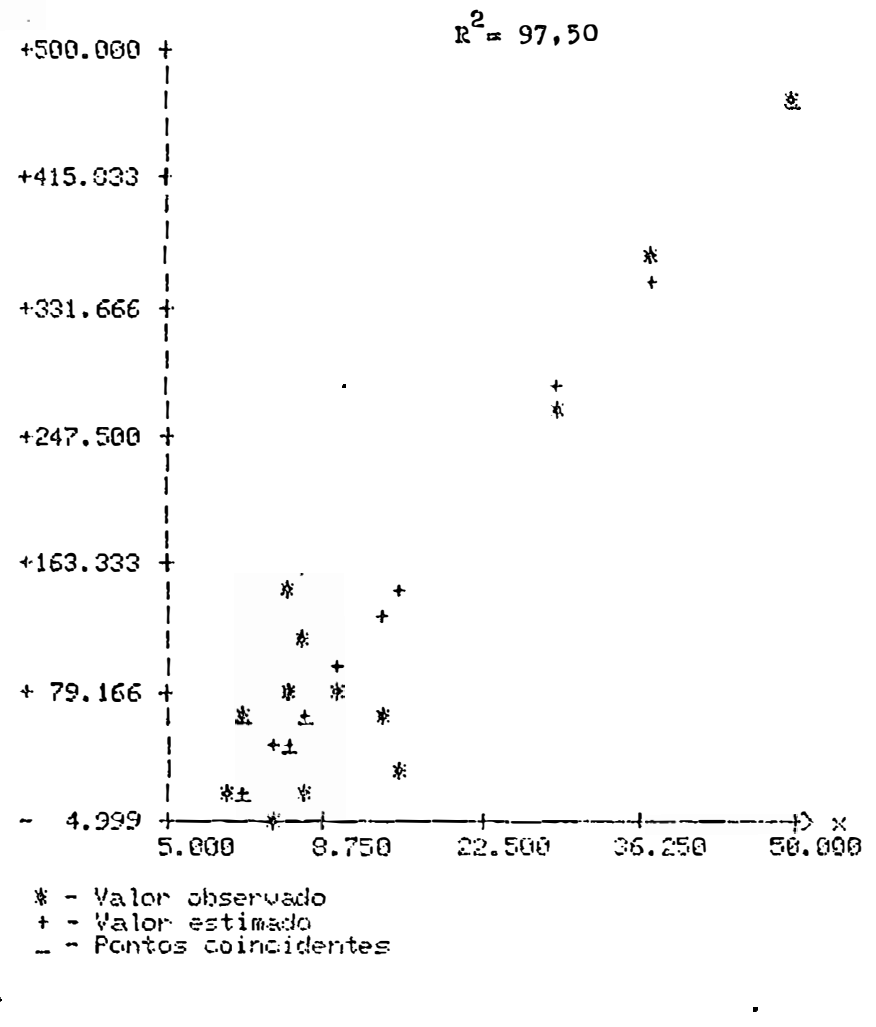

FIGURA 4. Equação de regressão entre espumas e adultos de cí garrinhas das pastagens, Deois flavopicta, para amostragem de adultos coletados em 75 redadas 15 di as após a amostragem de espumas, em Brachiaria de cumbens, no municipio de Sales 0liveira, SP, em $1979 / 80$. 


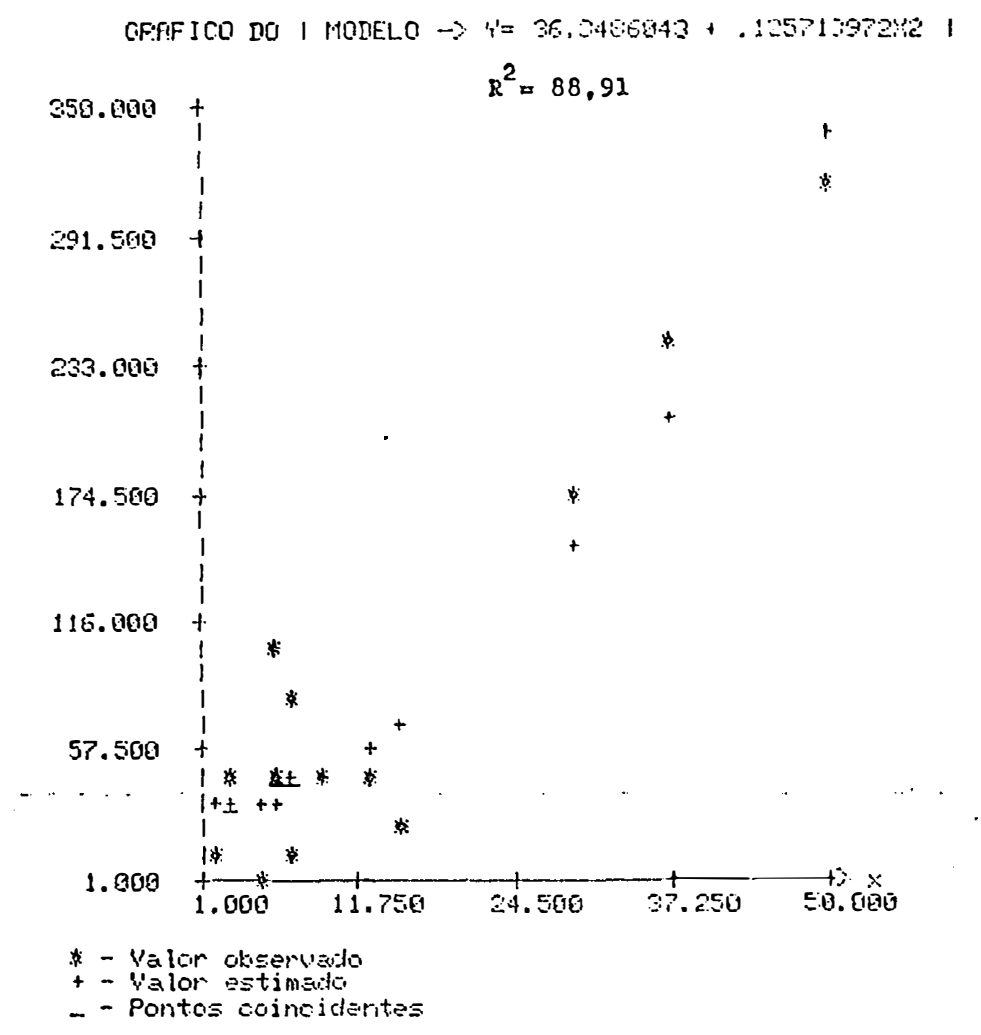

FIGURA 5. Equação de regressão entre espumas e adultos de cí garrinhas das pastagens, Deois flavopicta, para amostragem de adultos coletados em 50 redadas 15 di as após a amostragem de espumas, em Brachiaria decumbens, no municipio de Sales Oliveira, SP, em $1979 / 80$. 


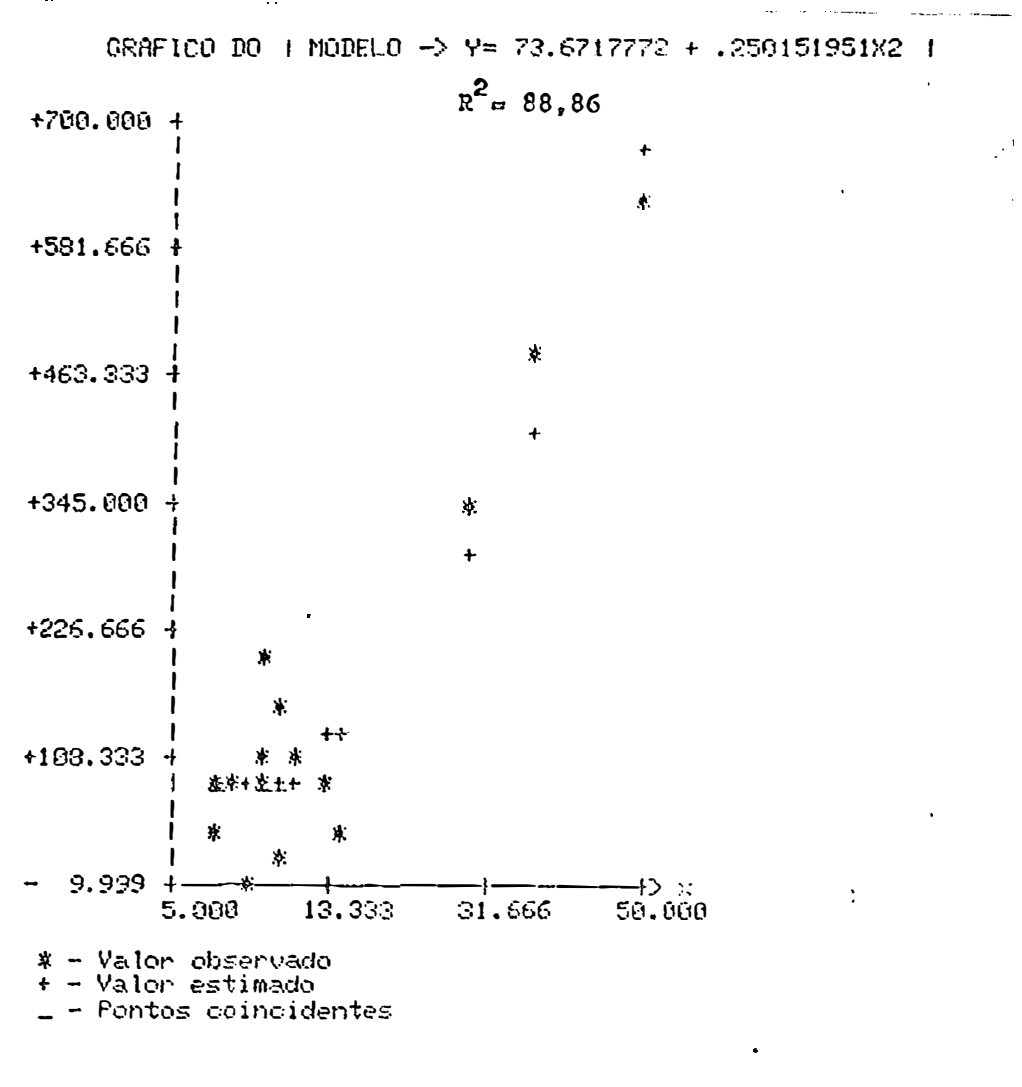

FIGURA 6. Equação de regressão entre espumas e adultos de cí garrinhas das pastagens, Deois flavopicta, para amostragem de adultos coletados em 100 redadas 15 dias após a amostragem de espumas, em Brachiaria decumbens, no municipio de Sales oliveira, SP, em $1979 / 80$. 
este o mesmo resultado observado na regressão linear (Tabe1a 18). Resultados inversos são observados ao se comparar o nümero de espumas com adultos coletados em diferentes redadas, onde se nota, de uma maneira geral, correlações altamen te significativas e o mesmo tipo de equação de regressão (Fí guras $7,8,9$ e 10), para os diferentes números de redadas, nos diferentes locais e média dos 4 locais,

Os resultados das comparações entre espumas e adultos 15 e 30 dias após estão em 1 inha com aqueles observa dos na regressão linear (Tabela 16), apesar de que os valores de $\mathrm{R}^{2}$ para comparaçóes de 15 dias após são bem superiores àqueles de 30 dias. Isto significa dizer que um aumento na população de espumas e/ou ninfas hoje, irá influir significativamente na população de adultos 15 e 30 dias após,prin cipalmente aos 15 dias após.

5.4. Comparação do número médio de adultos nos diferentes números de redadas, nas diferentes épocas de amostra gens

Analisando-se os dados (Tabela 24) verifica-se que a média de adultos coletados, aumentou linearmente à medida que se aumentou o número de redadas, independentemente da época de amostragem. O valor médio encontrado para adultos coletados em 100 redadas, diferiu estatisticamente da 
.71

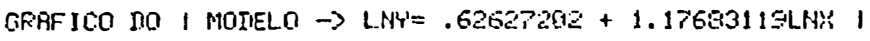

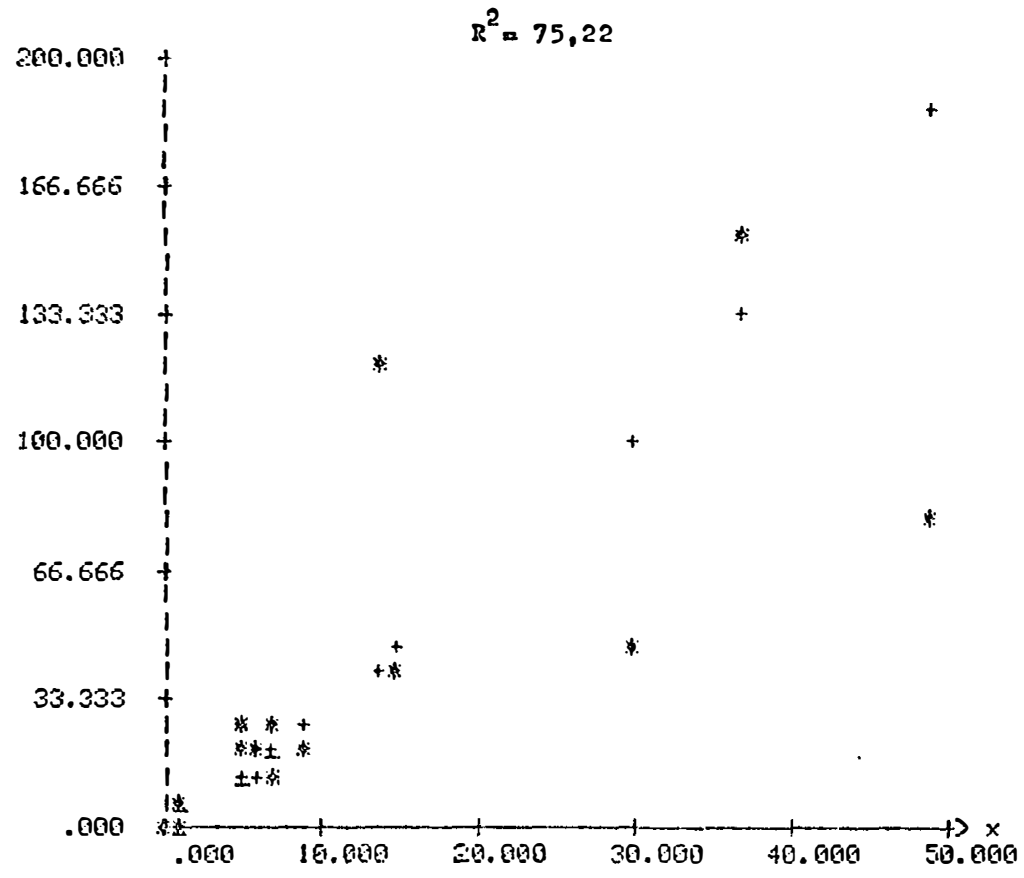

* Valor observado

+ - Valor estinado

- Pontos coinoidentes

FIGURA 7. Equação de regressão entre espumas e adultos de ci garrinhas das pastagens, Deois flavopicta, para amostragem de adultos coletados em 25 redadas 30 dias após a amostragem de espumas, em Brachiaria decumbens, no município de Sales 01 iveira, sP, em $1979 / 80$ 


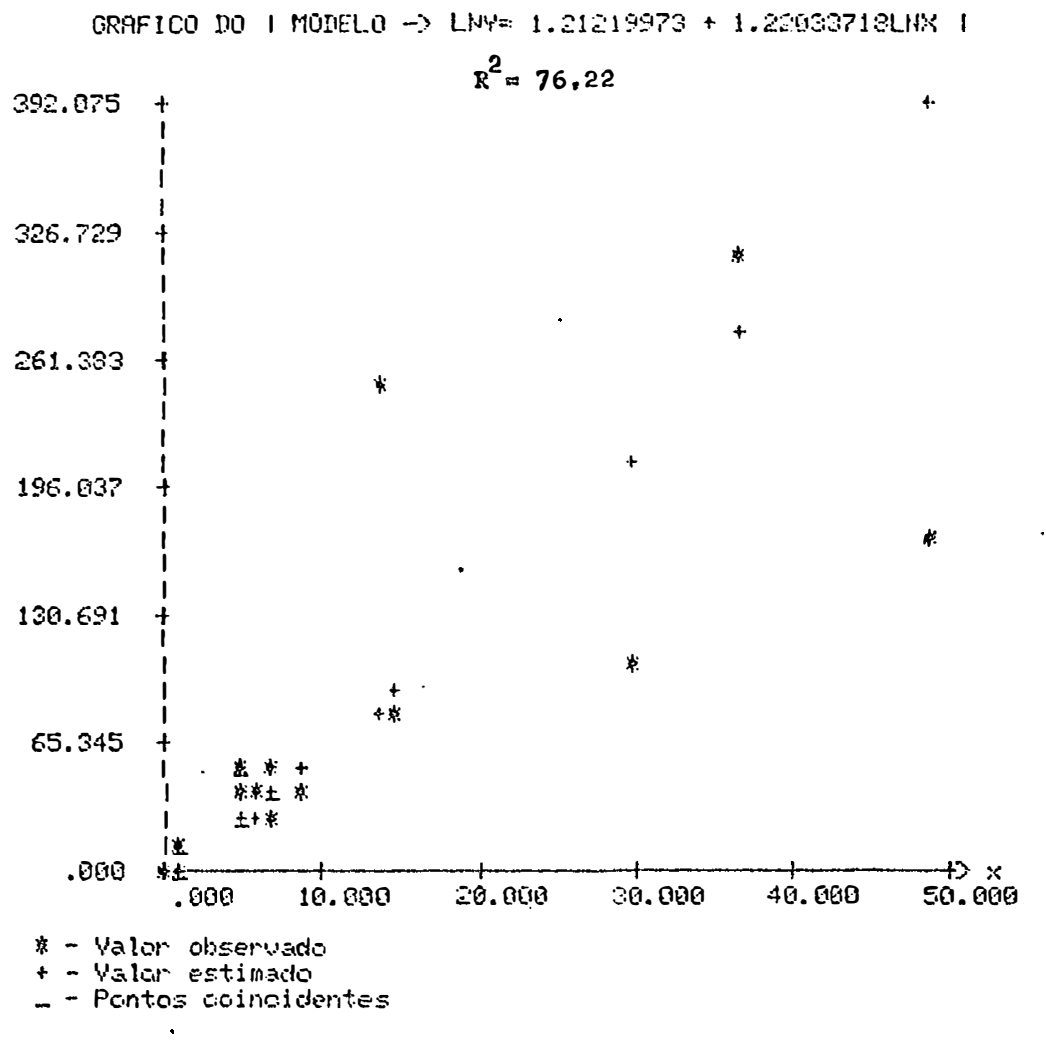

FIGURA 8. Equação de negpessão entre espumas e adultos de ci garrinhas das pastagens, Deois flavopicta, para amostragem de adultos coletados em 50 redadas 30 dias apōs a amostragem de espumas, em Brachiaria decumbens, no municipio de Sales 01 iveira, SP, em $1979 / 80$ 
.73.

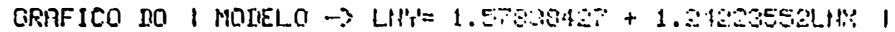

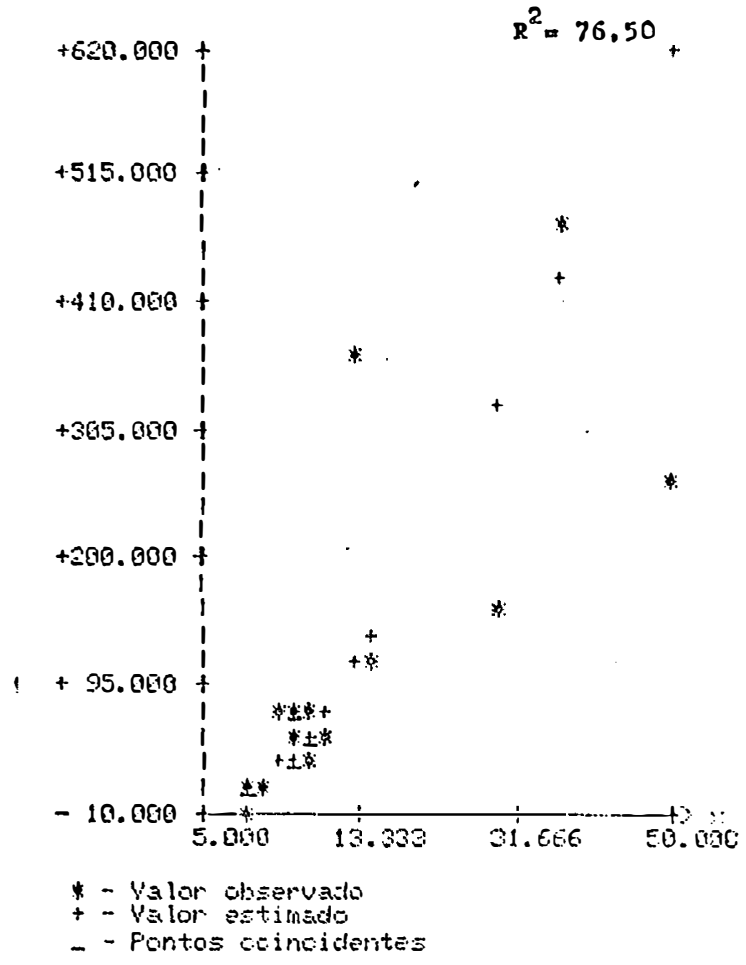

FIGURA 9, Equação de regressão entre espumas e adultos de c garrinhas das pastagens, Deois flavopicta, para amostragem de adultos coletados em 75 redadas 30 dias após a amostragem de espumas, em Brachiaria decumbens, no municipio de Sales 01 iveira, SP, em $1979 / 80$. 

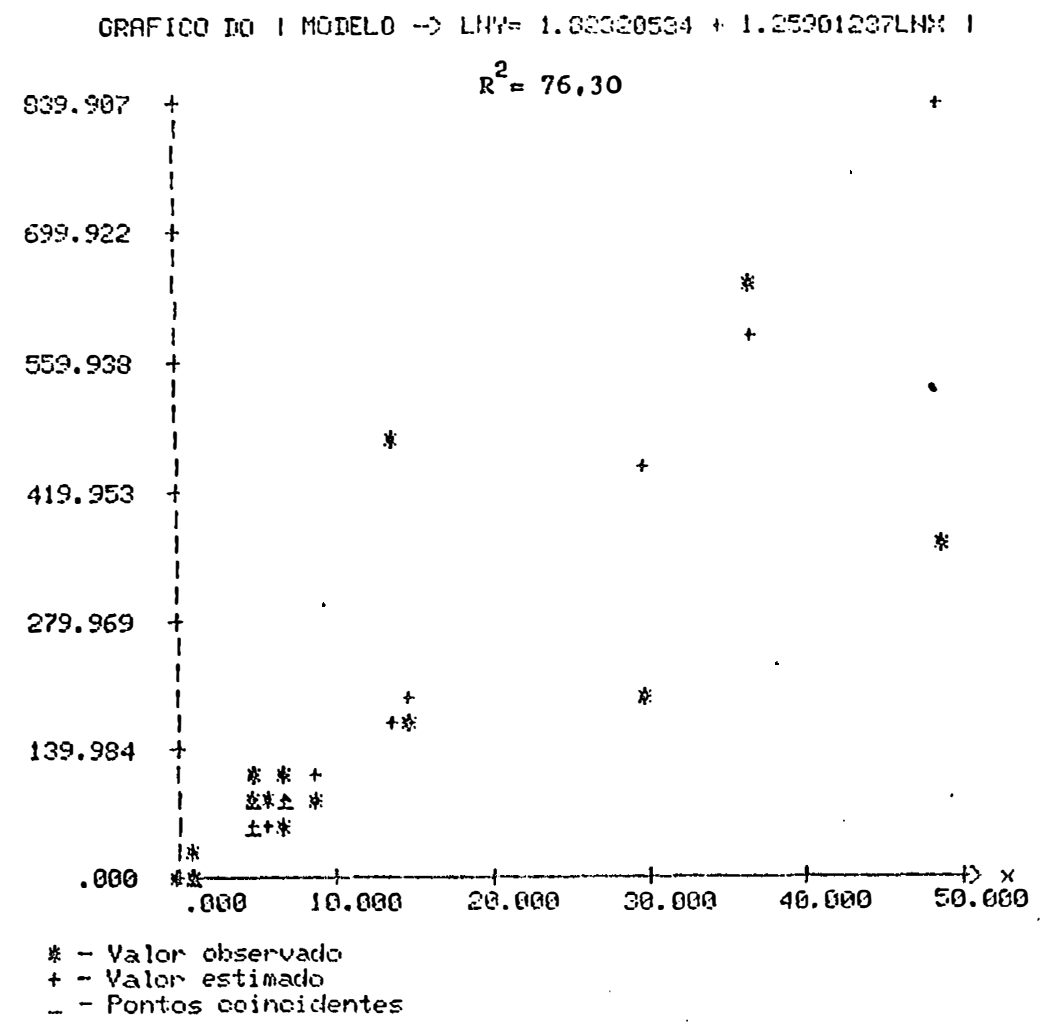

FIguRA 10, Equação de regressão entre espumas e adultos . de cigarrinhas das pastagens, Deois flavopicta, para amostragem de adultos coletados em 100 redadas 30 dias apös a amostragem de espumas, em Brachiaria decumbens, nọ município de Sales oliveira, sP, em $1979 / 80$ 
daquele obtido em 25 redadas, que por sua vez não diferiu dos demais,

Considerando-se que no quadro de médias obte-. ve-se valores bem prōximos para a série de 100 redadas, em qualquer época considerada, e que os valores médios aqui obtidos são mais representativos em termos numéricos, deve-se recomendar a utilização de 100 redadas por ponto de avaliação, as quais podem ser separadas em 4 sëries de 25 redadas, uma sërie para cada lado do ponto, principalmente consideran do-se estes dados para uma anälise mais profunda. 


\title{
6. CONCLUSOÕES
}

\author{
Com base nos resultados e discussão e nas con \\ dições em que foi conduzido o presente trabalho, pode-se cón \\ cluir que:
}

- Para estudos de flutuação populacional, dentro de uma mesma pastagem, não hä necessidade de se amostrar toda ärea, uma vez que não ocorrem diferenças no comportamento popula cional das àreas isoladamente, quando comparadas com a mén dia geral;

- A terceira geração das cigarrinhas è a responsável pelo maior pico populacional e próxima infestação, sendo a ēpoca desse pico variável com o periodo inicial de ocorrência; 
- Dos estágios da população estudados, os adultos e ninfas de instar I foram os mais influenciados pelos fatores climáticos, sendo que isoladamente as variáveis que mais influiram nesses estágios foram a temperatura do solo coberto a 5 cm de profundidade e precipitação pluviométrica, res pectivamente;

- O mümero total de espumas e ninfas é mais influenciado pela precipitação pluviomētrica e pela umidade relativa minima do ar sendo a curva populacional explicada em até $85 \%$ pelos fatores climáticos;

- Os instares ninfais mais jovens são bastante influenciados pela precipitação pluviomētrica e os instares intermediârios pela temperatura minima do ar, enquanto que, no final do desenvolvimento, estes sofrem malior influência da preci pitação pluviométrica e da umidade relativa mínima do ar;

- Existe alta cörrelação entre espumas e ninfas para a mesma época de amostragem, explicada pela equação $1 / Y=0,008$ t $t 0,76 / x$, bastando portanto amostrar o nümero de espumas, que è de mais fácil obtenção no campo;

- Não existe correlação entre espumas e adultos de diferentes redadas, para a mesma ëpoca de amostragem;

- Para amostragem de ninfas 15 dias após a amostragem de espumas, a correlação entre estes dois estágios é explicada 
pela equaçao $Y=7,18+0,98 X$

- A correlação entre espumas e adultos coletados 15 dias após é altamente significativa, sendo obtidas diferentes equações, dependendo do nümero de redadas, onde para 25 e 75 redadas as equações foram $\mathrm{Y}^{2}=72,20+9,33 \mathrm{X}^{2}$ e $\mathrm{Y}^{2}=$ $38,92+91,17 \mathrm{X}^{2}$ e para 50 e 100 redadas foram $Y=36,35+$ $+0,13 \mathrm{X}^{2}$ e $\mathrm{Y}=73,67+0,25 \mathrm{X}^{2}$, respectivamente;

- Aos 30 dias após a amostragem de espumas, não se verifica correlação destas com o número de ninfas;

- Existe correlação entre o número de espumas e adultos cole tados 30 dias apōs, sendo esta correlação explicada pelas equações LNY $=0,63+1,18 \mathrm{LNX}, \mathrm{LNY}=1,21+1,22 \mathrm{LNX}$, LNY $=1,58+1,24 \mathrm{LNX}$ e LNY $=1,82+1,26 \mathrm{LNX}$, respectivamente para $25,50,75$ e 100 redadas;

- A utilização da série de 100 redadas por ponto de avaliação é recomendada, devido a menor variação das médias obti das nas diferentes épocas de avaliação. 
.79.

\section{LITERATURA CITADA}

AZZI, G.M. e A.K. DODSON, 1971. Infestação de cigarrinha da raiz em canaviais de Piracicaba, SP (Mahanarva fimbriolata Sta1). Brasil Aqucareiro, Rio de Janeiro, 77(5): 36-42 .

BAL T'AR FILHO, A.F., 1967. Curva populacional durante um ano da cigarrinha da cana-denaçúcar (Mahanarva indica, Distant, 1909) em Pernambuco. Recife, Comis. de Defesa Sani täria da Lavoura Canavieira de Pernambuco, 63 p. (Boletim 27).

BECK, E.W., 1963. Observations on the biology and cultural insecticide control of Prosapia bicincta, a spittlebug, on Coastal Bermudagrass, J,Econ. Entom., Washington, 56(6): 747-752, 
BIANCO, R, A, VILLACORTA, 1978a. Dinâmica populacional de cigarrinhas das pastagens em diferentes tipos de forragei ras e sua correlação. In: Congresso Latino-Americano de Entomologia, 3, e Congresso Brasileiro de EntomoZogia, 5, Ilhéus … Itabuna, BA. (Resumos)

BIANCO, R. e A. V.ILLACORTA, 1978b. Desenvolvimento e preferência de Deois flavopicta por diferentes forrageiras. In: Congresso Latino-Americano de Entomologia, 3, e Congresso Brasileiro de Entomologia, 5, Ilhéus - Itabuna, BA. (Resumos).

BRASIL, J.N., 1967. Pragas e doenças da canandenaçûcar em Pernambuco, Recife, CODECAP, 19 p。 (Boletim 24).

BYERS, R.A., 1965, Biology and control of the spittlebug, Prosa pia bicincta (Say) on coastal bermudagrass. Technical Bulzetin, Georgia Agricultural Experimental Station, Geor gia (42): 26 p.

BYERS, R.A, e C.M. TALIAFERRO, 1967, Effects of age on the ability of the adult twonlined spittlebug, Prosapia bicincta to produce phytotoxenia of coastal bermudagrass. J. Econ, Entom., Washington, 60(6): 176.0त1761.

CORONADO, A.C., 1964. Mosca pinta de los pastos, distribuicion, biologia y combate. Fitófizo, México, 17(41): 16-20 . 
CosenzA, G.W., 1974. Controle integrado das cigarrinhas das pástagens. Projeto IPEACO, M,A, Sete Lagoas, MG, 1-10. COTTAS, M.P. e Z.A. RAMIRO, 1981. Flutuação populacional de cigarrinhas das pastagens em duas variedades de Brachiaria na Região do Pontal do Paranapanema, Estado de São Pau1o. Anais S.E.B., Jaboticabal, 10(1): 51-60.

DeBONA, A., N. SUPLICY, R. CALZA, E. AMANTE e H,L. SARTINI, 1967. Observações ecológicas das cigarrinhas dos pastos Tomaspis Gavopicta e Monecophora entreriana. In: . Reu. nião Anual da Sociedade de Defensivos Para a Lavoura e Pe cuāria," 1, São Paulo, Brasil, pg . 51-2-A.

DOMINGUES, J.M. e R.M.S. SANTOS, 1975. Estudo da biologia da cigarrinha das pastagens Zulia entreniana (Berg, 1879) e sua curva populacional no norte do Estado do Espirito Santo. EMCAPA, Vitória, ES. 43 p. (Boletim Técnico no 2).

EL-KADI, M.K., 1977a. Novas perspectivas no controle de cigarrinhas. CONFERENCIAS, PALESTRAS E EXPOSIÇÕES REALIZADAS No CONGRESSO BRASILEIRO DE ENTOMOLOGIA, 4, Goiānia, G0. $\quad 58-67$.

EL-KADI, M.K., 1977b. Palestra sobre controle económico da cigarrinha das pastagens, ENCONTRO SOBRE FORRAGEIRAS DO GENERO BRACHIARIA. Sec, Agric. do Estado de Goiás, EMgopa, Goiānia, G0, 143-157. 
EL-KADI, M.K。, 1978. Flut ua ção populacional de ciga minha das pastagens no Estado de São Paulo. In: Congresso Lat $\underline{i}$ no-Americano de Entomologia, 3, e Congresso Brasileiro de Entomologia, 5, Ilhèus - Itabuna, BA. (Resumos)

FAGAN, E.B. e L.C. KUITERT, 1968. Biology of the two lined spittlebug, Prosapia bicincta, on Florida pastures (Homop tera-Cercopidae). Flor. Entom., Gainesville; 52(3): 199$-206$

FAZOLIM, M, L.C, FORTI, F.A. MONTEIRO, 1977. Levantamentos de cigarrinhas de pastagens em Nova Odessa, SP. com o uso de armadilha de Malaise. In: Congresso Brasizeiro de Entomologia, 4, Goiânia, GO, pg, 81-82. (Resumos)

FEWKES, D.W., 1960. Number of nymphal instar of the sugar cane froghopper. Nature, London, 188 (4745): 167-168.

FEWKES, D.W., 1963. The effects of exposure to dry condition on the eggs of Aeneolamia varia saccharina (Homoptera-Cercopidae). Ann. Entom, Soc. Am., Columbus, $\underline{56}$ (5) : $719-720$.

FEWKES, D.W., 1964. The fecundity and fertility of the Trinidad sugar cane froghopper, Aeneolamia varia saccharina (Homoptera-Cercopidae). Trop. Agric. Trin., Trinidad, 41 (2): $165-174$. 
FEWKES, D.W., 1969. The biology of sugar cane froghopper. Eisewier Publishing Co., London: 283-307.

FEWKES, D.W., M.R. DEMIDECK-DemMIDOWIEZ, 1971. Rearing technique for sugar cane froghopper nimphs (Homoptera-Cer copidae). Ann. Entom. Soc. Am., Colombus, 64(6): 1471-1472 .

FONTES, L.F., 1977. Padronização de técnicas de amostragens. In: Congresso Brasileiro de Entomologia, 4, Goiânia, Go. pg. 69 .

FORTI, L.C., S, SILVEIRA NETO, J.R,P.PARRA, F,A. MONTEIRO, M. FAZOLIM e J.M. MILANEZ, 1977. Levantamento e flutuação populacional de algumas pragas de pastagens atravês de armadi.1ha luminosa, Bol. Ind, Anim., Nova Odessa, 34(1):113 $-120$

FREIRE, A.M., C.E. SOUTO, E.J. MARQUES, 1968, Combate bioló gico das cigarrinhas da cana-de-açüar. Brasil Asucareiro, Rio de Janeiro, $71(4): 41-44$

GAI $I_{1} O, D,, O$. NAKANO, S. S ILVEIRA NETO, R,P,L 。 CARVALHO, G . C, BATISTA, E, BERTI FILHO, R.A. ZUCCHI e S.B. ALVES, 1978. Manual de Entomologia Agricola. Praga das plantas e seu controle. Ed, Agron. Ceres, São Paulo, 431 . 
GALVÃo, F.E., A.F.LIMA, 1977. Capim Quicuio da Amazônia (Brachiaria humidicola) e suas perspectivas no Estado de Goiàs, EMGOPA, 27 p .

GONÇALVES, C.R., 1969. Relatörio de viagem a Bahia. Ord. Serviço no 21 de 07.07.69. Equip. Tec, Def, San, Veg., Lab. Central de Pat. Veg,, Ministério da Agricultura, RJ, $14 \mathrm{p}$.

GUAGLIUMI, R., 1970. As cigarrinhas dos canaviais (Homoptera-Cercopidae) no Brasil. (VI Contribuição), Nova nomen clatura e distribuição das espêcies mais importantes. Bra sil Asucareiro, Rio de Janeiro, 76(1): 75-89,

GUAGLIUMI, P., 1971a. As cigarrinhas das pastagens no nordeste do Brasil. Ruralidade, Goiânia, 1(4): 31 p.

GUAGLIUMI, P., $1971 \mathrm{~b}$. Luta integrada contra as cigarrinhas de cana e das pastagens no nordeste do Brasil. Comiss. Comb, à Cig。 em Pernambuco, 40 p, (Boletim no 3).

GUAGLIUMI, P., 1972。 Pragas da cana-de-açücar no nordeste do Brasil, Rio de Janeiro, M,I,C, e I.A,A, 632 p. (Cole ção Canavieira nọ 10).

LIMA, A.M. da, 1942. Homöpteros. In: Insetos dọ Brasil. Rio de Janeiro, ENA, v。3. (Sẻrie Didätica, nọ 4). 
MATIOLI, J.C., 1976. Algumas observações sobre as cigarrinhas das pastagens no Estado do Espirito Santo, EMCAPA. Cinc, no 1, março, $16 \mathrm{p}$.

MELO, I.A.S., 1982. Estudo populacional das cigarrinhas das pastagens (Homoptera-Cercopidae) sobre Brachiaria decumbens Stapf, na região de Monte Belo, MG. Piracicaba, ESALQ/USP, 68 p。 (Tese de Mestrado).

MENDES, A.C., 1976. Influência dos elementos climáticos sobre a população da broca da cana-de-açúcar, Diatraea sac charalis (Fabr.) e da cigarrinha da raiz, Mahanarva fimbriolata (Sta1), Araras, SP. Piracicaba, ESALQ/USP, 104 p. (Tese de Mestrado).

MILANEZ, J.M., 1980. Dinämica populacional de Zulia INotozu lia) entreniana (Berg., 1879) e Deois (Acanthodeois) blavopicta (Stal, 1854). (Homoptera-Cercopidae) em diferentes gramineas. Piracicaba, ESALQ/USP, 79 p. (Tese de Mes$\operatorname{trado})$.

MORA, J., 1972. Levantamento preliminar da incidência das cigarrinhas das pastagens no norte do Espirito Santo, Re Latörio de Viagem, Secr, Agric. mimeog. 8 p.

NEHRING, P., 1976. As duas braquiärias eleitas para a Alta Sorocabana. Correio Agropecuärio, São Paulo, 2ạ quinz. $\mathrm{pg} \cdot 7$. 
PACHECO, J.M., 1981. Aspectos da biologia e ecologia de Deois (Acanithodeois) flavopicta (Stal, 1854) (Homoptera -Cercopidae) na região de São Carlos; São Paulo, Brasil. São Carlos UN, FED., $111 \mathrm{p}$. (Tese de Doutoramento).

PADIlHa, R.C., E.C. ESQUILIANO, 1966. Campaña contra la mos ca pinta y la escama algodonosa de los pastos. Fitófizo, Mèxico, 19(50): 5-49.

PASS, B.C., J.K. REED, 1965, Biology and control of the spittlebug Prosapia bicincta in coastal bermudagrass. $J$. Econ. Entom., Washington, 58(2): 275-278.

RAMOS, I.M., 1976. Biologia das cigarrinhas das pastagens, Zulia entreriana (Berg,, 1879) (Homoptera-Cercopidae). Pi racicaba, ESALQ/USP, $72 \mathrm{p}$. (Tese de Mestrado).

REIS, P.R。, 1974. Cigarrinha das pastagens. Levantamento das espécies. Area de distribuição e controle integrado. Projeto EPAMIG - MG, 1-14.

REIS, P.R., L.A.S, MELO, C. GAEIRAS, W. BOTELHO, 1978. F1u tuação populacional das cigarrinhas das pastagens (HomopteranCercopidae) no Estado de Minas Gerais, identificação das espécies e àreas de distribuição. In: CONGRESSO LATI NO-AMERICANO DE ENTOMOLOGIA, 3 , e CONGRESSO BRASILEIRO DE entomologia, 5, Ilheus - Itabuna, BA (Resumos). 
RIBEMBOIM, J.A., G,M.A. CISNEIROS, 1967. Contribuição ao es tudo da biologia da cigarrinha da cana-de-açúcar (Mahanar va indica Distant, 1909) em Pernambuco, Recife. Minist. Agric, CCPCAP。 23: $16 \mathrm{p}$.

SA, L.A.N., 1981. Cigarrinhas das pastagens (Homoptera-Cercopidae): Distribuição geogräfica e variabilidade genética. Campinas, Instituto de Biologia/UnICAmp, $119 \mathrm{p}$. (Te se de Mestrado).

SCALzO, P.A., 1973. Controle da cigarrinha das pastagens evita redução da ärea de pastejo. J. Eng? Agro, São Pau1. o, $3(34): 1$.

SILVEIRA NETO, S., R.P.L. CARVALHO e S.B. PARANHOS, 1968. Flutuação da população de pragas da cana-demaçúcar em Piracicaba. Anais da I Reunião Anual da S,B,E., Piracicam ba, pg。 $26-27$.

Silveira NETO, S., O NAKANO, D. BARBIN, N.A. VIla NOVA, 1976. Manual de ecologia dos insetos. Ed. Agron. Ceres, São Paulo。 $419 \mathrm{p}$.

SILVEIRA NETO, S., 1976. Controle de insetos e outras pragas de pastagens. Anais do 39 Simpósio sobre manejo das pastagens, Fundação Cargill, Piracicaba, $137-190$. 
SOUZA, HoD。, 1967. As ciganxinhas da canande-açücar e seu controlle por inimigos Raturais no Estado do Rio de Janeino. I.A.A./D,A.P, 19 p.

SOUzA, H.M.F., 1976, Algumas corsiderações sobre os dados climäticos e os surtos das cigarrinhas das pastagens Zulia entreniana (Berg) e Alneolamia selecta (Wlken。), no periodo de 1973 a 1975. Boletim do Instituto Biolögico da Bahia, Sa1vador, 115(1): 110-116.

VENTOCILLA, J.A., 1969. Contribuição ao estudo da cigarrinha das pastagens Zulia entreriana Berg (Homoptera-Cercopidae) na Bahia. In: II Reunião Anual da S.B.E. Recife. (Resumos).

VILLACORTA, A., 1977. A procura de um método para combater as cigarrinhas. Agricultura de Hoje, 3․ (28): 28-30.

WILSON, P.N., D.W. EEWKES, M,G, EMSLEY, 1962, Notes on a heavy infestation of pangola grass (Digitaria decumbens Stent) by the sugar cane froghopper (Aeneolamia varia saㅌ Charia Distant), Trop. Agric, Trin., Trinidad, 39(1): $49-51$ 